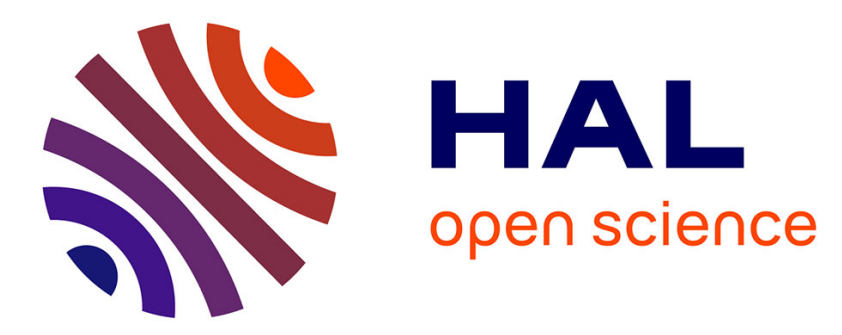

\title{
Dyes Depollution of Water Using Porous TiO2-Based Photocatalysts
}

Bénédicte Lebeau, Florian Jonas, Pierrick Gaudin, Magali Bonne, Jean-Luc Blin

\section{- To cite this version:}

Bénédicte Lebeau, Florian Jonas, Pierrick Gaudin, Magali Bonne, Jean-Luc Blin. Dyes Depollution of Water Using Porous TiO2-Based Photocatalysts. Environmental Nanotechnology, pp.35-92, 2020, 10.1007/978-3-030-26668-4_2 . hal-03065639

\section{HAL Id: hal-03065639 \\ https://hal.science/hal-03065639}

Submitted on 14 Dec 2020

HAL is a multi-disciplinary open access archive for the deposit and dissemination of scientific research documents, whether they are published or not. The documents may come from teaching and research institutions in France or abroad, or from public or private research centers.
L'archive ouverte pluridisciplinaire $\mathbf{H A L}$, est destinée au dépôt et à la diffusion de documents scientifiques de niveau recherche, publiés ou non, émanant des établissements d'enseignement et de recherche français ou étrangers, des laboratoires publics ou privés. 


\section{Dyes depollution of water using porous $\mathrm{TiO}_{2}$-based photocatalysts}

Bénédicte Lebeau ${ }^{\mathrm{a}, \mathrm{b}}$, Florian Jonas ${ }^{\mathrm{c}}$, Pierrick Gaudin ${ }^{\mathrm{c}}$, Magali Bonne ${ }^{\mathrm{a}, \mathrm{b}}$, Jean-Luc Blin ${ }^{\mathrm{c} *}$

${ }^{a}$ : Université de Haute Alsace, CNRS, IS2M UMR 7361, F-68100 Mulhouse, France

${ }^{\mathrm{b}}$ : Université de Strasbourg, France

benedicte.lebeau@uha.fr

magali.bonne@uha.fr

c : Université de Lorraine, Laboratoire Lorrain de Chimie Moléculaire UMR CNRS 7053 L2CM, 54500 Vandoeuvre-lès-Nancy,

florian.jonas@univ-lorraine.fr pierrick.gaudin@univ-lorraine.fr

jean-luc.blin@univ-lorraine.fr 


\section{Abstract}

Wastewater discharge from industries constitutes one of the main environmental issues. Particularly, dyes are a major concern because of their toxicity on human health. Among the different techniques developed to remove these pollutants from water, heterogeneous photocatalysis appears as a promising technology and it is one of the most studied for the decomposition of dyes in water phase over the few past decades. Due to its properties, titania has been widely studied in the water treatment processes. However, to be implanted at a large scale, the photocatalytic activity still needs to be enhanced, especially in the visible domain. One way to reach this goal consists in increasing the specific surface area of the photocatalyst. From this point of view porous $\mathrm{TiO}_{2}$ are excellent candidates to be considered in the water treatment technologies. In this Chapter, we will review the use of porous titania-based nanomaterials for the photocatalytic degradation of dyes contained in wastewater, since this process is the most promising. First a short presentation of common dyes used in the industry and their classification is given. The main information concerning $\mathrm{TiO}_{2}$ as potential good photocatalyst for dye removal from wastewater is then given to remind its structures and properties, describe the mechanisms proposed for pollutant photodegradation and present the parameters affecting its photoactivity efficiency. These aspects are the bases that orient researches in the synthesis of performant nanostructured $\mathrm{TiO}_{2}$ photocatalysts. Recent advances related to this topic are reviewed including the shaping and preparation of $\mathrm{TiO}_{2}$ based (nano)composites materials that have been developed to favor their use and/or integration in a process for potential industrial use. The last part is devoted to the progress of two most promising process for the implementation of viable system to remove dyes from wastewater at a large scale. Finally some patents and the interest of titania and photocatalysis in industry are reviewed. 
Keywords: Photodegradation, Titania, Nanomaterials, Doping, Membrane process, Flow reactor, Azo dyes 


\section{Introduction}

There are several different types of substances that may pollute water and contamination of surface water, groundwater and soil is a major problem (Dror et al. 2012). Because of their potential carcinogenic and toxic effects on human health, among the different pollutants such as detergents, fertilizers, volatile organic compounds (VOC), halogenated organic compounds (HOCs), dyes are a major environmental concern (Kolpin et al. 2002; Chen et al. 2011). Dyes are mainly discharged from pharmaceutics, printing, food coloring, cosmetics, paper, textiles and many others industries, involving an environmental pollution. Dyes can change the color of water, impact light penetration, reduce the solubility of gases such as oxygen and some of them are toxic, which further affect the ecology in the water (Epolito et al. 2005; Nandi et al. 2009). Over $7 \times 10^{5}$ tons of dyes and pigments comprising more than 10000 different molecules are produced annually worldwide (Dutta et al. 2014). Among the different kinds of dyes, the ones belonging to the azo family (Forgacs et al. 2004) are carcinogenic, resistant to biodegradation, highly toxic and mutagenic to both human beings and aquatic life (Cai et al. 2017). Because of this toxicity for human health, many efforts have been devoted to remove dyes wastewater and various processes such as filtration, gravity separation, flotation, biodegradation or photocatalysis have been developed (Forgacs et al. 2004; Gupta et al. 2009; Rafatullah et. 2010; Alventosa-de Lara et al. 2012). Due to its high efficiency and wide applicability, adsorption is the most employed process for removing water-soluble dyes and activated carbons are known to be efficient adsorbents for the removal of dyes (Forgacs et al. 2004; Mahmoud et al. 2013). However, activated carbons suffer from low adsorption capacity, high-cost production and regeneration (Cai et al. 2017). Therefore, other adsorbents such as clays, zeolites have been developed (Forgacs et al. 2004; Martorell et al. 2017). But, with this process the dyes are simply transfer from water to another medium causing secondary pollution. Other techniques such as filtration, gravity separation and flotation have high 
operating costs and could release toxic secondary pollutants into the ecosystem. Consequently, they are not able to treat the water to meet standards for reuse filtration or coagulation. Biodegradation of synthetic dyes have also been developed (Demarche et al. 2012; Martorell et al. 2017). This process is quite inexpensive and the end-products of complete mineralization are not toxic. However, many of the synthetic dyes are chemically stable and resistant to microbiological attack. In addition, when the discharges have low biodegradable portions for example waste discharges of chemical industries biological treatments are inefficient or insufficient (Oller et al. 2011). The development of an effective process to depollute water is therefore still of great and continuous interest. To reach this goal the heterogeneous photocatalytic appears a promising technology and it is one of the most studied for the decomposition of dyes in water phase over the few past decades (Julkalpi et a. 2014; Cambié et al. 2016; Karthileyan et al. 2017; de Lima et al. 2017; Sharma et al. 2017; Cai et al. 2017). Indeed this technique has some advantages: (1) complete degradation of organic pollutants to $\mathrm{CO}_{2}$ and water, (2) no waste-solids disposal problem, and (3) only mild temperature and pressure conditions are necessary. Photocatalytic degradation usually occurs at room temperature and pressure and may be more cost-effective than other conventional techniques such as activated carbon adsorption and chemical scrubbers, because the semiconductor catalysts are inexpensive and capable of oxidizing most organic compounds effectively. However, for most photocatalyst the activity still need to be enhanced in particular in the visible domain.

Most of the considered techniques for water treatment require the use of materials for adsorption of the dye prior to its elimination. Thanks to their properties related to their small size such as large surface area, more active surface available, quantum effect and so one, nanomaterials like nanoparticles, nanotubes or ordered mesoporous materials are excellent candidates to be integrated into the processes of dyes removal from water (Cai et al. 2017). 
For example, Lee et al. have shown that the ordered mesoporous silica MCM-41 may be an effective absorbent for basic dyes removal from aqueous solution (Lee et al. 2007). In addition, the nature and the strength of the interaction between the host molecules and the adsorbent can be tuned by functionalizing the surface of these supports (Qin et al. 2009; Donia et al. 2009). Qin et al. have modified MCM-41 by introducing ammonium group, according to the post-synthesis way, for the adsorption of anionic dyes (Qin et al. 2009). Authors have evidenced that the functionalized MCM-41 material has a high affinity for the considered dyes and that the electrostatic interaction was responsible of the colorants adsorption. Among the various nanomaterials, titania-based ones are of particular interest. In fact, $\mathrm{TiO}_{2}$ is known to be chemical stable, nontoxic, low cost and reusable. Even more, the main advantages of titania for water treatment concerns its photocatalytic properties. Therefore $\mathrm{TiO}_{2}$ is the most studied and used photocatalyst nowadays (Gaya et al. 2008; Chong et al. 2010; Lazar et al. 2012; Qiu et al. 2012; Lin et al. 2012; Ajmal et al. 2014). As it will be illustrated in this chapter, titanium dioxide represents a good photocatalyst for wastewater treatment. The adsorption and the photocatalytic efficiencies are favored by an increase of the surface area and from this point of view porous $\mathrm{TiO}_{2}$ are excellent candidates to be considered in the water treatment technologies. This chapter will be dedicated to the use of porous titania-based nanomaterials for the photocatalytic degradation of dyes contained in water treatment, since this process is the most promising.

\section{Dye classifications}

Synthetic dyes exhibit considerable structural diversity (Figure 1). The main dyes employed in the industry are azo, diazo, anthraquinone, sulfur, indigoid, triphenylmetyl and phthalocyamine derivatives (Forgacs et al. 2004) (Robinson et al. 2001). Among the wide variety of colorants available, azo dyes are the most used and represent over $50 \%$ of the 
colorants used in the industry (Forgacs, Cserháti, and Oros 2004). Azo dyes can be basic, acid or sulfur. Azoïc ones are characterized by the presence of a double bond between two nitrogen atoms $(-\mathrm{N}=\mathrm{N}-)$ where at least one of the two nitrogen atoms is bonded to an aromatic group. In addition to the $-\mathrm{N}=\mathrm{N}$ - and aromatics functions, dye molecules can possess several other organic functions such as carboxyl, hydroxyl, amino and sulfoxyl groups. Because of the presence of such organic functions, most of dyes exhibit amphoteric features. The charge of the dye is strongly dependent on the $\mathrm{pH}$. Indeed, the deprotonation of acidic groups lead to the formation of an anionic moiety (Robinson et al. 2001). On the contrary, the protonation of amino functions lead to cationic dye. The dye can also be non-ionic, dependently on the $\mathrm{pH}$ (Suteu and Malutan 2013). Non-ionic dyes refer to dispersed dyes, which do not ionize in water (Robinson et al. 2001).

The chemical structure of dyes can be very different from one to another and it is not straightforward to classify them only according to one parameter. Based on their general structure, dyes can be classified as anionic, non-ionic and cationic dyes (Robinson et al. 2001). A classification based on their source (natural, synthetic, animal, plants) and on their chemical structure (azo or non-azo dyes) was proposed by Ajmal et al. 2014 (Figure 2) (Ajmal et al. 2014).

\section{Titania photocatalyst}

Titanium dioxide is widely used in the formulation of sunscreen and plastics, as pigments or as catalyst (Carp et al. 2004). For example, when used in catalysis, it enhances the hydrodesulfurization (HDS) of transition metal sulfides (TMS) by transferring electronic density towards the TMS (Castillo-Villalón et al. 2009). More recently, thanks to their good biocompatibility titania-based materials have attracted much attention for enzyme immobilization. For example, Gao et al. have reported the immobilization of horseradich 
peroxidase (HRP) in templated titania through the biomimetic titanification process (Jiang et al. 2014). The authors have shown that the encapsulated HRP exhibits improvement of $\mathrm{pH}$ and thermal stability as well as tolerance against inactive agents. The encapsulated HRP also presents better removal efficiency than the free enzyme for the removal of both phenol and 2chlorophenol. Titania is a semiconductor that has received considerable attention mainly for its applications in electronics, electrochemical systems, including photoelectrochemical solar cells, electrocatalysis, optoelectronic sensors devices and high performance photocatalytic films (Fox et al. 1993; Hoffmann et al. 1995; Linsebigler et al. 1995; Chen et al. 2007).

\subsection{Structure and properties of $\mathrm{TiO}_{2}$.}

$\mathrm{TiO}_{2}$ exhibits three main polymorphs anatase, rutile and brookite (Figure 3) (Landmann et al. 2012; Pelaez et al. 2012). The $\mathrm{TiO}_{6}$ octahedron is the common primary structural unit of these phases. The structural difference of these phases is due to the different stacking arrangements of their octahedra. Rutile crystallizes in the tetragonal system $\left(\mathrm{P} 4_{2} / \mathrm{mnm}\right.$ space group). In rutile, each octahedron has 10 neighbors: two share edges and eight share corners. The neighbors share corners along the [110]-type direction. Anatase belongs also to the tetragonal system but to the $\mathrm{I}_{1} /$ amd space group. It is composed of $\mathrm{TiO}_{6}$ octahedra sharing faces. The corner-sharing octahedron forms [001] planes. Bulk brookite is a metastable phase, which crystallizes in the orthorhombic system (Pbca space group). At high pressure nonstoichiometric $\mathrm{TiO}_{2-\mathrm{x}}$ compounds can also be obtained. The bulk titania rutile structure is the most thermodynamically stable phase. However, at the nanosized level when the particles size is lower than $11 \mathrm{~nm}$ or comprised between 11 and $35 \mathrm{~nm}$, anatase and brookite become the more stable phase, respectively (Zhang et al. 2000a). The bandgap values of bulk rutile, anatase and bookite are 3.0, 3.2 and $3.4 \mathrm{eV}$, respectively (Table 1). The Raman spectrum of bulk anatase exhibits a very intense band at around $143 \mathrm{~cm}^{-1}$ (Eg band) and this mode shifts 
to higher wavenumbers in nanocrystalline materials (Kelly et al. 1997; Zhang et al. 2000b). As depicted in Table 2, due to its properties titania has been widely used in the water treatment processes such as adsorption or photodegradation. In particular, the last one has been widely considered for the removal of either anionic or cationic dye. In this chapter, we will focus on this method for dye removal from water. For this photocatalytic application, among the common crystalline forms of titania, anatase is generally recognized to be the most active phase.

\subsection{Mechanisms of photocatalysis and principle of pollutant degradation}

Titanium dioxide photocatalysis and photodegradation mechanisms (Figure 4a) are well described in literature (Carp et al. 2004; Gaya et al. 2008; Chong et al. 2010; Ajmal, 2014; Dong et al. 2015; Cai et al. 2017). Below we will just give a short overview of the basic principles of both processes. The photocatalytic properties of $\mathrm{TiO}_{2}$ evidenced by Fujishima and Honda in 1972 are because when the photons energy of incident light is larger than the band gap of the $\mathrm{TiO}_{2}$ particles, it can be adsorbed by the semiconductor (Fujishima and Honda 1972). Electrons of the valence band are in an excited state and migrate in the conduction band. This results in the creation of photoelectrons (e-) and electronic hole $\left(\mathrm{h}^{+}\right)$according to the reaction:

$$
\mathrm{TiO}_{2}+\mathrm{h} v \rightarrow \mathrm{e}^{-}+\mathrm{h}^{+}
$$

Recombination of these electron/hole $\left(\mathrm{e}^{-/ \mathrm{h}^{+}}\right)$pairs can occur in the solid, they can also be balanced by a gap or migrate to the $\mathrm{TiO}_{2}$ particle surface. The latter phenomenon is particularly interesting since oxydo-reduction reactions can take place with the donnor or acceptor groups adsorbed at the surface. The strong oxidizing action of the hole $\left(\mathrm{h}^{+}\right)$can involve the formation of highly reactive hydroxyl $\left(\mathrm{OH}^{\bullet}\right)$ or $\mathrm{R} \cdot$ radicals through the oxidation of water, of the superficial OH groups or of the organic compounds (R), such as dyes, adsorbed 
at the $\mathrm{TiO}_{2}$ surface. These radicals are very powerful oxidizing agents, which can react with the pollutants adsorbed at the material's surface through the following indirect reactions:

$$
\begin{aligned}
& \mathrm{h}^{+}+\mathrm{H}_{2} \mathrm{O}_{\mathrm{ads}} \rightarrow \mathrm{H}^{+}{ }_{\mathrm{ads}}+\mathrm{OH}^{\cdot}{ }_{\mathrm{ads}} \\
& \mathrm{h}^{+}+\mathrm{OH}^{-} \text {ads } \rightarrow \mathrm{OH}^{\cdot}{ }_{\mathrm{ads}} \\
& \mathrm{h}^{+}+\mathrm{R}_{\mathrm{ads}} \rightarrow \mathrm{R} \cdot \mathrm{ads}
\end{aligned}
$$

Electrons $\left(\mathrm{e}^{-}\right)$in the conduction band can also react with electron acceptors such as oxygen to lead to the formation of superoxide radicals $\mathrm{O}_{2} \cdot$ ads.

$$
\mathrm{e}^{-}+\mathrm{O}_{2} \rightarrow \mathrm{O}_{2}^{\cdot}{ }^{\cdot}
$$

This reaction is very important since it prevents the electron/hole recombination. In the absence of appropriated acceptors or donors of electrons the electron/hole recombination occurs. This process is very fast, in the range of the picosecond.

$$
\mathrm{TiO}_{2}+\mathrm{h}^{+}+\mathrm{e}^{-} \rightarrow \mathrm{TiO}_{2}
$$

The superoxide radical is protonated to form hydroperoxyl radical $\left(\mathrm{HO}_{2}{ }^{\circ}\right)$ and then subsequently hydrogen peroxide $\left(\mathrm{H}_{2} \mathrm{O}_{2}\right)$ is formed, which dissociates into two highly reactive hydroxyl radicals.

$$
\begin{aligned}
& \mathrm{O}_{2}{ }^{\circ}{ }_{\text {ads }}+\mathrm{H}+\rightarrow \mathrm{HO}_{2}{ }^{\circ} \text { ads } \\
& 2 \mathrm{HO}_{2}{ }^{\circ}{ }^{a d s} \rightarrow \mathrm{H}_{2} \mathrm{O}_{2 \text { ads }}+\mathrm{O}_{2} \\
& \mathrm{H}_{2} \mathrm{O}_{2 \text { ads }} \rightarrow 2 \mathrm{OH}^{\cdot}{ }_{\text {ads }}
\end{aligned}
$$

The hydroxyl radicals will degrade the pollutant $(\mathrm{R})$.

$$
\mathrm{R}+\mathrm{OH}^{\cdot} \cdot{ }_{\text {ds }} \rightarrow \text { Intermediates of reaction } \rightarrow \mathrm{CO}_{2}+\mathrm{H}_{2} \mathrm{O}
$$

Oxidation and reduction processes will also take place at the surface of the photocatalyst:

$$
\begin{aligned}
& \mathrm{R}+\mathrm{h}^{+} \rightarrow \text { oxidation products } \\
& \mathrm{R}+\mathrm{e}^{-} \rightarrow \text { reduction products }
\end{aligned}
$$

Since the recombination probability is $99.9 \%$, this electron/hole recombination is the limiting factor for the photocatalytic efficiency. They involve a loss of the photoelectrical energy in 
the form of heat. In addition, only a small fraction of the solar spectrum, around 5\%, can effectively be used to degrade pollutants such as dyes. Indeed the bandgap of anatase ( $3.2 \mathrm{eV})$ requires ultraviolet radiation for photocatalytic activation but UV light accounts for only $5 \%$ of the sun energy compared to the $45 \%$ of the visible light (Dong et al. 2015). Thus, many studies are devoted to the shift of $\mathrm{TiO}_{2}$ bandgap towards lower values to induce an optical response of titania in the visible domain. As described in section 4.4 the main way to reach this goal consist in doping titania or associating $\mathrm{TiO}_{2}$ with another semiconductor such as $\mathrm{ZnO}$. Besides the indirect degradation mechanism, under visible light, direct degradation of the dye (Figure 4b) can also occur (Ajmal et al. 2014). However, the latter is far slower reaction compared to the indirect mechanism (Ma and Yao 1998).

\subsection{Parameter affecting the $\mathrm{TiO}_{2}$ photoactivity efficiency}

The photocatalytic efficiency of $\mathrm{TiO}_{2}$ in solution depends on several factors such as the $\mathrm{pH}$, the crystal structure, the particle size, the surface area and the porosity of the photocatalyst $(\mathrm{Li}$ et al 2005; Kim et al. 2007).

At low $\mathrm{pH}$, the $\mathrm{TiO}_{2}$ surface is positively charged and cannot provide the hydroxyl groups, which are needed for hydroxyl radical formation. However, an acidic solution enhances the amount of $\mathrm{HO}_{2} \cdot$ ads radicals and hence increases the concentration of $\mathrm{H}_{2} \mathrm{O}_{2}$, promoting the photocatalysis performance ( $\mathrm{Paz}$ 2006). On the other hand, more efficient formation of hydroxyl radicals is expected to occur in alkaline solution since a higher $\mathrm{pH}$ value can provide a larger concentration of hydroxyl ions to react with the holes to form hydroxyl radicals. However, a too high $\mathrm{pH}$ can result in excess radicals, leading to self-quenching (TorresMartinez et a. 1999).

As mentioned above, the photocatalytic activity of $\mathrm{TiO}_{2}$ is mainly attributed to its anatase phase and it is reported that higher crystallinity enhanced drastically the photocatalytic activity 
of $\mathrm{TiO}_{2}$ materials (Othani et al. 1992; Pelizzetti et al. 1993; Kelly et al. 1997; Zhang et al. 2000b). Moreover, small crystallite size is considered to favorably increase the probability of mutual $\mathrm{e}^{-} / \mathrm{h}^{+}$recombination at both surface and bulk traps.

It was also reported that the photocatalytic degradation rate of azo dyes in the presence of $\mathrm{UV} / \mathrm{TiO}_{2}$ is strongly dependent on the chemical structure of the dye. Indeed, monoazo dyes are more easily decomposed than triazo dyes since the stability of both triazine nucleus and cyanuric acid intermediates makes triazo dyes difficult to fully oxidize (Reutergådh and Iangphasuk 1997; Minero et al. 1997). Fortunately, such intermediates are not toxic.

Competitive adsorption between water molecules and the target molecules can occur due to photogenerated oxidizing species, which may not migrate far away from their formation centres, explaining that there is no or very slow rate of degradation at few nanometer layers around the catalyst particles surface (Hufschmidt et al. 2002).

According to the configuration of the reactor, light intensity, nature of the dye and morphology of $\mathrm{TiO}_{2}$ catalyst, the optimum quantity of the catalyst required for an efficient removal of the dye can change. Several studies have been realized in order to determine this optimum quantity by studying the reaction rate of the photooxidation process. Indeed, when all dye molecules are adsorbed on $\mathrm{TiO}_{2}$ surface, it clearly appears that the addition of higher quantities of photocatalyst would have no further enhancing effect on the degradation efficiency. Moreover, Zhu et al reported in their study that the excess of photocatalyst particles may increase opacity of the suspension which may retard the degradation rate (Zhu et al. 2012). Furthermore increasing the quantity of catalyst in the medium will increase particle-particle interaction. In that case, activated molecules can be deactivated by collision with ground state titanium dioxide particles.

On the other hand, the quantity of the initial dye can also influence the mechanism of photodegradation. Indeed, when increasing dye concentration, dye ions will cover more active 
sites preventing the formation of $\mathrm{OH}$ radicals on the surface of $\mathrm{TiO}_{2}$ catalyst as described in paragraph 3.2. Several authors described this phenomenon by increasing (Zhu et al. 2012) (Ilinoiu et al. 2013) or decreasing (Kansal, Singh, and Sud 2008) the quantity of initial dye. In order to increase photooxidation rate, adding oxidative species such as hydrogen peroxide $\left(\mathrm{H}_{2} \mathrm{O}_{2}\right)$, ammonium persulfate $\left(\left(\mathrm{NH}_{4}\right)_{2} \mathrm{~S}_{2} \mathrm{O}_{8}\right)$, potassium bromate $\left(\mathrm{KBRO}_{3}\right)$ or potassium peroxydisulfate $\left(\mathrm{K}_{2} \mathrm{~S}_{2} \mathrm{O}_{8}\right)$ (Qamar et al. 2005; Saquib et al. 2008) is often used in the photocatalytic process. Indeed, the electron/hole recombination causes waste of energy, and to avoid this, it is essential to prevent this latter phenomenon. In heterogeneous catalysis, molecular oxygen plays the role of an electron acceptor, so, the addition of external oxidant (electron acceptor) in the medium will increase the photocatalytic degradation of contaminants. This phenomenon is well described in literature and based in three steps (Ahmed et al. 2010):

- Removal of the electron-hole recombination

- Increase of the hydroxyl radical concentration and so of the intermediate rate compounds

- Generation of more radicals and other oxidizing species in order to increase the degradation photocatalytic rate of the compounds.

The addition of the oxidant species exhibits a dual function: acting as strong oxidants they will tend to increase the formation of hydroxyl radicals but also inhibit the electron / hole (e$/ \mathrm{h}+)$ pair recombination, however all the oxidizing agents do not have the same impact on photocatalytic degradation. Indeed, among those cited above, researchers have shown that $\mathrm{H}_{2} \mathrm{O}_{2}$ is generally the most effective oxidant (Ahmed et al. 2010). In that case, the enhancement of the degradation can be explained as follows (Akpan et al):

$$
\begin{aligned}
& \mathrm{H}_{2} \mathrm{O}_{2}+{ }^{\circ} \mathrm{O}_{2}^{-} \rightarrow{ }^{\bullet} \mathrm{OH}+\mathrm{OH}^{-}+\mathrm{O}_{2} \\
& \mathrm{H}_{2} \mathrm{O}_{2}+h v \rightarrow 2^{\cdot} \mathrm{OH} \\
& \mathrm{H}_{2} \mathrm{O}_{2}+\mathrm{e}^{-} \rightarrow{ }^{\cdot} \mathrm{OH}+\mathrm{OH}^{-}
\end{aligned}
$$


This effect of $\mathrm{H}_{2} \mathrm{O}_{2}$ has been demonstrated by Chiou et al in the photocatalytic degradation of phenol where the increase of the removal efficiency is observed (58 to $84 \%$ within $3 \mathrm{~h}$ with the addition of $\mathrm{H}_{2} \mathrm{O}_{2}$ from $1.77 \mathrm{mM}$ to $8.82 \mathrm{mM}$ ) (Chiou et al. 2008). In this study, they also show the total degradation of phenol within $2.5 \mathrm{~h}$ and $1 \mathrm{~h}$ by increasing the $\mathrm{H}_{2} \mathrm{O}_{2}$ concentration from $44.1 \mathrm{mM}$ to $88.2 \mathrm{mM}$.

In addition, it has been generally shown that the $\mathrm{UV}_{\mathrm{TiO}} /$ oxidant degradation process is more effective in acidic than in basic medium (Ahmed et al. 2010).

Some studies, however, have shown that an optimal concentration of $\mathrm{H}_{2} \mathrm{O}_{2}$ should be taken into account. In fact, at higher concentrations, for example, the degradation of Orange $\mathrm{G}$ on N-doped $\mathrm{TiO}_{2}$ decrease (Akpan and Hameed 2009). This can be explained by the consumption of $\bullet \mathrm{OH}$ radicals and holes by $\mathrm{H}_{2} \mathrm{O}_{2}$ itself as described as follows (Mahmoodi et al. 2006; Coleman et al. 2007):

$\cdot \mathrm{OH}+\mathrm{H}_{2} \mathrm{O}_{2} \rightarrow \mathrm{HO}_{2}^{\bullet}+\mathrm{H}_{2} \mathrm{O}$

$\cdot \mathrm{OH}+\mathrm{HO}_{2} \cdot \rightarrow \mathrm{O}_{2}+\mathrm{H}_{2} \mathrm{O}$

$\mathrm{h}^{+}+\mathrm{H}_{2} \mathrm{O}_{2} \rightarrow \mathrm{O}_{2}+2 \mathrm{H}^{+}$

In parallel, the recombination of radicals must be taken into account as a competitive reaction that can occur:

$\cdot \mathrm{OH}+{ }^{\circ} \mathrm{OH} \rightarrow \mathrm{H}_{2} \mathrm{O}_{2}$

Both ${ }^{\circ} \mathrm{OH}$ and $\mathrm{h}+\mathrm{can}$ finally be considered as strong oxidants for organic pollutants but in the excess of $\mathrm{H}_{2} \mathrm{O}_{2}$ concentration, the photocatalytic degradation can be inhibited. Moreover, $\mathrm{H}_{2} \mathrm{O}_{2}$ can be adsorbed on $\mathrm{TiO}_{2}$ particles that leads to surface modification and thus to the photocatalytic degradation (Tanaka et al. 1989).

However, in various studies many authors have reported adsorption of compounds or intermediates that may acts as poison on the catalyst surface such as e.g. a multilayer of dye molecules around the catalyst particles surface which leads to limited interaction between 
excited dye molecule and the catalyst and thus a decrease in photooxidation process (Bizani et al. 2006).

To develop efficient photocatalysts, the specific surface area is also a crucial parameter that should be considered. Generally, large surface area is likely to exhibit better photocatalytic activity, because a large surface area provides more active sites for adsorbing dyes. Recently, much attention was paid to the synthesis of the nanostructured mesoporous photocatalysts with high surface area and uniform pore size distribution. In this chapter, we will particularly focus on this point.

\section{Porous $\mathrm{TiO}_{2}$ photocatalysts}

\subsection{Templated nanostructured $\mathrm{TiO}_{2}$}

Usually mesoporous titania are synthesized from the sol-gel process using titanium alkoxides as precursors. For example, using this technique and starting from titanium isopropoxide as precursor and performing a hydrothermal treatment at different temperatures from 40 to $240^{\circ} \mathrm{C}$, Rasalingam et al. have synthesized efficient photocatalysts for the degradation of rhodamine B under visible light irradiation (Rasalingam et al. 2015). Using the sol-gel approach the textural properties of the $\mathrm{TiO}_{2}$ materials are mainly controlled by the synthesis conditions such as the $\mathrm{pH}$, the gel composition, the humidity and so on (Simonsen M.E. and Søgaard 2010). The textural properties of the porous $\mathrm{TiO}_{2}$ can also be enhanced by combining the sol-gel process with the surfactant templating mechanism, reported for the preparation of the ordered mesoporous silica materials (Li et al. 2014; Baghari et al. 2015, Kimura 2016). Two methods can lead to the formation of mesostructured $\mathrm{TiO}_{2}$ mesostructures. The first one is the hard-templating route. In that case, the mesoporous titania is prepared in a confined space, for example via replication of mesoporous silica. Since the template prevents collapse of the mesostructure upon calcination, the main advantage of this method is the preservation 
of the ordered mesopore channel array during the crystallization step at high temperature. However, this procedure is time consuming, non eco-friendly (it usually requires hydrofluoric acid to remove the hard template) and it is quite difficult to completely fulfill the mesopores of the hard template with the titania precursor. By contrast, the second mechanism labelled the soft templating pathway is less time consuming and more eco-friendly. A large variety of structure-directing agents such as ionic liquid, poly(ethylene glycol), diblock copolymer, polyoxoethylene fluoroalkyl ether, cyclodextrins or home-made block copolymers (BCPs) have been used to prepare the porous titania material though the soft templating route (Zimny et al. 2010; Veliscek-Carolan et al. 2015; Lannoy et al. 2014; Cao et al. 2016; Preethi et al. 2017). Nevertheless, among these templates, thanks to their large molecular weights, the triblock copolymers such as Pluronic P123 or F127 are the most widely considered for the preparation of porous $\mathrm{TiO}_{2}$ (Ismail and Bahnemann 2011). Nevertheless, the main difficulty is to control the alkoxide precursor hydrolysis and condensation that are much faster than for silicon. To reach this goal, different strategies have been developed and, for example, this control can be achieved by the use of mixed inorganic precursor or hydrolysis controlling agents, such as acetylacetone, or hydrogen peroxide (Tian et al. 2002; Tian et al. 2003; Li et al. 2008). For example, in 1995 Antonelli and Ying have reported the first example of mesoporous titania by using tretradecyl phosphate as surfactant and titanium acetylacetonate trisisopropoxide as $\mathrm{Ti}$ source. Acetylacetone acts as a hydrolysis controlling agent of the titanium precursor (Antonelli and Ying 1995). The obtained material adopts a hexagonal pore ordering but the structure partially collapses after the pores are freed from the surfactant by calcination at $350{ }^{\circ} \mathrm{C}$. More recently, we have developed a synthesis procedure of ordered mesoporous materials, having semi-crystalline framework and with high specific surface area (> $250 \mathrm{~m}^{2} / \mathrm{g}$ ). Our strategy is based on the evaporation-induced self-assembly method, usually used for the preparation of the mesoporous films and on the liquid crystal templating 
mechanism (Zimny et al. 2010). The obtained mesostructured $\mathrm{TiO}_{2}$ materials with semicrystalline framework are effective photocatalyst for dyes degradation such as methyl orange (Zimny et al. 2012; Assaker et al. 2015). The efficiency of the process depends on the working conditions and the optimal conditions are: one hour of dark adsorption, a $\mathrm{TiO}_{2}$ concentration of $0.5 \mathrm{~g} / \mathrm{L}$, a methyl orange concentration of $15 \mathrm{mg} / \mathrm{L}$ at acidic $\mathrm{pH}(\mathrm{pH}=4)$ with an incident light intensity of 10-5 Einstein $\mathrm{L}^{-1} \mathrm{~s}^{-1}$. The rates of Methyl Orange decomposition follow Langmuir-Hinshelwood kinetics. The dependence of the reaction rate on the incident light intensity is first order. No change in the activity of the catalyst is observed at the first 4 cycles, which indicates that the $\mathrm{TiO}_{2}$ is able to use repeatedly (Blin et al. 2012). We have also succeeded in introducing a second level of porosity and we have shown that thanks to the synergic effect of the presence of the two pore networks, the dual mesoporous titania are more efficient for the photo-degradation of methyl orange, used as model dye, than the mono-modal ones (Naboulsi et al. 2017). However, one main drawback still persists: it concerns the limitation of the crystallization temperature around $400^{\circ} \mathrm{C}$, which is far under the required temperature $\left(550^{\circ} \mathrm{C}\right)$ to completely transform amorphous $\mathrm{TiO}_{2}$ into anatase.

Another dual templating approach has been reported to produce hierarchical macro/mesoporous $\mathrm{TiO}_{2}$ by a bi-template interface directed deposition mechanism based on a combination of soft-templating with P123 surfactant for mesoporous network and hardtemplating with macroporous carbon gabarit (Zhao et al. 2016). Macroporous carbon gabarit was first synthesized and immersed in the precursor solution of the mesoporous $\mathrm{TiO}_{2}$ network. The resulting hierarchical macro/mesoporous $\mathrm{TiO}_{2}$ material presents a regular array of macropores surrounded by ordered mesoporous titania walls composed of well crystallized anatase nanocrystals. Due to its high specific surface area, high porosity, well-connected channels and abundant hydroxyl groups, a high capacity of adsorption toward rhodamine B dye was observed. Under stimulated sunlight the rhodamine B was fully decomposed in the 
presence of this hierarchical macro/mesoporous $\mathrm{TiO}_{2}$ in $8 \mathrm{~min}$. The photodecomposition of rhodamine $\mathrm{B}$ was slower with two reference catalysts: $\mathrm{TiO}_{2}$ hollow microsphere arrays and commercial Degussa $\mathrm{P} 25 \mathrm{TiO}_{2}$. Macroporosity was also generated by an interesting approach derived from particle-stabilized emulsions to produce macrostructure-controlled titania ceramics has been reported by $\mathrm{Li}$ et al. (Li et al. 2016). With 3D interpenetrating highly porous structure and uniform 3-18 $\mu \mathrm{m}$ pores, the materials has showed high adsorption capacity and an excellent photocatalytic performance for the degradation of rhodamine B. Interestingly, sucrose has been added in the synthesis medium to produce $\mathrm{C}$ coating on the $\mathrm{TiO}_{2}$ surface by sintering the solid at $500^{\circ} \mathrm{C}$ under $\mathrm{N}_{2}$. The C-coating of macroporous $\mathrm{TiO}_{2}$ ceramic has improved both the dye adsorption capacity and the photodegradation rate of rhodamine B.

\subsection{Nanoparticles and nanotubes}

When $\mathrm{TiO}_{2}$ materials are synthesized as particles with nanosize they results in high specific surface area materials with exalted photocatalytic properties. $\mathrm{TiO}_{2}$ nanoparticles have been widely studied for photodegradation of organic pollutants in aqueous solutions and showed high potentiel for water waste treatments. In particular, they have been studied for their ability to decompose organic dyes in aqueous solutions. There are several methods to synthesize $\mathrm{TiO}_{2}$ nanomaterials such as sol-gel, sol, hydrothermal, solvothermal and chemical vapor deposition that are well described in the recent review of M. M. Mahlambi et al (Mahlambi et al. 2015). The synthesis method and the experimental conditions are determinant on the structural and textural characteristics such as crystalline phase, crystallinity degree, particle size, and morphology, which directly influence the photocatalytic properties. Nanoparticles can be prepared at low temperature via a sol-gel or sol route but result in $\mathrm{TiO}_{2}$ amorphous phase and thus a subsequent thermal treatment has to be applied to get the anatase $\mathrm{TiO}_{2}$ crystalline phase. W-C. Lin et al. have prepared anatase $\mathrm{TiO}_{2}$ nanoparticles by using a sol-gel method with 
titanium isopropoxide (TTIP), isopropanol as solvent, acetylacetone (AcAc) as stabilizer for TTIP and in the presence of polyethylene glycol that allowed controlling specific surface area (Lin et al. 2012). The synthesis experimental conditions have been optimized with the Tagushi experimental design method $\left(\mathrm{L}_{9}\left(3^{4}\right)\right)$. The post-synthesis calcination treatment to form pure anatase nanoparticles was also investigated and a temperature of $550^{\circ} \mathrm{C}$ was found optimal. The synthesized nanoparticles processed as powder or as films have been shown to be efficient photocatalyst for the degradation of methyl blue, methyl orange and indigo dyes in water after 10h of UV light irradiation. Among the four parameters varied for the experimental design matrix, the molar ratio AcAc/TTIP was found to have the greatest impact on the photocatalytic degradation of dyes in water. It was also observed that the presence of hydroxyl groups can improve the photocatalytic activity. The size of $\mathrm{TiO}_{2}$ particles is also paramount of importance for photocatalytic efficiency. The influence of the morphology on the photocatalytic activity $\mathrm{TiO}_{2}$ nanoparticles has been investigated and the nanorod shape aroused a particular interest. The sol-gel route allows introducing polymers or block copolymers, amphiphilic or not, in the synthesis medium to control morphology, particles size and aggregation. For a practical and an economical point of view, it is highly desired to develop facile and surfactant/polymer-free methods for the morphology control of $\mathrm{TiO}_{2}$ nanostructures. Anatase $\mathrm{TiO}_{2}$ nanorods have been synthesized via a simple two-step method: a hydrothermal treatment of the commercial $\mathrm{P} 25 \mathrm{TiO}_{2}$ nanoparticles in a composite-hydroxide eutectic system of 1:1 $\mathrm{M} \mathrm{KOH} / \mathrm{NaOH}$, followed by acid post-treatment (Hafez 2009). The obtained $\mathrm{TiO}_{2}$ nanorods have a good crystallinity with the dimensions of 200-300 nm length and of 30-50 nm diameter. Furthermore, they are mesoporous with an average pore size of $6.2 \mathrm{~nm}$ and have a BET specific area of $85 \mathrm{~m}^{2} / \mathrm{g}$. Compared to their precursor anatase/rutile $\mathrm{TiO}_{2} \mathrm{P} 25$ and the titanate nanotubes, the pure anatase $\mathrm{TiO}_{2}$ nanorods are more efficient for the photodegradation of the commercial cibacrown red (FN R) textile dye under UV irradiation. Hierarchical rutile $\mathrm{TiO}_{2}$ 
superstructures made of nanorods assembled at a water-dicloromethane interface have been prepared by a hydrothermal treatment of dichloromethane solution of $\mathrm{TiCl}_{4}$ (Wang et al. 2009). Size and shape of nanostructures were easily modified by varying the $\mathrm{H}_{2} \mathrm{O} / \mathrm{TiCl}_{4}$ molar ratio. The resulting $\mathrm{TiO}_{2}$ hierarchical superstructures showed higher photocatalytic property to decompose methylene blue under UV light irradiation in aqueous solution (92\% in $30 \mathrm{~min}$ ) compare to that of commercial P25 (47\% in $30 \mathrm{~min}$ ). The hydrothermal synthesis route based on a water-dicloromethane interface has allowed obtaining $\mathrm{TiO}_{2}$ nanostructures as powder or as freestanding film. The film is composed of greater crystallites, have a lower specific surface area and shows lower photocatalytic efficiency, however it offers an easier handling. The synthesis of $\mathrm{TiO}_{2}$ nanorods have been also realized by a rapid microwave-assisted polyol route from titanium glycolate followed by water treatment under microwave irradiation or calcination at $500^{\circ} \mathrm{C}$ (Gerasimova et al. 2016). Following this route or a conventional polyol route, the synthesized nanorods are micro-mesoporous. The post-synthesis water treatment under microwave allowed forming anatase nanocrystallites of $5.4 \mathrm{~nm}$ size and increasing specific surface area. The as-synthesized $\mathrm{TiO}_{2}$ nanorods show a better photocatalytic activity for the removal of rhodamine B (97\% decomposition of rhodamine B after 30 min of UV light irradiation). The post-synthesis calcination at $500^{\circ} \mathrm{C}$ has resulted in the formation of mesoporous nanorods with bigger anatase crystallites $(19.3 \mathrm{~nm})$, a lower specific surface area and a lower capacity of dye adsorption, but having higher photocatalytic efficiency $(98 \%$ decomposition of rhodamine B after 15 min of UV light irradiation).

Titania nanotubes (TNT) have been also considered for the removal of dyes from aqueous solutions (Lai et al. 2014). The three general approaches in preparing TNT, are alkaline hydrothermal route, anodization techniques, and chemical (template) synthesis. The hydrothermal synthesis is recognized as a facile and low cost method and leads after a first step to titanate nanotubes that can be transformed into anatase TNT by acid post-treatment 
and calcination (Xu et al. 2011). The obtained mesoporous anatase TNT photocatalyst have shown a good photocatalysis efficiency toward the degradation of acid orange 7 dye. Recently, a single post-acid treatment after hydrothermal synthesis of titanate nanotubes in highly concentrated $\mathrm{NaOH}$ solution was reported to be sufficient to obtain anatase nanotubes with high surface $\mathrm{OH}$ density (Tsai et. 2017). The resulting materials are active photocatalysts for the decomposition of congo red and crystal violet dyes due to their high dye pre-adsorption capacity.

The hydrothermal synthesis of titanate nanotubes with different temperatures and durations, and the investigation of their photocatalytic properties for the removal of methylene blue under UV light irradiation from an aqueous environment was reported by Liu et al. (Liu et al. 2015) and Subramaniam et al. (Subramaniam et al. 2017). Compared to their $\mathrm{P} 25 \mathrm{TiO}_{2}$ nanoparticle precursor, they are mesoporous with larger specific surface area and present both a higher dye absorption capacity and a better photocatalytic performance for the dye decomposition under UV light irradiation in aqueous solutions.

\section{3. (Nano)composites : $\mathrm{TiO}_{2}$ supported on porous matrices}

Mesoporous $\mathrm{TiO}_{2}$ are not thermally stable and usually exhibit low porous characteristics, or even a collapse of the mesostucture, after thermal treatment that is necessary to get highly crystalline anatase walls for good photocatalytic efficiency. To overcome these drawbacks silica-embedded titania and/or titania-silica mixed oxides have been prepared. The introduction of silica is also a way to modulate surface properties for improving the adsorption of dyes and thus the photocatalytic performance of the material. Highly ordered 2D hexagonal mesoporous $\mathrm{TiO}_{2} / \mathrm{SiO}_{2}$ composite with variable $\mathrm{Ti} / \mathrm{Si}$ ratios have been prepared by evaporation induced co-assembly process using titanium isopropoxide and tetraethylorthosilicate as precursors, triblock P123 copolymer as template and a large amount 
of $\mathrm{HCl}$ to control co-condensation of precursors (Dong et. 2007). The obtained $\mathrm{TiO}_{2} / \mathrm{SiO}_{2}$ nancomposites have large regular mesopores $(6-8 \mathrm{~nm})$ and are ultra thermally stable, over $900^{\circ} \mathrm{C}$ when $\mathrm{Ti} / \mathrm{Si} \leq 80 / 20$, with high specific surface area $\left(200-300 \mathrm{~m}^{2} / \mathrm{g}\right)$. Their walls are constituted of anatase nanocrystallites glued by amorphous silica. The photocatalytic activities of these composites for the degradation of rhodamine B in aqueous solution were found excellent and higher than those of commercial $\mathrm{TiO}_{2} \mathrm{P} 25$. The study of their photocatalytic properties has been extended to the degradation of a large variety of anionic and cationic dyes (Dong et al. 2012). It was demonstrated that the surface properties of these $\mathrm{TiO}_{2} / \mathrm{SiO}_{2}$ nanocomposites can be modulated by varying the $\mathrm{Ti} / \mathrm{Si}$ ratio and the calcination temperature to adapt them for an optimal adsorption (number of surface hydroxyls) and efficient photodegradation (size and crystallinity of anatase nanocrystals) according the nature of the dye. Recently, it was reported that the extraction of silica from these $\mathrm{TiO}_{2} / \mathrm{SiO}_{2}$ nanocomposites leads to stable and reusable three-dimensional interconnected mesoporous anatase photocatalysts. The photocatalytic activity for the degradation of dyes in aqueous solution under UV light irradiation is much higher than the $\mathrm{TiO}_{2} / \mathrm{SiO}_{2}$ parent materials and commercial P25 (Dong et al. 2017). The departure of silica from the wall has left interlinked mesoporous network that helps the diffusion of dye molecules. The introduction of silica precursor as a stabilizer has been also reported for the solvothermal synthesis of silicaembedded titania rhombic shaped nanoparticles (Yao et al. 2013). The presence of silica allows growing well defined anatase crystals with high specific surface area that increases linearly with the introduced amount of silica and due to textural mesoporosity. Due to the high specific surface area and the high crystallinity, the photocatalytic activity of the optimal silicaembedded titania nanocomposite for methylene blue photodegradation under UV light irradiation is higher than those of pure $\mathrm{TiO}_{2}$ nanoparticles and commercial $\mathrm{P} 25$. 
Coupling $\mathrm{TiO}_{2}$ with another material can be an effective tool to tune the electron/hole recombination. As the photocatalysis mechanism of $\mathrm{ZnO}$ is very similar to the one of $\mathrm{TiO}_{2}$, both oxides are often associated (Jing et al. 2004; Lin et al. 2005). For example, Serpone et al., which have examined many coupled oxides for the photodegradation of aromatic compounds, demonstrated during the reaction that a transfer of electrons and holes happens in the $\mathrm{ZnO} / \mathrm{TiO}_{2}$ (Serpone et al. 1995). This transfer inhibits the recombination of the charge carriers and enhances the photocatalytic activity. Pérez-Larios et al. have reported the preparation of $\mathrm{ZnO} / \mathrm{TiO}_{2}$ mixed oxides by sol-gel method varying the amount of $\mathrm{ZnO}$ in the materials between 1 and 10 wt\%. (Pérez-Larios et al. 2012). They showed that obtained materials present a photocatalytic activity in water splitting six times higher than that presented by the bare $\mathrm{TiO}_{2}$. Xu et al. (Xu et al. 2004, 2005) prepared $\mathrm{ZnO} / \mathrm{TiO}_{2}$ mixed oxides by simple wet impregnation of $\mathrm{ZnO}$ precursor on $\mathrm{TiO}_{2}$ pre-synthesized nanoparticles (Xu et al. 2004; $\mathrm{Xu}$ et al. 2005). The authors showed that when $\mathrm{ZnO}$ is located on the surface of $\mathrm{TiO}_{2}$ nanoparticles it acts as recombination center of charge carriers. Consequently, the photocatalytic activity of obtained materials is enhanced. Shifu et al. investigated the preparation of $\mathrm{ZnO} / \mathrm{TiO}_{2}$ mixed oxides by ball milling in water (Shifu et al. 2008). These authors tested the effect of the amount of $\mathrm{Zn}$ on photocatalytic oxidation of methyl orange and reduction of $\mathrm{Cr}_{2} \mathrm{O}_{7}{ }^{2-}$. They demonstrated that the photocatalytic degradation efficiency of methyl orange decreases with the increase of $\mathrm{Zn}$ amount in the $\mathrm{ZnO} / \mathrm{TiO}_{2}$ materials. However, the photocatalytic reduction of $\mathrm{Cr}_{2} \mathrm{O}_{7}^{2-}$ depends on the amount of $\mathrm{Zn}$ on the material and reaches its optimum when this amount is of $5 \mathrm{wt}$. \%. They showed also that the materials photocatalytic activity is influenced by the ball milling time, and the reduction of $\mathrm{Cr}_{2} \mathrm{O}_{7}^{2-}$ is increased when milling time is up to 12 hours. Guo et al. explain that high amount of $\mathrm{ZnO}$ increases the percentage of voids due to the lack of oxygen in the crystallites of anatase (Guo et al. 2010). These gaps are likely to induce an intermediate energy level close to the 
conduction band of the anatase phase and therefore to trap photogenerated electrons, by inhibiting the recombination of $\mathrm{e}^{-} / \mathrm{h}^{+}$, which consequently improves the photocatalytic activity of the material. In the same context, Liao et al. attribute the increasing of the photocatalytic activity of the $\mathrm{ZnO} / \mathrm{TiO}_{2}$ compared to $\mathrm{TiO}_{2}$, to the presence of $\mathrm{ZnO}$ particles which cover the surface of $\mathrm{TiO}_{2}$ (Liao et al. 2008). Thus, an electron (e') transfer occurs between the $\mathrm{ZnO}$ conduction band and that of the $\mathrm{TiO}_{2}$ and inversely for the photogenerated holes $\left(\mathrm{h}^{+}\right)$, which move from the valence band of $\mathrm{TiO}_{2}$ to that of $\mathrm{ZnO}$. The separation of charge carriers increases their life and improves the photocatalytic efficiency. In both cases, the presence of $\mathrm{ZnO}$ aggregates on the surface of mesoporous $\mathrm{TiO}_{2}$ reduces the recombination of $\mathrm{e}^{-/ h^{+}}$and improves the photocatalytic activity of $\mathrm{TiO}_{2}$.

The hydrothermal synthesis of mixed porous $\mathrm{TiO}_{2} / \mathrm{SnO}_{2}$ templated by polystyrene beads was also reported with higher photocatalytical activity toward the photodegradation of rhodamine B under UV light irradiation than the one of commercial P25 (Wang et al. 2014). However, the correlation between crystalline structures, mesoporous porous structure with photocatalytical activity when molar ratio $\mathrm{Ti} / \mathrm{Sn}$ is varied was not clearly evidenced.

Concerning $\mathrm{TiO}_{2}$ nanoparticles, they are highly photocatalytically active for the photodegradation of organic pollutant in solution. However, their morphology makes them difficult for handling and for recovering. To overcome these problems, various strategies to synthesize $\mathrm{TiO}_{2}$ nanoparticles supported composites as photocatalysts for dye degradation have been developed. Two series of $\mathrm{TiO}_{2}-\mathrm{SiO}_{2}$ composites have been prepared by post-synthesis impregnation of a $\mathrm{TiO}_{2}$ precursor onto SBA-15 silica matrices and a subsequent thermal treatment at $400{ }^{\circ} \mathrm{C}$ under air (Besançon et al. 2016). The influence of the textural properties (pore size from 4 to $8 \mathrm{~nm}$ ) of the SBA-15 and the $\mathrm{TiO}_{2}$ content (20-80 wt $\%$ ) on the dispersion of $\mathrm{TiO}_{2}$ and its crystallization in anatase were evaluated. For $\mathrm{TiO}_{2}$ content superior to $25 \mathrm{wt} \%$ and mesopores smaller than $8 \mathrm{~nm}$, 
the impregnation occurred inside and outside the porosity of the hosts and $\mathrm{TiO}_{2}$ crystallized as anatase nanoparticles on the SBA-15 particle surface. The quantity of crystallized anatase was determined by XRD using an internal standard when crystalline particles were detected. Their photocatalytic activity was evaluated by following the degradation of methyl orange and compared to commercial $\mathrm{TiO}_{2}$ references (P25 from Degussa and pure anatase $10 \mathrm{~nm}$ from Alfa Aesar). While P25 reference appeared to be the best photocatalyst for the degradation of methyl orange in the used conditions, the photoactivity of the composites containing crystallized anatase were similar to that of Alfa Aesar commercial fully crystallized anatase with a particle size of the same order of magnitude. It clearly appeared that comparing the composites, the one with $44 \mathrm{wt} \%$ of crystallized anatase (experimental $80 \mathrm{wt} \% \mathrm{TiO}_{2}$ ), so more than twice less than commercial anatase references, exhibit the highest methyl orange degradation rate, very closed to the one observed for P25. The presence of the amorphous $\mathrm{SiO}_{2}$ support has led to a well dispersion of $20 \mathrm{~nm}$ well-crystallized anatase particles and assured a high density of hydroxyl groups that consequently improved the catalytic performance of $\mathrm{TiO}_{2}-\mathrm{SBA} 15$ composite.

Supported $\mathrm{TiO}_{2}$ on silica SBA-15 have been also prepared with varied $30-80 \mathrm{wt} \% \mathrm{TiO}_{2}$ loading by a post-synthesis step based on Ti-alkoxide hydrolysis in a support/isopropanol suspension and subsequent calcination $500-900^{\circ} \mathrm{C}$ (Yang et al. 2006). The presence of mesoporous $\mathrm{SiO}_{2}$ amorphous support allowed having high specific area, delaying anatase-to-rutile transformation (only the anatase phase was detected by $\mathrm{XRD}$ for calcination temperature up to $800^{\circ} \mathrm{C}$ ) and controlled-size anatase nanocrystals. As a consequence, the $\mathrm{TiO}_{2}$-supported SBA-15 composites were found to be more active for the photodegradation under UV irradiation of methylene blue in aqueous solution than the commercial P25. Mesoporous aluminosilicate Al-SBA-15 
prepared in supercritical carbon dioxide $(\mathrm{Sc}-\mathrm{CO} 2)$ was also considered for supporting $\mathrm{TiO}_{2}$ nanoparticles (Chang et al. 2013). It was observed that $\mathrm{TiO}_{2} / \mathrm{Al}-\mathrm{SBA}-15$ composites showed good methylene blue decolorization in aqueous solutions that was much higher than those of $\mathrm{TiO}_{2} / \mathrm{SBA}-15$ and commercial $\mathrm{P} 25 \mathrm{TiO}_{2}$. The photocatalytic activity can be mainly related to a higher dye adsorption capacity due to the enhanced specific surface area when some $\mathrm{Si}$ species are substituted by $\mathrm{Al}$ species. $\mathrm{TiO}_{2}$ supported photocatalyst have been also obtained by using microporous supports such as zeolites. Mesoporous $\mathrm{TiO}_{2}$ supported ZSM-5 zeolite with large specific surface area have been prepared by a direct templating method with P123 as surfactant, 1,3,5triisopropylbenzene (TIPB) as swelling micelle agent (Znad et al. 2018). The inorganic component are commercial and hydrothermally treated with P123/TIPB aqueous solution to form a multilamellar mesoporous $\mathrm{TiO}_{2} / \mathrm{ZSM}-5$ that is photocatalytically active for the total and fast degradation of methyl orange dye under solar light irradiation in aqueous media. Moreover, the regeneration and the reuse of the photocatalyst was demonstrated. The high photocatalytic efficiency seems to be due in large part to the high specific surface area, however, in this paper the structural and textural characteristics are not clearly exploited and discussed.

Porous titania-supported composites have been also synthesized with the highly stable Metal-Organic Framework (MOF) UiO-66 that has a high specific surface area (Wang et al. 2017). Different amounts of commercial $\mathrm{TiO}_{2} \mathrm{P} 25$ were directly introduced in the precursor solution of the UiO-66. The presence of UiO-66 allowed greatly increasing the methyl orange and rhodamine B dye adsorption in aqueous solutions and the photocatalytic decomposition under visible light was faster with increasing amount of $\mathrm{TiO}_{2}$. An optimal molar ratio $\mathrm{TiO}_{2} / \mathrm{Zr}$ (from UiO-66) of 49 was found for the most efficient photocatalyst, which correspond to the nanocomposite with the most reduced 
bandgap and recombination of electron-hole pairs. Moreover, the reusability of these $\mathrm{TiO}_{2} / \mathrm{MOF}$ photocatalyst has been demonstrated.

Other problems that meet $\mathrm{TiO}_{2}$ nanoparticles are related to their small size and very active surface that make them prone to deformation and agglomeration during reactions, leading to the loss of their catalytic activity. Besides disperse $\mathrm{TiO}_{2}$ nanoparticles on the surface of a solid matrix, another approach consisting in coating them with a mesoporous $\mathrm{SiO}_{2}\left(\mathrm{mSiO}_{2}\right)$ layer. A 3-D network of core shell P25@ $\mathrm{mSiO} 2$ has been prepared by a simple surfactant assisted sol-gel method (Gong et al. 2017). The resulting nanocomposite have shown improved photocatalytic activity for the degradation of methyl orange due to the presence of the $\mathrm{mSiO}_{2}$ coating that stabilizes the nanosized photocatalysts, increases dye adsorption capacity, and binds $\mathrm{TiO}_{2}$ particles, providing mechanical reinforcement of the nanocomposite. Moreover, it was suggested that hydroxyl radicals $(\cdot \mathrm{OH})$ play a major role in enhancing the performance of $\mathrm{P} 25 @ \mathrm{mSiO}_{2}$. A mechanism for the $\cdot \mathrm{OH}$ radical generation and transport in these nanocomposites has been proposed.

Interestingly, since powder materials are difficult to manipulate and to recover from liquid suspension, the introduction of iron oxide phase was realized in $\mathrm{TiO}_{2} / \mathrm{SiO}_{2}$ composites to allow easy magnetic removal of the catalyst from water after reaction (Fisli et al. 2017). $\mathrm{Fe}_{3} \mathrm{O}_{4} / \mathrm{SiO}_{2} / \mathrm{TiO}_{2}$ composite has been prepared by the heteroagglomeration method. $\mathrm{Fe}_{3} \mathrm{O}_{4}$ magnetite nanoparticles particles were co-precipitated with $\mathrm{SiO}_{2}$ that forms an amorphous coating. A suspension of commercial $\mathrm{TiO}_{2}$ nanoparticles dispersed in ammonium sulfate aqueous solution was added to the obtained $\mathrm{Fe}_{3} \mathrm{O}_{4} / \mathrm{SiO}_{2}$ suspension. $\mathrm{TiO}_{2}$ nanoparticles is a mixture of anatase and rutile phase. The photocatalytic activity of the $\mathrm{Fe}_{3} \mathrm{O}_{4} / \mathrm{SiO}_{2} / \mathrm{TiO}_{2}$ composite was evaluated for the photodegradation of methylene blue in aqueous solution under UV light irradiation. $\mathrm{SiO}_{2}$ coating plays the role of a barrier between $\mathrm{Fe}_{3} \mathrm{O}_{4}$ and $\mathrm{TiO}_{2}$ 
that improve photocatalytic properties and increase the dye adsorption capacity. Although the photocatalytic activity of the $\mathrm{Fe}_{3} \mathrm{O}_{4} / \mathrm{SiO}_{2} / \mathrm{TiO}_{2}$ composite is slightly lower than the one of the commercial $\mathrm{TiO}_{2}$ in terms of amount of degraded methylene blue, it can be easily collected from the aqueous solution after reaction by using a magnetic bar.

For an economical and environmental point of view, the use of natural porous materials as support for $\mathrm{TiO}_{2}$ nanoparticles can present a great interest. $\mathrm{TiO}_{2}$ modified kaolin photocatalysts have been prepared by physical mixing with $\mathrm{P} 25$ and impregnation with $\mathrm{TiO}_{2}$ sol (Hajjaji et al. 2016). Good photocatalytic performances for the removal of methylene blue and orange II dyes from aqueous solutions have been reported due to the combination of photocatalytic and adsorption processes. Diatomite, a natural porous silica material was used as support for producing $\mathrm{TiO}_{2} /$ diatomite composites by a modified sol-gel method and a subsequent calcination step at different $450-950^{\circ} \mathrm{C}$ temperatures (Wang et al. 2015). The presence of an interfacial anchoring strength between the $\mathrm{TiO}_{2}$ nanoparticles and diatom skeleton via Si-O-Ti bonds has been shown. The best photocatalytic activity for the photodegradation of rhodamine $\mathrm{B}$ was observed for the $\mathrm{TiO}_{2} /$ diatomite composite calcined at $750^{\circ} \mathrm{C}$ for $2 \mathrm{~h}$ and having $90 / 10$ weight ratio of anatase/rutile. Hydroxyapatite/titania nanocomposites were synthesized by a dissolution/precipitation method from a titanium alkoxide and a natural phosphate. These low-cost photocatalysts were found efficient for the removal of patent blue $\mathrm{V}$ and methylene blue dyes from water by combination of adsorption and photodegradation processes. Milimeter-size porous $\mathrm{TiO}_{2} /$ alginate beads have been produced by an ionotropic gelation route with commercial anatase titania powder (Gjipalaj et al. 2017). The composite beads were found good adsorbents for anionic and cationic dyes, such as methyl orange and methylene blue, respectively. However, their photocatalytic efficiencies were observed reduced compared to the non-aggregated nanopowders. 
Nevertheless, they have the advantages to be easy to recover and reusable, making them promising materials as green photocatalysts.

Porous carbon matrices such as activated carbon [Gao et al. 2011] or ordered mesoporous carbon [Wei et al. 2014] have also been considered as interesting porous support for TiO2 nanoparticles because of the chemical inertness and stability in both acid and basic media, and tunable textural and chemical properties. The resulting increase in photocatalytic performance for the degradation of organic pollutant such as dyes has been related to their porosity. Larger pores were found preferable to avoid the pore blockage by $\mathrm{TiO}_{2}$ nanoparticles that results in lower dye adsorption capacity. Nanostructured carbon materials such as carbon nanotubes, fullerens, graphene nanosheets have arisen increasing attention due to their unusual structural and electronical properties [Wang and Zhang, 2012]. In particular, graphene has emerged as one of the most promising materials to its large surface area that improves dye adsorption capacity and its high electron mobility that reduces the electron-hole pair recombination [Morales-Tirres et al. 2012; Giovannetti et al. 2017].

\subsection{Doping of $\mathrm{TiO}_{2}$}

Another method to limit the $\mathrm{e}^{-} / \mathrm{h}^{+}$recombination and thus to enhance the photocatalytic efficiency consists in doping titania (Xu et al. 2005; Chen et al. 2008; Zaleska et al. 2008; Devi et al. 2010; Zhang et al. 2012). The objective of doping is also to shift the band gap of titania in the visible region. In fact, the photocatalytic efficiency of $\mathrm{TiO}_{2}$ depends partially upon the relative degree of branching of the reactive electron-hole pairs into interfacial charge

transfer reactions (Hoffmann et al. 1995). Because of the shift of the band gap of the photocatalyst, the presence of the dopant, such as a metal ion, in the $\mathrm{TiO}_{2}$ crystalline structure can change both the charge carrier recombination rates and interfacial electron-transfer rates. The dopant can act either as an electron trap or a hole trap. Lee et al. proceeded to doping of $\mathrm{TiO}_{2}$ with $\mathrm{Fe}$ and $\mathrm{W}$, and demonstrated that the photocatalytic activity of metal-doped $\mathrm{TiO}_{2}$ 
decreased as the concentration of dispersed $\mathrm{W}$ or Fe ion in the lattice of $\mathrm{TiO}_{2}$ was increased (Lee et al. 2001). Xu et al. were the first group preparing zinc ion surface-doped $\mathrm{TiO}_{2}$ nanoparticles and nanotubes through ligand exchange reaction, proving that the surface-doped materials exhibits a higher photoactivity than the pure ones, by decreasing the electron/hole pair recombination rate (Xu et al. 2004; $\mathrm{Xu}$ et al. 2005). Ku et al. demonstrated that an excessive $\mathrm{ZnO}$ on the surface of $\mathrm{TiO}_{2}$ might decrease the photocatalytic activity of the material by serving as recombination centers of electron-hole pairs (Ku et al. 2011). This diminution of the photocatalytic performance at large dopant concentrations (low band gap values) can be explained in terms of charge recombination. For a random distribution of substitutional acceptors/donors of charge dopants, a gaussian like density of states appears at the upper/lower part of the valence/conduction band. The corresponding density of states is roughly proportional to the dopant concentration. Nevertheless, high doping concentration (low band gap) may have detrimental effects because tunneling between trapped charges carriers makes a significant contribution to charge (electron-hole) recombination. Consequently, the photocatalytic rate constant typically decreases with the shortening of the electron-hole pair distance due to a growing level of dopant (Moser et al. 1987). This trend can be also interpreted in terms of band positions (top of valence band and bottom of conduction band, (ii)). The positions of valence band and conduction band of semiconductor reflect the oxidation ability of hole and reduction ability of electron, respectively. From the thermodynamic point of view, if the conduction band is more negative than the $\mathrm{O}_{2} / \mathrm{O}_{2}^{-}$couple, the photogenerated electrons could reduce $\mathrm{O}_{2}$ to produce $\mathrm{O}_{2} \cdot$. Meanwhile, if the position of the valence band is more positive than the $\mathrm{OH}^{-} / \mathrm{OH}^{\cdot}$ couple, the photogenerated holes could oxide $\mathrm{OH}^{-}$or $\mathrm{H}_{2} \mathrm{O}$ to form $\mathrm{OH}^{\bullet}$. When the bandgap decreases, i.e for high dopant content titania, the conduction band edge position and the valence band edge position shift downward and upward, respectively. It is now well established that the low conduction band position of 
doped titania would be the main reason for the low activity in photooxidation of organic molecule for low band gap. The oxidizing potential of the valence band holes remains more positive than the standard potential of $\mathrm{OH}^{-} / \mathrm{OH} \cdot$ couple and the reduction potential of the conduction band electrons becomes less negative than the potential of $\mathrm{O}_{2} / \mathrm{O}_{2}$. This indicates that photogenerated holes could react with chemisorbed $\mathrm{OH}^{-}$or $\mathrm{H}_{2} \mathrm{O}$ to produce $\mathrm{OH}^{\bullet}$. However, the electrons transferred to the surface of semiconductor particles could not interact with $\mathrm{O}_{2}$ to form $\mathrm{O}_{2} \cdot$. This accelerates the recombination of the photo-generated electrons and holes, thus reducing the formation rate of $\mathrm{OH}^{\circ}$. Therefore, only a low degradation rate is observed for these photocatalysts. Different strategies such as addition of metal salt into the $\mathrm{TiO}_{2}$ colloid, sol-gel, ion implantation, impregnation, chemical vapor deposition have been tested for the syntheses of metal-doped titania (Zaleska et al. 2008). For example through a post-synthesis Tayade et al. have doped mesoporous titania with different transition metal ions (Tayade et al. 2006). The authors have first prepared the $\mathrm{TiO}_{2}$ by the hydrolysis of titanium isopropoxide in the absence of surfactant, and thus no mesopore ordering was obtained. In a second step, the metal was introduced by using the wet impregnation method. The obtained doped materials have been tested for the degradation of acetophenone and nitrobenzene present in aqueous solution. The authors have demonstrated that the photocatalytic activity of the silver metal ion impregnated $\mathrm{TiO}_{2}$ photocatalyst has the highest initial rate of photocatalytic degradation for both compounds due to the interstitial position of impregnated silver metal ion in the $\mathrm{TiO}_{2}$ lattice. Among the different strategies to introduce the metal ion dopant, the direct sol gel way is of particular interest (Zaleska et al. 2008; Chauhan et al. 2012). Indeed, this technique does not required complicated instruments, since it is simple and easy. In addition, the incorporation of an active dopant in the sol during the gelation stage allows the doping element to have a direct interaction with the support. Mesoporous $\mathrm{TiO}_{2}$ was also modified with silver nanoparticles that were photogenerated during the wet impregnation 
by $\mathrm{AgNO}_{3}$ of the preformed $\mathrm{TiO}_{2}$ (Xiong et al. 2011). The $\mathrm{Ag}$ particles formed on the $\mathrm{TiO}_{2}$ surface were assumed to increase the affinity of the surface to oxygen, which is supposed to be the major role in enhancing the photocatalytic degradation of rhodamine B under UV light irradiation. The doping by metal such as bismuth has also been considered for mesoporous $\mathrm{TiO}_{2} / \mathrm{MCM}-41 \mathrm{SiO}_{2}$ nanocomposites to enhance photocatalytic activity under visible light for methylene blue removal from water solution (Mohamed et al. 2018). Synergetic effects of interfaces between $\mathrm{Bi}_{2} \mathrm{O}_{3}$ and $\mathrm{TiO}_{2}$ were assumed to enhance the catalytic performance of the composite Bi/Ti-MCM-41. Co-doping with $\mathrm{N}$ has allowed narrowing the band gap energy of the photocatalysts resulting in greater visible light photocatalytic activity for the degradation of acid Red 85-a, a fabric dye (Thejaswini et al. 2016). Co-doping with metal such as Zr and Si can affect anatase phase stability, crystallinity, particle size and optical properties of $\mathrm{TiO}_{2}$, resulting in enhanced photocatalytical activity in the photodegradation of methyl orange in aqueous solution under visible light (Ilkhechi et al. 2014).

Non-metal doping of $\mathrm{TiO}_{2}$ with boron, carbon, sulfur, fluorine or nitrogen has also been reported. For example, $\mathrm{N}$-doped $\mathrm{TiO}_{2}$ have been prepared by treating powder $\mathrm{TiO}_{2}$ in a $\mathrm{NH}_{3}$ gas flow (Zhang et al. 2010). In that case, $\mathrm{N}$-doping induces oxygen vacancies and contributes to the absorption as well as photoactivity in the visible region. It is also reported that modified $\mathrm{N}$ doped $\mathrm{TiO}_{2}$ such as $\mathrm{C}-\mathrm{N}-\mathrm{TiO}_{2}$, usually shows favorable effects for improving the photocatalytic activity in the visible compared to $\mathrm{N}$-doped $\mathrm{TiO}_{2}$ (Zhang et al. 2010). The photocatalytic activity towards degradation of rhodamine B dye under visible light was enhanced by doping with non metal dopants, N, N/S and N/F hierarchical macro-/mesoporous $\mathrm{TiO}_{2}$ and combining with water-mediated adsorption (Pan et al.2013). Beside the advantage to make the $\mathrm{TiO}_{2}$ photocalyst active under visible light, the doping with non metal such as carbon could be also be benefit for increasing dye adsorption capacity and improve the photocatalyst activity for dye removal by combination of adsorption and degradation (Xu et 
al. 2016). Doping with sulfur creates acid sites on the photocatalyst surface that enhance photocatalytic activity for the degradation of organic molecules such as dyes. Sulfur is usually introduced in the synthesis medium with thiourea (Guo et al. 2010), but the use of elemental sulfur was also reported and claimed to be less harmful (Galenda et al. 2017). The main drawback of the non-metal doping concerns the long-term instability of the photocatalyst. Codoping with non-metal and metal dopants have been explored for getting synergetic effect from the two dopants. For producing photocatalyst highly active in the visible, co-doping with $\mathrm{S}$ and $\mathrm{Cu}$ has been achieved to get advantage of $\mathrm{S}$ to lower bandgap of $\mathrm{TiO}_{2}$ and of $\mathrm{Cu}$ to trap the electrons in the conduction band of $\mathrm{TiO}_{2}$ in order to prevent charge recombination of electrons with holes (Yi et al. 2014).

It is noteworthy that other strategies such as encapsulation of photosensitive molecules within porous photocatalysts have been developed to improve photocatalytic properties in the visible. Heteropolytungstic acid (HPA) that is photosensive has been incorporated by direct synthesis in SBA-15 and Ti-SBA-15 materials (Anandan et al. 2007). The photodegradation of methyl orange in aqueous solution under visible light was observed faster in the presence of HPA-TiSBA-15 than those in HPA-SBA-15 and Ti-SBA-15.

\subsection{Shaping}

Most of the $\mathrm{TiO}_{2}$ photocatalysts are synthesized as nano- or micro-sized particles and are powdered materials that is limiting for their applicative use. The shaping to integrate them in processes that can be developed at the industrial scale is necessary and often remains a challenge since properties of the photocalysts has to be preserved. Processing photocatalysts as films has been explored according different strategies. $\mathrm{TiO}_{2}$ nanoparticles prepared by a sol-gel method in presence of polyethylene glycol have been processed as thin films by spincoating the obtained $\mathrm{TiO}_{2}$ sol on glass substrates and applying a subsequent thermal treatment 
(Lin et al. 2012). The film thickness was varied by repeating the film deposition procedure. The obtained films have been showed to be efficient for the photodegradation of methylene blue, methyl orange and indigo in water under UV light irradiation. Increasing film thickness results in increasing degradation rate to a certain extent. Indeed the photocatalytic reactions were found to occur mainly on the surface of $\mathrm{TiO}_{2}$ thin films. For thick films, the $\mathrm{TiO}_{2}$ particles in the interior region are less active because of the difficulty to access for the reactant and the low diffusion in solution for the reaction by-products. Moreover, an increase of opacity and light scattering were observed for thick films that decreases the light transmission in the film. Microfibrous palygorskite clay was mixed to a precursor nanocrystalline $\mathrm{TiO}_{2}$ sol containing Triton X-100 non ionic surfactant and the resulting mixture was spread on a glass slides by dip-coating (Stathatos et al. 2017). A subsequent thermal treatment at $500^{\circ} \mathrm{C}$ was applied to remove organic component. Highly nanostructured porous palygorskite/ $\mathrm{TiO}_{2}$ composite films with variable quantities of palygroskite were produced and tested as catalysts for the photodecomposition of basic blue azo-dye in water under UV light irradiation. The film with an optimal palygorskite/ $\mathrm{TiO}_{2}$ weight ratio of $3 / 2$ was found the most effective photocatalyst. It was observed that palygoskite has a low photocatalytic activity under UV illumination probably due to the presence of light activated oxides such as $\mathrm{Fe}_{2} \mathrm{O}_{3}$ and $\mathrm{TiO}_{2}$ present in the clay, and it is assumed that the coexistence of $\mathrm{MgO}$ and $\mathrm{CaO}$ helps to a better hydroxylation of the surface or to slower charge recombination. The photocatalytic activites of the composites is due to a synergetic effect of the palygoskite clay and anatase nanoparticles. The reusability of the palygorskite/ $\mathrm{TiO}_{2}$ composite films have been evidenced for 4 cycles. An interesting approach is the immobilization of $\mathrm{TiO}_{2}$ nanoparticles on macroporous alumina (or clay) disk (or tubular) membranes for filtration. Titania and titaniasilica sols were deposited on macroporous alumina disk membranes (Tajer-Kajinebaf et al. 2014). To get anatase with the most favorable crystallite size of $10 \mathrm{~nm}$ a thermal treatment at 
$400^{\circ} \mathrm{C}$ was optimal for both $\mathrm{TiO}_{2}$-alumina and $\mathrm{TiO}_{2} / \mathrm{SiO}_{2}$-alumina membranes. The membrane composites have been successfully used for removing methyl orange from aqueous solution by coupling membrane separation process with photocalytique technique. Since the presence of silica delays the phase transformation anatase to rutile and inhibits grain growth of anatase, the $\mathrm{TiO}_{2} / \mathrm{SiO}_{2}$-alumina membranes were assumed to have great potential for efficient water treatment. $\mathrm{TiO}_{2}$ nanoparticles have been also incorporated polysulfone (PSf) ultrafiltration membrane for a selective degradation of methylene blue (Melvin et al. 2017). First, commercial $\mathrm{P} 25 \mathrm{TiO}_{2}$ nanoparticles were modified and molecularly imprinting with methylene blue as template in a polymer matrix. The imprinted $\mathrm{TiO}_{2}$ was then introduced in the precursor mixture of the PSf membrane. The photocatalytic and selective properties of $\mathrm{TiO}_{2}$ entrapped in PSf membrane was successfully evidenced in an integrated photodegradation-ultrafilration system. The incorporation of photoactive $\mathrm{TiO}_{2}$ nanoparticles onto textile fibers has been studied for self-cleaning (Wang et al. 2015). It is an interesting approach for water treatment since $\mathrm{TiO}_{2}$-supported onto textile can facilitate the photocatalyst recovery from reaction medium. The use of textile such as sacklotch for $\mathrm{TiO}_{2}$ photocatalyst support offers the opportunity to produce a composite highly active to photodegrade acid black 26, a dye used in the textile, and stable for applications in water treatment (Vaez et al. 2012). Embedding of titania nanoparticles into porous cellulose aerogel is also attractive for water treatment since the composite is like a textile felt that can be easily handled and used for filtration (Jiao et al. 2015). The obtained anatase $\mathrm{TiO}_{2} /$ cellulose aerogel showed a high photocatalytic activity for indigo carmine dye degradation in aqueous solution under UV light and maintained the well-define shape throughout the radiation process. Another interesting shaping is the production of $\mathrm{TiO}_{2}$ nanofibers by electrospinning that can be used as reactive filtration materials for water treatment applications (Nalbandian et al. 2015). 


\section{Examples of processes for dyes removal from water using $\mathrm{TiO}_{2}$ photocatalyst}

In most of processes developed for photocatalytic water treatment, $\mathrm{TiO}_{2}$ is usually introduced as slurry in the reactor. This can lead to several problems of filtration and/or micro-reactor clogging and light transport in the reaction medium (Bouguer-Lambert-Beer law) (Cambié et

al. 2016). Up to now, the main drawback of industrial $\mathrm{TiO}_{2}$-based advanced oxidation processes is due to post operational separation of the catalyst (filtration, coagulationfloculation-sedimentation) from the reaction medium (N. Wang et al. 2014). This drawback can be overcome thanks to processes such as sedimentation, membrane filtration or cross-flow filtration, which allow the physical separation of particles from the slurry (Molinari et al. 2002; Fernández-Ibáñez et al. 2003; Doll and Frimmel 2005). An alternative is to use a packed-bed reactor but in this case, the light is not able to reach the center of the reactor. Another alternative allows overcoming such limitation by coating a thin catalyst layer on the reactor's walls of a continuous-flow photochemical micro-reactor.

\subsection{Photocatalytic membrane reactors (PMRs)}

\subsubsection{Membrane process}

Membrane process is a separation technique extensively implemented in numerous industries such as cosmetics, chemical, electronic, food, pharmaceutical, as well as for desalination and wastewater treatment industries. The main advantages of membrane-based processes lie in the low energy cost, suitability for implementing continuous processes, low cost maintenance, the production of stable quality of water almost independent of the wastewater composition and the easy scale up by simple increasing the number of membrane modules (Mozia 2010). On the other hand, among the main drawbacks of such technology, one can specify the membrane lifetime and the membrane fouling with particles and colloids present in the feed.

The two main technologies used are the pressure driven membrane processes and those where the concentration difference is the driving force (dialysis, pervaporation and direct contact 
membrane distillation) (Mozia 2010). In the case of pressure driven membrane processes, the smaller the pore size is, the smaller the molecules separated are. Pore sizes can be classified as follow: microfiltration $(\mathrm{MF})>$ ultrafiltration $(\mathrm{UF})>$ nanofiltration $(\mathrm{NF})>$ reverse osmosis (RO). MF membranes allows the separation of particles $>0.1 \mu \mathrm{m}$, UF membranes is efficient for particles $>2 \mathrm{~nm}$ and NF membrane allows the separation of particles $<2 \mathrm{~nm}$. In reverse osmosis process, almost all salts, metal ions and small organic molecules are separated (Koros et al. 1996). As expected, decreasing the pore size leads to an increase of the resistance of the membrane and consequently the pressure to apply in the process increases while decreasing the pore size.

Membrane processes can be implemented either in a dead end mode, cross-flow mode and submerged membranes (Chin et al. 2007a; Chin et al. 2007b; Huang et al. 2007; Choo et al. 2008; Fu et al. 2006). In the dead end mode, the membrane acts as a simple filter and all the feed is flowed through the membrane. The main drawback of this configuration is the accumulation of particles, colloids and other substance on the membrane, leading to the formation of a cake, which can clog the pores of the membrane. Consequently, such a configuration is not suitable for large-scale industrial applications. The submerged mode is close to the dead end configuration but the design of the reactor allows reducing the membrane fouling. In the cross flow configuration, the incoming feed moves parallel to the membrane surface that limits the deposition of foulants on the membrane surface since the feed flowing tangentially to the membrane removes partially the deposit (Mozia 2010).

\subsubsection{Generalities about photocatalytic membrane reactors (PMRs)}

Photocatalytic membrane reactors (PMRs) is a promising technology to remediate drawbacks such as separation of the photocatalyst as well as products/by-products from the reaction medium in the field of wastewater treatment (Ollis 2003; Augugliaro et al. 2006; Mozia 2010). 
In such technology, photocatalysis is coupled with a membrane process. The role of the membrane is to act as a simple barrier for the photocatalyst and a selective barrier for the molecules to be degraded (Molinari et al. 2002).

Some advantages of membrane reactors with respect to conventional ones are: 1) the confining of the photocatalyst in the reaction environment by means of the membrane, which allows the implementation of a continuous process with simultaneous catalyst and product separation from the reaction environment, 2) the control of the residence time of molecules in the reactor. As a result, post operational separation of the catalyst from the reaction medium involving coagulation-floculation-sedimentation operations is avoided. This allows reducing energy cost and sizing the installation.

As for conventional (photo) catalytic processes, two kind of PMRs can be distinguished: 1) reactors where the catalyst is suspended in the reaction mixture and 2) those where the catalyst is immobilized on/in the membrane (photocatalytic membrane) (Augugliaro et al. 2006; Ma et al. 2010; Mozia 2010). In the first configuration (catalyst is suspended in the reaction mixture) the main drawback is the membrane fouling by the catalyst particles, especially in the case of pressure driven processes and more particularly in the cases of microfiltration and ultrafiltration. Photocatalytic membranes, where the photocatalytic reaction occurs on the external surface and within the pores of the membrane, allow overcoming such drawback. However, the membrane has to be resistant to UV irradiation and the coating of the catalyst on and/or in the membrane results in a decrease of surface area and consequently of the photocatalytic activity.

As expected, when the pore size of the membrane increases, (microfiltration (MF) > ultrafiltration (UF) > nanofiltration (NF) > reverse osmosis (RO)) the amount of organics products in the permeate increases as well (Tomaszewska et al. 1998; Molinari et al. 2004; Mozia et al. 2006) and the pressure to be applied decreases. 
Most of the photocatalytic membrane reactors studied in the literature combine photocatalysis with membrane process, involving microfiltration (Erdei et al. 2008; Shon et al. 2008; Benotti et al. 2009), ultrafiltration (Sun et al. 2004; Fu et al. 2006; Tsarenko et al. 2006) and nanofiltration (Augugliaro et al. 2005; Molinari et al. 2006: Molinari et al. 2008 In order to overcome the fouling phenomenon, new types of PMRs combining membrane reactors with direct contact membrane distillation (Mozia et al. 2008; Mozia, et al. 2009), pervaporation (Camera-Roda and Santarelli 2005) and dialysis (Azrague et al. 2007), were developed more recently.

\subsubsection{Photocatalytic membranes}

\section{- $\mathrm{TiO}_{2}$ immobilized on/in the membrane}

In such configuration, the light source is located in a way to ensure the irradiation of the membrane (Figure 5). The photodegradation of dyes occurs at the surface and/or within the pores of the membrane. Two asymmetric configurations (Figure 6a and 6b) of membrane reactors can be found (Mozia 2010). In the first one, the photoactive separation layer is deposited on a non-photocatalytic support. The membrane acts as both a filter and a photocatalyst. The light source is located in the photoactive separation layer (photocatalytic membrane) side.

In such configuration, the main advantage is that the organic compounds present in the solution are decomposed on/in the membrane, thus preventing cake formation and membrane fouling (Tsuru et al. 2001). The main drawback is that the membrane can be damaged by UV radiations (Ollis 2003) (Chin et al. 2006). Actually the membrane resistance to UV radiation depends on its composition and manufacturing (Molinari et al. 2000; Chin et al. 2006;). This limitation can be overcome by the use of ceramic (Alem et al. 2009; Romanos et al. 2013) or 
metallic (Bellobono et al. 2005) membranes but the main drawback of such membranes is their cost.

In the second configuration, the non-photoactive separation layer is deposited on a photoactive support. The light source is located in the photoactive support side. In such configuration, filtration (membrane) and photocatalysis (photoactive support) are separated. Such configuration allows obtaining a higher permeate quality and prevents the membrane degradation by UV radiation (Mozia 2010). The main drawbacks are that only the permeate is purified, the possible fouling of the non-photoactive membrane and the non-degradation of high molecular weight organics. Indeed, such large molecules are blocked by the pore size of the membrane and thus cannot cross the membrane to reach the photocatalytic support. Both configurations were compared by Bosc et al. by using mesoporous $\mathrm{TiO}_{2}$ base membranes for the photocatalytic degradation of methylene blue (Bosc et al. 2005). Romanos et al. even implemented "double side active photocatalytic ultrafiltration (UF) membranes" which consists in coating and irradiating both sides of the membrane (Romanos et al. 2013). From their results on the photocatalytic degradation of methyl orange, authors claimed that such a process exhibits similar performances as compared to the highly efficient standard nanofiltration, and with the advantages such as lower energy consumption without the generation toxic by-products.

Several studies report dye photodegradation through photocatalytic membranes $\left(\mathrm{TiO}_{2}\right.$ immobilized on/in the membrane) (Zhang et al. 2006a; Wang et al. 2008; Papageorgiou et al. 2012; Mendret et al. 2013; Romanos et al. 2013; Zhang et al. 2014).

Zhang et al. reported the synthesis of a $\mathrm{TiO}_{2}$ hollow fiber based membrane, which was evaluated for the photocatalytic degradation of acid orange 7 (Zhang et al. 2014). The influence of the calcination temperature was found to strongly influence membrane properties: the higher the calcination temperature, the smaller the pore size and the photocatalytic activity, 
the higher the mechanical robustness. The best calcination temperature was reported to be $900^{\circ} \mathrm{C}$, which allows removing $90.2 \%$ of organics at a water flux of $12.2 \mathrm{~L} \cdot \mathrm{m}^{-2} \cdot \mathrm{h}^{-1}$.

Alem et al. reported the synthesis of a multilayer mesoporous $\mathrm{TiO}_{2}$ coated on alumina membrane with a high surface area $\left(83 \mathrm{~m}^{2} \cdot \mathrm{g}^{-1}\right.$ and a pore size of $\left.4 \mathrm{~nm}\right)$ for the photodegradation of methyl orange (Alem et al. 2009). Such membrane allows increasing the photocatalytic activity by $60 \%$ without sacrificing its permeation compared to colloidal monolayer membrane. Mendret et al. reported the photodegradation of acid orange 7 on a $\mathrm{TiO}_{2} / \mathrm{Al}_{2} \mathrm{O}_{3}$ membrane (Mendret et al. 2013). They found that such a process enhances ceramic membrane wettability and allows preventing membrane fouling while improving flux stability. Moreover, membrane cleaning was performed by irradiating membrane surface under static conditions, without chemicals. Papageorgiou et al. 2012 implemented photocatalytic/ultrafiltration process using a composite of $\mathrm{AEROXIDE}^{\circledR} \mathrm{TiO}_{2} \mathrm{P} 25$ and alginate polymer fibers based membrane which were found to be 3 fold more efficient than conventional membrane for the photocatalytic degradation of methyl orange (Papageorgiou et al. 2012).

\section{- $\mathrm{TiO}_{2}$ suspended in the reaction mixture}

In such configuration, the photocatalytic process is ensured by $\mathrm{TiO}_{2}$ introduced as a slurry in the incoming feed and the membrane acts as a filter for $\mathrm{TiO}_{2}$ particles, thus ensuring the permeate to be free of $\mathrm{TiO}_{2}$ particles. Indeed, most of the studies reported the high efficiency of the membrane filtration resulting in a very low concentration of $\mathrm{TiO}_{2}$ particles in the permeate (Meng et al. 2005; Tomaszewska and Morawski 2006; Huang et al. 2007; Mozia and Morawski 2009). For reactors where the catalyst is suspended in the reaction mixture, three main configurations can be distinguished: irradiation of the feed tank, irradiation in a specific module (photoreactor) located between the feed tank and the membrane, irradiation of the membrane. 
One advantage of such process is the photocatalytic efficacy given that $\mathrm{TiO}_{2}$ particles are not embedded in the membrane, allowing a higher surface area available for the photocatalytic process. It also allows obtaining a higher permeate quality and prevents the membrane degradation by UV radiation. On the other hand, the main drawbacks is membrane fouling, especially by $\mathrm{TiO}_{2}$ particles, leading to the decline of the permeate flow (Molinari et al. 2006; Molinari et al. 2008). As a general trend, the higher the $\mathrm{TiO}_{2}$ particles concentration is, the fastest the fouling of the membrane is (Sopajaree et al. 1999a; Sopajaree et al. 1999b; Shon et al. 2008). The membrane fouling strongly depends on the pressure and flow applied in the process (Sopajaree et al. 1999a; Sopajaree et al. 1999b). A high flow allows preventing the formation of the cake by removing continuously $\mathrm{TiO}_{2}$ particles. Under such conditions (high flow) the influence of the pressure on the fouling of the membrane is negligible. However at low flow, the influence of the transmembrane pressure becomes predominant and membrane clogging can occur. One alternative is the implementation of submerged membrane process, which is less sensitive to membrane fouling (Chin et al. 2007a; Chin et al. 2007b; Molinari et al. 2008). Low permeate flux results in higher residence time that favors the process efficiency (Molinari et al. 2000; Rivero et al. 2006; Chin et al. 2007b). Other parameters such as pH or ionic strength will also affect the process (Mozia 2010). Especially, the $\mathrm{pH}$ strongly influences $\mathrm{TiO}_{2}$ particles agglomeration (Xi and Geissen 2001; Paz 2006). Also, the presence of humic acid was found to render the cake more resistant to the flow (backpressure increase) (Lee et al. 2001). However, one can expect the photodegradation of organic products of the cake by the application of UV light (Choo et al. 2008), especially with the configuration where the membrane is irradiated. The shaping of the catalyst also impacts the membrane clogging. Indeed, by using a ball-shaped $\mathrm{TiO}_{2} / \mathrm{SiO}_{2}$ catalyst, the fouling phenomenon was found to be reduced as compared to the standard Degussa P25 (Fu et al. 2006). The batch mode is 
generally found to be more effective than the continuous mode but the latter is better suited for industrial scale applications ( $\mathrm{Li}$ and Zhao 1999; Molinari et al. 2002).

Others processes such as dialysis, pervaporation or direct contact membrane distillation also exist. For example, Azrague et al. developed a photocatalytic membrane process where the mass transport through the membrane is not achieved by transmembrane pressure but thanks to the difference of concentration (dialysis). The main advantage of such process is that it prevents the fouling of the membrane observed with pressure driven processes (Azrague et al. 2007). Authors observed that under their conditions, the rate-limiting step is the mass transport rather than the photodegradation. Camera-Roda et al. have also reported a process combining pervaporation and photocatalysis (Camera-Roda and Santarelli 2005). They reported that the integration of photocatalysis to the pervaporation process improved its efficiency. However, in the process presented, the photocatalyst remains in the treated wastewater. Finally, direct contact membrane distillation coupled with photocatalysis process were implemented for the removal of dyes (Mozia et al. 2005a; Mozia and Morawski 2006; Mozia et al. 2007; Mozia and Morawski 2009) as well as for others pollutants (Mozia et al. 2014). In such process, the feed flows through the membrane under gas phase. In this case, the process is driven by the vapor pressure difference between the two sides of the membrane. The main advantage of this technology is that membrane fouling does not occur, even after $180 \mathrm{~h}$ of stream and independently of the $\mathrm{TiO}_{2}$ source (Mozia 2010). Another advantage is that theoretically, 100\% of the non-volatile compounds such as salts, dyes or others large organic molecules are separated (Tomaszewska et al. 1998; Curcio et al. 2010). As a result, permeate was found to be of high quality. However, such process suffers from several drawbacks among which highenergy consumption and a low flux as compared to pressure driven processes.

Several studies report dye treatment using $\mathrm{TiO}_{2}$ particles in suspension in the reaction mixture (Molinari et al. 2002; Molinari et al. 2004; Ryu et al. 2005; Cui et al. 2006; Jiang et al. 2010; 
Damodar et al. 2010). For example, Molinari et al. reported the removal of congo red and patent blue from wastewater through a pressure driven membrane process using the reference $\mathrm{TiO}_{2}$ Degussa P25 catalyst in suspension in the feed (Molinari et al. 2004). A comparison between suspended and entrapped $\mathrm{TiO}_{2}$ as well as the influence of different parameters such as system configuration, irradiating source and its position, the pressure in the membrane cell and the initial concentration of the substrates, the recirculation rate were studied. It was found that the photodegradation rate of congo red was 50 times higher with the immersed UV lamp than that found with the external lamp. Also, as discussed above, the use of the photocatalyst in suspended form was more efficient than $\mathrm{TiO}_{2}$ entrapped in a polymeric membrane. Damodar et al. developed a process coupling a polytetrafluoroethylene membrane with a $\mathrm{TiO}_{2} / \mathrm{UV}$ slurry reactor that was implemented for the degradation of reactive black 5 (Damodar et al. 2010). Such a system was found capable of removing 75-82\% TOC, operating efficiently for long periods with high removal efficiency, as well as efficiently recycling of the catalyst. Jiang et al. reported the photocatalytic degradation of acid red B in a slurry photocatalytic membrane reactor (Jiang et al. 2010). It was observed that the $\mathrm{TiO}_{2}$ loading and the initial dye concentration strongly influence the reaction rate.

Cui et al. studied the performances of a slurry photocatalytic reactor coupled with a membrane for the photodegradation of methyl orange (Cui et al. 2006). They found that the degradation rate is higher as compared to a cylindrical reactor and the rejection rate of the $\mathrm{TiO}_{2}$ photocatalyst particles reaches $99.9 \%$.

Additionally to the dyes, numerous pollutants such as sodium dodecylbenzene sulfonate $(\mathrm{H}$. Zhang et al. 2006b), trichloroethylene (Choo et al. 2008) biologically treated sewage effluent (Shon et al. 2008), fluvic acids (Fu et al. 2006), Para-Chlorobenzoate (Huang et al. 2007), bisphenol A (Chin et al. 2007a; Chin et al. 2007b), lyncomycin (Augugliaro et al. 2005; 
Augugliaro et al. 2006) and others (Choo et al. 2008) can be decontaminated through photocatalytic membrane reactors.

An alternative process to membrane reactors which emerged the past years consists in implementing photocatalytic micro-reactors.

\subsection{Continuous-flow photochemical micro-reactor}

\subsubsection{Flow reactors}

A micro-reactor (or flow reactor, microfluidic reactor) is a chemical reactor where the reaction occurs in a confined channel with a diameter below $1 \mathrm{~mm}$ (J. Zhang et al. 2017). Such microreactors and their applications undergone intense development and were extensively reviewed the past years (Hartman and Jensen 2009; Jensen et al. 2014; Gemoets et al. 2015; Cambié et al. 2016; Rossetti and Compagnoni 2016: Heggo and Ookawara 2017; Jensen 2017; J. Zhang et al. 2017). Thanks to their small size, micro-reactors exhibit a high surface to volume ratio, what favors mixing, heat and mass transfer (Gemoets et al. 2015; J. Zhang et al. 2017). Consequently, flow reactors allow favoring heterogeneous reactions such as liquid-liquid, liquid-gas, liquid-solid and gas-liquid-solid reactions by favoring the contact area between reactants and catalyst. Indeed, it was reported that specific interfacial areas can reach values as high as: liquid-liquid: $1000-10000 \mathrm{~m}^{2} / \mathrm{m}^{3}$, gas-liquid: $160-1300 \mathrm{~m}^{2} / \mathrm{m}^{3}$, thus improving mass transfer as compared to conventional batch reactors (Nieves-Remacha et al. 2012; Nieves-Remacha et al. 2013). Mass transfer coefficients were found to be: liquid-liquid: 1.9$41 \mathrm{~s}^{-1}$, gas-liquid: 0.2-3 s $\mathrm{s}^{-1}$ (Yue et al. 2009; Woitalka et al. 2014). As a result, the general trend is that the use of micro-reactors results in a better efficiency as compared to conventional ones (Anderson 2012; Mizuno et al. 2016; Cambié et al. 2016). Moreover, thanks to the small reactor volume, safety of the process is improved, even for harsh conditions (Hessel et al. 2011; Gutmann et al. 2015). Indeed, such reactors allow implementing high temperature 
and/or high-pressure reactions, as well as explosive reactants/products. Additionally, microreactors also present many advantages from a point of view of green chemistry since they allow improving the safety of the process, the energy efficiency, higher yields and reduced wastes (Newman and Jensen 2013; Rossetti and Compagnoni 2016). The reproducibility and low cost scale up are often spotlighted among advantages of micro reactors. Indeed, it is often claim that the scaling up simply consists in multiplying the number of reactors but the reality is not as straightforward (Rossetti and Compagnoni 2016). Indeed, the fluid distribution to ensure an accurate control of the flow and the cost of scaling up still represent a major challenge. Three main scaling up strategies were reported in the literature: parallel numberingup (reactors in parallel), consecutive numbering-up (reactors in series) and scale-out by suitable dimension enlarging (Zhang et al. 2017; Kuijpers et al. 2017). Flow reactors can be made of glass, polymer, silicon, ceramic or metal (Anderson 2012; Heggo and Ookawara 2017). They can be used in numerous configurations and can be coupled with sonochemistry, microwave and photocatalysis (Wegner et al. 2011).

\subsubsection{Photochemical flow reactors}

Photochemical micro-reactors result from the coupling of a micro-reactor with photocatalytic process (photocatalyst + irradiation source) (Van Gerven et al. 2007; Coyle and Oelgemöller 2008; Su et al. 2014; Heggo and Ookawara 2017). The operating principle of such reactors is schematized in the Figure 7.

The implementation of photochemical micro-reactors allows overcoming some drawbacks of conventional batch reactors, more especially the attenuation effect of photon transport, which makes the scale-up difficult, by ensuring a uniform irradiation of the reaction mixture and/or of the catalyst (Colina-Márquez et al. 2010; N. Wang et al. 2014; Cambié et al. 2016). Indeed, their high surface to volume ratio results in a high accessible photocatalytic surface area. It 
was evidenced that mass transfer from the reaction medium to the catalyst is improved (Gorges et al. 2004: N. Wang et al. 2014).

The separation of the catalyst from the reaction medium can be overcome by coating a thin photocatalyst layer on the reactor's walls of a continuous-flow photochemical micro-reactor (Heggo and Ookawara 2017). Thus, the catalyst can be fully irradiated. However, such a coating of the catalyst results in a decrease of the accessible surface area (Mozia 2010; Cambié et al. 2016). Fortunately, this phenomenon is compensated thanks to the high surface to volume ratio (up to $11667 \mathrm{~m}^{2} \cdot \mathrm{m}^{-3}$ ) of micro-photoreactors compared to conventional slurry photoreactors $\left(2631 \mathrm{~m}^{2} . \mathrm{m}^{-3}\right)$ (Gorges et al. 2004).

Micro-reactors can implemented according to different configurations among which slurrybubble reactor, monolith reactor, membrane reactor, fluidized bed reactor, falling film reactor, planar reactor, microchannel and capillary reactors, silicon reactors and multiphase microdroplet reactors.

Flow photoreactors are mostly implemented in organic photochemical reactions and, in a minor extent, $\mathrm{TiO}_{2}$-based photocatalytic degradation of dyes degradation (Gutmann et al. 2015; Mizuno et al. 2016).

\subsubsection{Dye degradation using photochemical flow reactors}

Several example of photocatalytic dye degradation in micro-reactors were reported in the literature. Most of them use methylene blue as a model dye. Some studies focus on immobilization of the catalyst on the inner walls of the reactor. For example, Li et al. reported that by using $\mathrm{TiO}_{2} @ \mathrm{SiO}_{2}$ coated walls of a micro-reactor, the degradation rate of methylene blue was increased by more than 150 times as compared to conventional system (X. Li et al. 2003). In another work, methylene blue was photodegraded both on $\mathrm{TiO}_{2}-\mathrm{P} 25$ and $\mathrm{TiO}_{2}-$ graphène photocatalysts deposited on the walls of a glass chip micro-reactor (Padoin et al. 
2016). The degradation rate of methylene blue was found to be one order of magnitude higher than with equivalent macroscopic reactor. In order to increase the photocatalytic efficiency for the methylene blue degradation, Lindstrom et al. coated a mesoporous anatase film with a high surface area on the inner walls of the reactor (Lindstrom et al. 2007). As a general feature of micro-reactors they found that the rate limiting parameter for the photodegradation of methylene blue is not the catalyst surface area, neither the adsorption properties but the oxygen concentration in the water phase, meaning that the reaction is not limited by heat and mass transfer in such conditions. Lin et al. studied the influence of light and $\mathrm{TiO}_{2}$ doping for the photodegradation of methylene blue while comparing micro-channel and planar photocatalytic micro-reactors (C. Lin et al. 2016). The planar micro-reactor was found to be more efficient than the micro-channel one and doped $\mathrm{TiO}_{2}$ were reported to be more efficient than $\mathrm{TiO}_{2}$ under natural sunlight.

The influence of reaction parameters on the photodegradation rate and the global process efficiency are strongly dependent on the reactor technology. Zhang et al. reported that the photocatalytic degradation rate of methylene blue in a $\mathrm{TiO}_{2}$ packed bed micro-reactor was increased by 520 as compared to a conventional bulk container of $15 \mathrm{~mL}$ (Zhang et al. 2013). The implementation of a $\mathrm{TiO}_{2}$ coated monolith in a micro-reactor for the photocatalytic degradation of methylene blue was reported by Teekateerawej et al. (Teekateerawej et al. 2005). Additionally to the $\mathrm{TiO}_{2}$ coating method, which influences the photocatalyst efficiency, they found that, in such configuration, irradiation light angle is the main parameter governing the catalytic reaction rate given that the light does not cross the monolith. Yang et al. compared three mini-fluidized bed reactors for the photocatalytic degradation of methylene blue (Z. Yang et al. 2016). The first one with $\mathrm{Fe}^{3+} / \mathrm{TiO}_{2}$ photocatalyst coated on the inner wall of the reactor, the second one where the $\mathrm{Fe}^{3+} / \mathrm{TiO}_{2}$ photocatalyst is coated on the surface of fluidized particles (glass beads) and an third one with $\mathrm{Fe}^{3+} / \mathrm{TiO}_{2}$ photocatalyst coated both on the wall 
of the reactor and on the fluidized glass beads. The fluidization of glass beads allows increasing mass transfer coefficient by $11-13$ and apparent reaction rate constant is multiplied by 4.9. The third reactor combing the two forms of catalyst $\left(\mathrm{Fe}^{3+} / \mathrm{TiO}_{2}\right.$ photocatalyst coated both on the wall of the reactor and on the fluidized glass beads) was found to be 5 to $35 \%$ more efficient as compared to the two other configurations.

Interestingly, Aran et al. reported a gaz-liquid-solid heterogeneous photocatalytic process by coupling a micro-reactor with a $\mathrm{TiO}_{2}$-based photocatalytic membrane (Figure 8 ) whose role is to ensure a continuous delivery of oxygen in the aqueous feed (Aran et al. 2011). Advantageously, such a tri-phasic system implemented at the micro-scale improves gasliquid-solid interface. Authors reported that the photocatalytic degradation rate of phenol was increased thanks to oxygen supply. However, no significant effect was observed for the degradation of methylene blue, likely due to the lower initial concentration that lowers the amount of oxygen required for its degradation.

Even if such a technology is promising, there is still a lack of knowledge to develop the scale up of the process at the industrial scale.

\section{Titania and photocatalysis in industry}

Up to now titania-based systems for the water treatment by photocatalysis remains mainly at the laboratory stage and efforts are mainly focused on the preparation of efficient photocatalysts. Beside the different studies reported in academic publications and cited in this chapter, some patents also exist (Park et al. 2002; Willmer et al. 2002; A. Toledo et al. 2014; P. Balaya et al. 2015). For example Willmer et al. have patented the preparation method of doped $\mathrm{TiO}_{2}$ with lanthanide metal. Materials are obtained by the acid-catalyzed sol-gel process and the obtained photocatalysts exhibit an enhanced efficiency for the photochemical degradation of the organic substrates such as p-Chlorophenoxyacetic acid than the unmodified 
$\mathrm{TiO}_{2}$ (Willmer et al. 2002). To implant such material at the industrial scale much attention should be paid on the shaping. As a matter of fact the main drawback of using titania is due to the fact that powder form of $\mathrm{TiO}_{2}$ is considered and that a filtration step is required. This filtration step is a drawback for the economic viability of photocatalysis process based on titania. Nevertheless, it should be noted that several company such as Clearwater industries, Photox Bradford Ltd, Lynnetch Inc., Ishihara Sangya Kaisha Ltd...have products at the development stage for water purification using semiconductor photocatalyst (B.E. Butters et al. 1996; A. Gonzalez-Martin et al. 1998; A. Gonzalez-Martin et al. 2000, B.E. Butters et al. 2000). For example the Lynntech Inc. company has patented a method and an apparatus based on the photocatalytic oxidation method using a porous titanium dioxide membrane for the mineralization of organic contaminants in water (A. Gonzalez-Martin et al. 1998). The photocatalytic reactor operates effectively at ambient temperature and low pressures. A packed-bed photoreactor using photocatalyst coated particles is also proposed (A. GonzalezMartin et al. 2000). More recently, Kisalius and Kinsinger have patented a method for synthesis doped or undoped titania with controlled size, phase, morphology and porosity (Kisalius and Kinsinger 2017). The prepared photocatalysts are integrated in a device for water treatment. The few examples reported above concerning water treatment allow to conclude that photodegradation of dyes by porous titania is a promising technology that will grow in the future and that it can reach the commercialization stage if we succeed to control the shaping of the photocatalysts.

\section{Conclusions}

Because of their potential toxic effects on human health water pollution by dyes is a major issue and many efforts are devoted to solve it. Among the different methods considered to remove dye, photodegradation is one of the most promising methods since it leads to the 
complete mineralization of the organic pollutants to $\mathrm{CO}_{2}$, water and mineral acids. In addition, such process avoids the production of solid-wastes and only mild temperature and pressure conditions are required. Thanks to its properties, titania has been widely considered as photocatalyst for dyes removal and many efforts have been devoted to increase the specific surface area since this parameter is crucial for the photocatalytic activity.

Various types of porous $\mathrm{TiO}_{2}$ nanomaterials such as powder mesostructured titania, nanoparticles, nanotubes or nanorods have been successfully used for dyes photodegradation such as methylene blue, rhodamine B or methyl orange. However up to now these materials are barely incorporated in a process and most of the tests are performed at the laboratory scale. Many efforts are devoted to the shape modeling to integrate these materials in processes and formation of films or the immobilization of $\mathrm{TiO}_{2}$ on support such as membrane disks have been considered.

Properties of titania and in peculiar the specific surface area can also be tuned by associating it with another material to get nanocomposites. By the way both the specific surface area and the thermal stability are increased. As a consequence, in comparison with the performances of commercial titania such as P25, the photocatalytic efficiency of the composites is enhanced. Coupling $\mathrm{TiO}_{2}$ with another material can also induce a decrease of the bandgap, which allows enhancing the activity under the visible light. This can also be achieved by doping, which limits the electron/hole recombination and therefore favors the photocatalytic activity. Up to now, membrane-based photocatalytic process is one of the most studied techniques to remove dyes from water at a large scale. Nevertheless, micro-reactors also appear as a promising technology for wastewater treatment. The main challenge that still persists is to implant the porous titania in these processes and to develop them at the industrial scale. 


\section{References}

Abramian L., El-Rassy H.. (2009) Adsorption kinetics and thermodynamics of azo-dye Orange II onto highly porous titania aerogel. Chem. Eng. J. 150: 403-410. doi: 10.1016/j.cej.2009.01.019

Ahmed S., Rasul M.G., Martens W.N., Brown R., Hashib M.A. (2010) Heterogeneous photocatalytic degradation of phenols in wastewater: A review on current status and developments. Desalination 261: 3-18. doi: 10.1016/j.desal.2010.04.062

Ajmal A., Majeed I. Malik R.N., Idriss H., Nadeem M.A. (2014) Principles and mechanisms of photocatalytic dye degradation on $\mathrm{TiO}_{2}$ based photocatalysts: a comparative overview. RSC Adv. 4:37003-37026. doi: 10.1039/c4ra066584

Akpan U.G., Hameed B.H. (2009) Parameters affecting the photocatalytic degradation of dyes using $\mathrm{TiO}_{2}$-based photocatalysts: A review. J. Hazard. Materials 170: 520-529. doi: 10.1016/j.jhazmat.2009.05.039

Alem A., Sarpoolaky H., Keshmiri M. (2009) Sol-gel preparation of titania multilayer membrane for photocatalytic applications. Ceram. Int. 35:1837-1843. doi: 10.1016/j.ceramint.2008.10.034

Alventosa-de Lara E., Barredo-Damas S., Alcaina-Miranda M.I., Iborra-Clar M.I. (2012) Ultrafiltration technology with a ceramic membrane for reactive dye removal: optimization of membrane performance. J Hazard Mater 209:492-500. doi: 10.1016/j.jhazmat.2012.01.065

Anandan S., Yoon M. (2007) Photocatalytic degradation of Methyl Orange using heteropolytungstic acid-encapsulated TiSBA-15. Solar Energy Mater. \& Solar Cells 91:143-147. doi: 10.1016/j.solmat.2006.07.009

Anderson N.G. (2012) Using Continuous Processes to Increase Production. Org. Process. Res. Dev 16:852-869. doi:10.1021/op200347k

Antonelli M.M., Ying J.Y. (1995) Synthesis of hexagonally packed mesoporous $\mathrm{TiO}_{2}$ by a modified sol-gel method. Angew. Chem. Int. Ed. Engl. 34:2014-2017. doi: 10.1002/anie. 199520141

Aran H.C., Salamon D., Rijnaarts T., Mul G., Wessling M., Lammertink R.G.H. (2011) Porous Photocatalytic Membrane Microreactor (P2M2): A new reactor concept for photochemistry. J. Photochem. Photobiol. A Chem. 225:36-41. doi: 10.1016/j.jphotochem.2011.09.022

Assaker K., Benamor T., Michelin L., Lebeau B., Marichal C., Stébé M.J., Blin J.L. (2015) Mesoporous titania with anatase walls by flash induction calcination, Microporous Mesoporous Mater. 201:43-49. doi: 10.1016/j.micromeso.2014.09.028

Asuha S., Zhou X.G., Zhao S. (2010) Adsorption of Methyl Orange and $\mathrm{Cr}(\mathrm{VI})$ on mesoporous $\mathrm{TiO}_{2}$ prepared by hydrothermal method. J. Hazard. Mater. 181:204-210. doi: 10.1016/j.hazmat.2010.04.117

Augugliaro V., García-López E., Loddo V., Malato-Rodríguez S., Maldonado I., Marcì G., Molinari R., Palmisano L. (2005) Degradation of lincomycin in aqueous medium: Coupling of solar photocatalysis and membrane separation. Sol Energy 79:402-08. doi: 10.1016/j.solener.2005.02.020

Augugliaro V., Litter M., Palmisano L., Soria J. (2006) The combination of heterogeneous photocatalysis with chemical and physical operations: A tool for improving the photoprocess performance. J Photochem Photobiol C Photochem. Rev. 7:127-144. doi: 10.1016/j.jphotochemrev.2006.12.001 
Azrague K., Aimar P., Benoit-Marquié F., Maurette M.T. (2007) A new combination of a membrane and a photocatalytic reactor for the depollution of turbid water. Appl. Catal. B Environ 72:197-204. doi: 10.1016/j.apcatb.2006.10.007

Bagheri S., Hir Z.A.M., Yousefi A.T., Hamid S.B.A. (2015) Progress on mesoporous titanium dioxide: synthesis, modification and applications. Microporous Mesoporous Mater. 218:206-222. doi: 10.1016/j.micromeso.2015.05.028

Balaya P., Krishnamoorthy A. , Kuppan S. (2015) Crystalline mesoporous titaniumdioxide and the use in electrochemical device. US patent US 8,968,931 B2

Bekkali C.E., Bouyarmane H., Saoiabi S., Karbane M.E., Rami A., Saoiabi A., Boujtita M., Laghzizil A. (2016) Low-cost composites based on porous titania-apatite surfaces for the removal of Patent Blue V from water: effect of chemical structure of dye. J. Adv. Res. 7:1009-1017 doi: 10.1016/j.jare.2016.05.001

Bellobono I.R., Morazzoni F., Bianchi R., Mangone E.S., Stanescu R., Costache C., Tozzi P.M. (2005) Solar energy driven photocatalytic membrane modules for water reuse in agricultural and food industries. Pre-industrial experience using s-triazines as model molecules. Int. J. Photoenergy. doi: 10.11155/S1110662X05000139

Benotti M.J., Stanford B.D., Wert E.C., Snyder S.A. (2009) Evaluation of a photocatalytic reactor membrane pilot system for the removal of pharmaceuticals and endocrine disrupting compounds from water. Water. Res. 43:1513-1522. doi: 10.1016/j.watres.2008.12.049

Besançon M., Michelin L., Josien L., Vidal L., Assaker K., Bonne M., Lebeau B., Blin J.L. (2016) Influence of the porous texture of SBA-15 mesoporous silica on the anatase formation in $\mathrm{TiO}_{2}-\mathrm{SiO}_{2}$ nanocomposites. New J. Chem. 40:4386-4397. doi: $10.1039 / \mathrm{c} 5 \mathrm{nj} 02859 \mathrm{k}$

Binas V.D., Sambani K., Maggos T., Katsanaki A., Kiriakidis G.. (2012) Synthetis and photocatalytic activity of $\mathrm{Mn}$-doped $\mathrm{TiO}_{2}$ nanostructured powders under UV and visible light. Appl. Catal., B 113:79-86. doi: 10.1016/j.apcatb.2011.11.021

Bizani, E., Fytianos K., Poulios I., Tsiridis V. (2006) Photocatalytic Decolorization and Degradation of Dye Solutions and Wastewaters in the Presence of Titanium Dioxide. J. Hazard. Mater. 136: 85-94. doi: 10.1016/j.jhazmat.2005.11.017

Blin J.L., Stébé M.J., Roques-Carmes T. (2012) Use of ordered mesoporous titania with semicrystalline framework as photocatalyst. Colloids Surf., A, 407:177-185. doi: 10.1016/j.colsurfa.2012.05.029

Bosc F., Ayral A., Guizard C. (2005) Mesoporous anatase coatings for coupling membrane separation and photocatalyzed reactions. J. Membr. Sci. 265:13-19. doi: 10.1016/j.memsci.2005.04.039

Butters B.E., Powell A.L. (1996) Advanced filtration technique for fluid purification US patent 5,589,078

Butters B.E., Powell A.L. (2000) System and method for photocatalytic treatment of contaminated media

Cai, Z., Sun, Y., Liu W., Sun P., Fu J. (2017) An overview of nanomaterials applied for removing dyes from water. Environ. Sci. Pollut. Res. 24:15882-15904. doi: 10.1007/s11356-017-9003-8

Cambié D., Bottechia C., Straathof N.J.W., Hessel V., Noël T. (2016) Applications of continuous-flow photochemistry in organic synthesis, material science and water treatment. 116:10276-10341. doi: 10.1021/acs.chemrev.5b00707

Camera-Roda G., Santarelli F. (2005) Intensification of Water Detoxification by Integrating Photocatalysis and Pervaporation. J. Sol. Energy Eng. 129:68-73. doi:10.1115/1.2391204 
Cao S., Zhao Y., Qu T., Wang P., Guan S., Xu Y., Rao F., Li Y., Chen A., Lyoda T. (2016) Ordered mesoporous crystalline titania with high thermal stability from comb-like liquid crystal block copolymers. RSC Adv. 6:55834-55841. doi: 10.1039/C6RA10352A

Carp O., Huisman C.L., Reller A. (2004) Photoinduced reactivity of titanium dioxide. Prog. Solid State Chem. 32:33-177. doi: 10.1016/j.progsolidstchem.2004.08.001

Castillo-Villalón P., Ramírez J. (2009) Spectroscopic Study of the Electronic Interactions in $\mathrm{Ru} / \mathrm{TiO}_{2}$ HDS Catalysts. J. Catal. 268: 39-48. doi: 10.1016/j.jcat.2009.08.014

Chaker H., Chérif-Aouali L., Khaoulani S., Bengueddach A., Fourmentin S. (2016) Photocatalytic degradation of Methyl Orange and real wastewater by silver doped mesoporous $\mathrm{TiO} 2$ catalysts J. Photochem. Photobiol., A. 318: 142-149. doi: 10.1016/j.photochem.2015.11.025

Chang F., Wang G., Xie Y., Zhang M., Zhang J., Yang H.J., Hu X. (2013) Synthesis of $\mathrm{TiO}_{2}$ nanoparticles on mesoporous aluminosilicate Al-SBA-15 in supercritical $\mathrm{CO}_{2}$ for photocatalytic decolorization of Methylene Blue. Ceram. Int. 39:3823-3829. doi: 10.1016/j.ceramint.2012.10.223

Chauhan R., Kumar A., Chaudhary R.P. (2012) Structural and optical characterization of Zn doped $\mathrm{TiO}_{2}$ nanoparticles prepared by sol-gel method. J. Sol. Sci. Technol. 61:585-591. doi: 10.1007/s10971-011-2664-8.

Chen C., Weimin C., Mingce L., Jingyi Z., Baoxue Z., Yahui W., Deyong W. (2010) Template-free sol-gel preparation and characterization of free-standing visible light responsive C,N-Modified porous monolithic $\mathrm{TiO}_{2}$. J. Hazard. Mater. 178:560-565. doi: 10.1016/j.jhazmat.2010.01.121

Chen C., Gunawan P., Xu R. (2011) Self-assembled $\mathrm{Fe}_{3} \mathrm{O}_{4}$-layered double hydroxide colloidal nanohybrids with excellent performance for treatment of organic dyes in water. J. Mater. Chem. 21:1218-1225. doi: 10.1039/c0jm01696a

Chen X., Mao S.S. (2007) Titanium Dioxide Nanomaterials: Synthesis, Properties, Modifications, and Applications. Chem. Rev. 107:2891-2959. doi: 10.1021/cr0500535

Chen J., Yao M., Wang J. (2008) Investigation of transition metal ion doping behaviors on $\mathrm{TiO}_{2}$ nanoparticles. J. Nanopart. Res. 10:163-171. doi: 10.1007/s11051-007-9237-3

Chen Y., Wang J., Li W., Ju M.. (2015) Microwave-assisted hydrothermal synthesis of $\mathrm{Au} / \mathrm{TiO}_{2} / \mathrm{SBA}-15$ for enhanced visible-light photoactivity. Mater. Lett. 159:131-134. doi: 10.1016/j.matlet.2015.04.030

Chin S.S., Chiang K., Fane A.G. (2006) The stability of polymeric membranes in a $\mathrm{TiO}_{2}$ photocatalysis process. J Membr Sci 275:202-211 . doi: 10.1016/j.memsci.2005.09.033

Chin S.S., Lim T.M., Chiang K., Fane A.G. (2007a) Hybrid low-pressure submerged membrane photoreactor for the removal of bisphenol A. Desalination 202:253-261. doi: 10.1016/j.desal.2005.12.062

Chin S.S., Lim T.M., Chiang K., Fane A.G. (2007b) Factors affecting the performance of a low-pressure submerged membrane photocatalytic reactor. Chem. Eng. J. 130:53-63. doi: 10.1016/j.cej.2006.11.008

Chiou C.H., Wu C.Y., Juang R.S. (2008) Influence of operating parameters on photocatalytic degradation of phenol in $\mathrm{UV} \mathrm{TiO}_{2}$ process. Chem. Eng. J. 139: 322-329. doi: 10.1016/j.cej.2007.08.002

Chong M.N., Jin B., Chow C.W.K., Saint C. (2010) Recent developments in photocatalytic water treatment technology: A review. Water Res. 44:2997-3027. doi: 10.1016/j.watres.2010.02.039

Choo K.H., Chang D.I., Park K.W., Kim M.H. (2008a) Use of an integrated photocatalysis/hollow fiber microfiltration system for the removal of trichloroethylene in water. J. Hazard. Mater. 152:183-190. doi: 10.1016/j.jhazmat.2007.06.117 
Choo K.H., Tao R., Kim M.J. (2008b) Use of a photocatalytic membrane reactor for the removal of natural organic matter in water: Effect of photoinduced desorption and ferrihydrite adsorption. J. Membr. Sci. 322:368-374. doi: 10.1016/j.memsci.2008.05.069

Coleman H.M., Vimonses V., Leslie G., Amal R. (2007) Degradation of 1,4-dioxane in water using $\mathrm{TiO}_{2}$ based photocatalytic and $\mathrm{H}_{2} \mathrm{O}_{2} / \mathrm{UV}$ processes. J. Hazard. Mater. 146: 496-501. doi: 10.1016/j.jhazmat.2007.04.049

Colina-Márquez J., Machuca-Martínez F., Puma G.L. (2010) Radiation Absorption and Optimization of Solar Photocatalytic Reactors for Environmental Applications. Environ. Sci. Technol. 44:5112-5120. doi:10.1021/es100130h

Coyle E.E., Oelgemöller M. (2008) Micro-photochemistry: photochemistry in microstructured reactors. The new photochemistry of the future? Photochem. Photobiol. Sci. 7:1313-1322. doi:10.1039/B808778D

Cui P., Zhao X., Zhou M., Wang L. (2006) Photocatalysis-Membrane Separation Coupling Reactor and Its Application. Chin. J. Catal. 27:752-754. doi:10.1016/S18722067(06)60041-7

Curcio E., Ji X., Di Profio G., Sulaiman A.O., Fontananova E., Drioli E. (2010) Membrane distillation operated at high seawater concentration factors: Role of the membrane on $\mathrm{CaCO}_{3}$ scaling in presence of humic acid. J. Membr. Sci. 346:263-269 . doi:

Damodar RA, You S-J, Ou S-H (2010) Coupling of membrane separation with photocatalytic slurry reactor for advanced dye wastewater treatment. Sep. Purif. Technol. 76:64-71. doi: 10.1016/j.seppur.2010.09.021

De Lima, L.B., Pereira L.O., de Moura S.G., Magalhães (2017) Degradation of organic contaminants in effluents-synthetic and from the textile industry-by Fenton, photocatalysis and $\mathrm{H}_{2} \mathrm{O}_{2}$ photolysis. Environ. Sci. Pollut. Res. 24:6299-6306. doi: 10.1007/s11356-0166973-x

Demarche P., Junghanns C., Nair R.R., Agathos S.N. (2012), Harnessing the power of enzymes for environmentalstewardship. Research review paper. Biotechnol. Adv. 30:933953. doi: 10.1016/j.biotechadv.2011.05.013

Devi L.G., Kottam N., Murthy B.N., Kumar S.G. (2010) Enhanced photocatalytic activity of transition metal ions $\mathrm{Mn}^{2+}, \mathrm{Ni}^{2+}$ and $\mathrm{Zn}^{2+}$ doped polycrystalline titania for the degradation of Aniline Blue under UV/solar light. J. Mol. Catal. A 328:44-52. doi: 10.1016/j.molcata.2010.05.021

Doll T.E., Frimmel F.H. (2005) Cross-flow microfiltration with periodical back-washing for photocatalytic degradation of pharmaceutical and diagnostic residues-evaluation of the long-term stability of the photocatalytic activity of $\mathrm{TiO}_{2}$. Water. Res. 39:847-854. doi: 10.1016/j.watres.2004.11.029

Dong H., Zeng G., Tang L., Fan C., Zhang C., He X, He Y. (2015) An overwiew on the limitations of $\mathrm{TiO}_{2}$-based particles for photocatalytic degradation of organic pollutants and the corresponding countermeasures. Water Res. 29: 128-146. doi: 10.1016/j.watres.2015.04.038

Dong W., Sun Y., Lee C.W., Hua W., Lu X., Shi Y., Zhang S., Chen J., Zhao D. (2007) Controllable and Repeatable Synthesis of Thermally Stable Anatase Nanocrystal-Silica Composites with Highly Ordered Hexagonal Mesostructures. J. Am. Chem. Soc. 129 :13894-13904. doi: 10.1021/ja073804o

Dong W., Sun Y., Ma Q., Zhu L., Hua W., Lu X., Zhuang G., Zhang S., Guo Z., Zhao D. (2012) Excellent photocatalytic degradation activities of ordered mesoporous anatase $\mathrm{TiO}_{2}-\mathrm{SiO}_{2}$ nanocomposites to various organic contaminants. J. Hazardous Mater. 229230:307- 320. doi: 10.1016/j.jhazmat.2012.06.002

Dong W., Yao Y., Li L., Sun Y., Hua W., Zhuang G., Zhao D., Yan S., Song W. (2017) Threedimensional interconnected mesoporous anatase $\mathrm{TiO}_{2}$ exhibiting unique photocatalytical 
performance. Appl. Catal. B: Environmental 217:293-302. doi: 10.1016/j.apcatb.2017.05.083

Donia A.M., Atia A.A., Al-amrani W.A., El-Nahas A.M. (2009) Effect of structural properties of acid dyes on their adsorption behaviour from aqueous solutions by amine modified silica J. Hazard. Mater 161:1544-1550. doi: 10.1016/j.jhazmat.2008.05.042

Dror I., Jacov O.M., Cortis A., Berkowitz B. (2012) Catalytic transformation of persistent contaminants using a new composite material based on nanosized zero-valent iron. ACS Appl. Mater. Interfaces 4:3416-3423. doi: 10.1021/am300402q

Dutta R., Nagarjuma T.V., Mandavgane S.A., Ekhe J.D. (2014) Ultrafast removal of cationic dye using agrowaste-derived mesoporous adsorbent. Ind. Eng. Chem. Res. 54:1855818567. doi: 10.1021/ie5030003

Epolito W.J., Lee Y.H., Bottomley L.A., Pavlostathis S.G. (2005) Characterization of the textile anthraquinone dye Reactive Blue 4. Dyes Pigm. 67:35-46. doi: 10.1016/j.dyepig.2004.10.006

Erdei L., Arecrachakul N., Vigneswaran S. (2008) A combined photocatalytic slurry reactorimmersed membrane module system for advanced wastewater treatment. Sep. Purif. Technol. 62:382-388. doi: 10.1016/j.seppur.2008.02.003

Fernández-Ibáñez P., Blanco J., Malato S., Nieves F.J. de las (2003) Application of the colloidal stability of $\mathrm{TiO}_{2}$ particles for recovery and reuse in solar photocatalysis. Water Res. 37:3180-3188. doi:10.1016/S0043-1354(03)00157-X

Fisli A., Ridwan, Krisnandi Y.K., Gunlazuardi J. (2017) Preparation and Characterization of $\mathrm{Fe}_{3} \mathrm{O}_{4} / \mathrm{SiO}_{2} / \mathrm{TiO}_{2}$ composite for Methylene Blue removal in water. Int. J. Technol. 1: 7684. doi: 10.14716/ijtech.v8i1.2888

Forgacs E., Cserháti T., Oros G. (2004) Removal of synthetic dyes from wastewaters: a review. Environ. Int. 30:953-971. doi: 10.1016/j.envint.2004.02.001

Fox M., Dulay M. (1993) Heterogeneous. Photocatalysis. Chem. Rev. 93:341-357. doi: $10.1021 / \mathrm{cr} 00017 \mathrm{a} 016$

Fu J., Ji M., Wang Z., Jin L., An D. (2006a) A new submerged membrane photocatalysis reactor (SMPR) for fulvic acid removal using a nano-structured photocatalyst. J. Hazard. Mater. 131:238-242. doi: 10.1016/j.jhazmat.2005.09.039

Fu J., Ji M., Zhao Y., Wang L. (2006b) Kinetics of aqueous photocatalytic oxidation of fulvic acids in a photocatalysis-ultrafiltration reactor (PUR). Sep. Purif. Technol. 50:107-113. doi: 10.1016/j.seppur.2005.11.017

Fujishima A., Honda K. (1972) Electrochemical photolysis of water at a semiconductor electrode. Nature 238: 37-38. doi: 10.1038/238037a0

Gao B., Yap P.S., Lim T.M., Lim T.-T. Lim (2011) Adsorption-photocatalytic degradation of Acid Red 88 by supported TiO2: Effect of activated carbon support and aqueous anions. Chem. Eng. J. 171:1098-1107. doi: 10.1016/j.cej.2011.05.006

Gaya U.I., Abdullah A.H. (2008) Heterogeneous photocatalytic degradation of organic contaminants over titanium dioxide: A review of fundamentals, progress and problems. J. Photochem. Photobiol., C 9:1-12. doi: 10.1016/j.photochemrev.2007.12.003

Galenda A., Visentin F., Gerbasi R., Battiston S., El Habra N. (2017) Effective and Low-Cost Synthesis of Sulphur-Modified $\mathrm{TiO}_{2}$ Nanopowder with Improved Photocatalytic Performances in Water Treatment Applications. Water Air Soil Pollut. 228: 416. doi: 10.1007/s11270-017-3600-5

Gemoets H.P.L., Su Y., Shang M., Hessel V., Luque R., Noël T. (2015) Liquid phase oxidation chemistry in continuous-flow microreactors. Chem. Soc. Rev. 45:83-117. doi: 10.1039/C5CS00447K

Genuino, Homer C., Dambar B.H, You J.F., Suib S.L. (2012) Synergetic effects of ultraviolet and microwave radiation for enhanced activity of $\mathrm{TiO}_{2}$ nanoparticles in degrading organic 
dyes using a continuous-Flow reactor. J. Phys. Chem. C 116:14040-14051. doi:10.1021/jp3040192

Gerasimova T.V., Evdokimova (Galkina) O.L., Kraev A.S., Ivanov V.K., Agafonov A.V. (2016) Micro-mesoporous anatase $\mathrm{TiO}_{2}$ nanorods with high specific surface area possessing enhanced adsorption ability and photocatalytic activity. Microporous Mesoporous Mater. 235:185-194. doi: 10.1016/j.micromeso.2016.08.015

Giovannetti R., Rommozzi E., Zannotti M., D'Amato C. A. (2017) recent advances in graphene based $\mathrm{TiO} 2$ nanocomposites $(\mathrm{GTiO} 2 \mathrm{Ns})$ for photocatalytic degradation of synthetic dyes. Catalysts 7:305-339. doi:10.3390/catal7100305.

Gjipalaj J., Alessandri I. (2017) Easy recovery, mechanical stability, enhanced adsorption capacity and recyclability of alginate-based $\mathrm{TiO}_{2}$ macrobead photocatalysts for water treatment. J. Environ. Chem. Eng. 5 :1763-1770. doi: 1 0.1016/j.jece.2017.03.017

Gong Y., Wang D.P., Wu R., Gazi S., Soo H.S., Sritharan T., Chen Z. (2017) New insights into the photocatalytic activity of 3-D core-shell P25@silica nanocomposites: impact of mesoporous coating. Dalton Trans. 46:4994-5002. doi: 10.1039/C7DT00797C

Gonzalez-Martin A., Murphy O.J., Hodko D. (1998) Photocatalytic oxidation of organics using a porous titanium dioxide membrane and an efficient oxidant US patent 5,779,912

Gonzalez-Martin A., Murphy O.J., Hodko D. (2000) Photocatalytic oxidation of organics using a porous titanium dioxide membrane and an efficient oxidant US patent 6,136, 86

Gorges R., Meyer S., Kreisel G. (2004) Photocatalysis in microreactors. J. Photochem. Photobiol. Chem. 167:95-99. doi: 10.1016/j.jphotochem.2004.04.004

Guo J., Li J., Yin A., Fan K., Dai W. (2010) Photodegradation of Rhodamine B on sulfur doped $\mathrm{ZnO} / \mathrm{TiO}_{2}$ nanocomposite photocatalyst under visible-light irradiation. Chinese $\mathrm{J}$. Chem. 28:2144-2150. doi: 10.1002/cjoc.201090355

Guo J., Jianhua C., Wen W., Zishan Z., Dongfang W. (2014) Adsorption behavior of Congo Red from aqueous solution on $\mathrm{La}_{2} \mathrm{O}_{3}$-doped $\mathrm{TiO}_{2}$ nanotubes. Korean J. Chem. Eng. 20:3081-3088. doi: 10.1016/j.jiec.2013.11.047

Gupta V.K., Suhas (2009), Application of low-cost adsorbents for dye removal: a review. J. Environ. Manage 90:2313-2342. doi: 10.1016/j.jenvman.2008.11.017

Gupta V.K., Rajeev J., Shilpi A., Arunima N., Meenakshi S. (2012), Photodegradation of hazardous dye Quinoline Yellow catalyzed by $\mathrm{TiO}_{2}$. J. Colloid Interface Sci.366:135-140. doi: 10.1016/j.jcis.2011.08.059

Gutmann B., Cantillo D., Kappe C.O. (2015) Continuous-Flow Technology-A Tool for the Safe Manufacturing of Active Pharmaceutical Ingredients. Angew. Chem. Int. Ed. 54:6688-6728. doi: 10.1002/anie.201409318

Hafez H.S. (2009) Synthesis of highly-active single-crystalline $\mathrm{TiO} 2$ nanorods and its application in environmental photocatalysis. Mater. Lett. 63:1471-1474. doi: 10.1016/j.matlet.2009.03.057

Hajjaji W., Andrejkovicova S., Pullar R.C., Tobaldi D.M., Lopez-Galindo A., Jammousi F., Rocha F., Labrincha J.A. (2016) Effective removal of anionic and cationic dyes by kaolinite and $\mathrm{TiO}_{2} /$ kaolinite composites. Clay Minerals $51: 19-27$. doi: 10.1180/claymin.2016.051.1.02

Hartman R.L., Jensen K.F. (2009) Microchemical systems for continuous-flow synthesis. Lab. Chip. 9:2495-2507. doi: 10.1039/B906343A

Heggo D., Ookawara S. (2017) Multiphase photocatalytic microreactors. Chem. Eng. Sci. 169:67-77. doi: 10.1016/j.ces.2017.01.019

Hessel V., Cortese B., de Croon M.H.J.M. (2011) Novel process windows-Concept, proposition and evaluation methodology, and intensified superheated processing. Chem. Eng. Sci. 66:1426-1448. doi: 10.1016/j.ces.2010.08.018 
Hoffmann M., Martin S., Choi W., Bahnemann D. (1995) Environmental Applications of Semiconductor Photocatalysis. Chem. Rev 95: 69-96. doi: 10.1021/cr00033a004

Huang X., Meng Y., Liang P., Qian Y. (2007) Operational conditions of a membrane filtration reactor coupled with photocatalytic oxidation. Sep. Purif. Technol. 55:165-172. doi: 10.1016/j.seppur.2006.11.018

Hufschmidt D., Bahnemann D., Testa J.J., Emilio C.A., Litter M.I. (2002) Enhancement of the Photocatalytic Activity of Various $\mathrm{TiO}_{2}$ Materials by Platinisation. J. Photochem. Photobiol. A: Chem. 148:223-231. doi:10.1016/S1010-6030(02)00048-5.

Ilinoiu E.C., Pode R., Manea F., Colar L.A., Jakab A., Orha C., Ratiu C., Lazau C., Sfarloaga P. (2013) Photocatalytic Activity of a Nitrogen-Doped $\mathrm{TiO}_{2}$ Modified Zeolite in the Degradation of Reactive Yellow 125 Azo Dye. J. Taiwan Inst. Chem. Eng. 44: 270-278. doi: 10.1016/j.jtice.2012.09.006

Ilkhechi N.N, Kaleji B.K. (2014) High temperature stability and photocatalytic activity of nanocrystalline anatase powders with $\mathrm{Zr}$ and $\mathrm{Si}$ co-dopants. J. Sol-Gel Sci.Technol. 69:351-356. doi : 10.1007/s10971-013-3224-1

Im, J.H., Seung J.Y., Chang H.Y., Chong R.P. (2012). Simple Fabrication of carbon/TiO Composite Nanotubes Showing Dual Functions with Adsorption and Photocatalytic Decomposition of Rhodamine B. Nanotech. 23:1-10. doi:10.1088/09574484/23/3/035604.

Ismail A.A., Bahnemann D.W. (2011) Mesoporous Titania Photocatalysts: Preparation, Characterization and Reaction Mechanisms. J. Mater. Chem. 21:11686-11707. doi: 10.1039/C1JM10407A

Jensen K.F., Reizman B.J., Newman SG (2014) Tools for chemical synthesis in microsystems. Lab. Chip. 14:3206-3212. doi:10.1039/C4LC00330F

Jensen K.F. (2017) Flow chemistry-Microreaction technology comes of age. AIChE J 63:858869. doi:10.1002/aic. 15642

Jiang H., Zhang G., Huang T., Chen J., Wang Q., Meng Q. (2010) Photocatalytic membrane reactor for degradation of Acid Red B wastewater. Chem. Eng. J. 156:571-577 doi: 10.1016/j.cej.2009.04.011

Jiang Y., Tang W., Gao J., Zhou L., He Y. (2014) Immobilization of horseradish peroxidase in phospholipid-templated titania and its applications in phenolic compounds and dye removal Enzyme Microb. Technol. 55:1-5. doi: 10.1016/j.enzmictec.2013.11.005

Jiao Y., Wan C., Li J. (2015) Room-temperature embedment of anatase titania nanoparticles into porous cellulose aerogels. Appl. Phys. A 120:341-347. doi: 10.1007/s00339-01591922

Jing L.Q., Wang B.Q., Xin B.F., Li S.D., Shi K.Y., Cai W.M., Fu H.G. (2004) Investigations on the surface modification of $\mathrm{ZnO}$ nanoparticle photocatalyst by depositing Pd. J. Solid State Chem. 177:4221-4227. doi: 10.1016/j.jssc.2004.08.016

Julkapli N., Bagheri S., Hamid S.B.A. (2014) Recent advances in heterogeneous photocatalytic decolorization of synthetic dyes. The ScientificWorld Journal. Article ID 692307, 25 pages. .doi:10.1155/2014/692307

Kansal, S. K., Singh M., Sud D. (2008) Studies on $\mathrm{TiO}_{2} / \mathrm{ZnO}$ Photocatalysed Degradation of Lignin. J. Hazard. Mater. 153: 412-417. doi: 10.1016/j.jhazmat.2007.08.091

Karthikeyan N., Sivaranjani T., Dhanavel S., Gupta V.K., Narayanan V., Stephen A. (2017) Visible light degradation of textile effluent by electrodeposited multiphase $\mathrm{CuInSe} 2$ semiconductor photocatalysts. J. Mol. Liq. 227:194-201. doi: 10.1016/j.molliq.2016.12.019

Kasanen J., Salstela J., Suvanto M., Pakkanen T.T. (2011) Photocatalytic degradation of methylene blue in water solution by multilayer $\mathrm{TiO}_{2}$ coating on HDPE. Appl. Surf. Sci.. 258:1738-1743. doi: 10.1016/j.apsusc.2011.10.028 
Kelly, S., Pollak, F.H., Tomkiewicz, M. (1997) Raman spectroscopy as a morphological probe for $\mathrm{TiO}_{2}$ aerogels J. Phys. Chem. B 101:2730-2734. doi: 10.1021/jp962747a

Kim D.S., Han S.J., Kwak S.Y. (2007) Synthesis and photocatalytic activity of mesoporous $\mathrm{TiO}_{2}$ with the surface area, crystallite size, and pore size. J. Colloid. Interface Sci. 316:8591. doi: 10.1016/j.jcis.2007.07.037

Kimling M.C., Dehong C., Caruso R.A. (2015) Temperature-induced modulation of mesopore size in hierarchically porous amorphous $\mathrm{TiO}_{2} / \mathrm{ZrO}_{2}$ beads for improved dye adsorption capacity. J. Mater. Chem. 3:3768-3776. doi: 10.1039/C4TA06289B

Kimura T. (2016) Evaporation-induced self-assembly process controlled for obtaining highly ordered mesoporous materials with demanded morphologies. Chem. Rec. 16:445-457. doi: 10.1002/tcr.201500262

Kolpin D. W., Furlong E. T., Meyer M. T., Thurman E. M., Zaugg S. D., Barber L. B., Buxton H. T. (2002) Pharmaceuticals, hormones, and other organic wastewater contaminants in US streams, 1999-2000: A national reconnaissance. Environ. Sci. Technol. 36:1202-1211. doi: 10.1021/es011055j

Koros W.J., Ma Y.H., Shimidzu T. (1996) Terminology for membranes and membrane processes (IUPAC Recommendations 1996). Pure Appl. Chem. 68:1479-1489. doi: $0.1351 /$ pac199668071479

$\mathrm{Ku}$ Y., Huang Y.H., Chou Y. C. (2011) Preparation and characterization of $\mathrm{ZnO} / \mathrm{TiO}_{2}$ for the photocatalytic reduction of $\mathrm{Cr}(\mathrm{VI})$ in aqueous solution. J. Mol. Catal. A: Chem. 342343:18-22. doi: 10.1016/j.molcata.2011.04.003

Kuijpers K.P.L., Dijk M.A.H. van, Rumeur Q.G., Hessel V., Su Y., Noël T. (2017) A sensitivity analysis of a numbered-up photomicroreactor system. React. Chem. Eng. 2:109115. doi: 10.1039/C7RE00024C

Lai C.W., Juan J.C., Ko W.B., Abd Hamid S.B. (2014) An Overview: Recent Development of Titanium Oxide Nanotubes as Photocatalyst for Dye Degradation. Int. J. Photoenergy. doi :1155/2014/524135

Landmann M., Rauls E., Schmidt W.G. (2012) The electronic structure and optical response of rutile, anatase and brookite $\mathrm{TiO}_{2}$. J. Phys. Condens. Matter 24: Article Number: 195503. doi: 10.1088/0953-8984/24/19/195503

Lannoy A., Bleta R., Machut C., Monflier E, Ponchel A. (2014) Block copolymercyclodextrin supramolecular assemblies as soft templates for the synthesis of titania materials with controlled crystallinity,porosity and photocatalytic activity. RSC. Adv. 4:4061-4070. doi: 10.1039/c4ra05994h

Lazar M.A., Varghese S., Nair S.S. (2012) Photocatalysis water treatment by titanium dioxide: Recent updates. Catalysts 2: 572-601. doi: 10.3390/catal2040572

Lee C.K., Liu S.S., Juang L.C., Wang C.C., Lin K.S., Lyu M.D. (2007) Application of MCM41 for dyes removal from wastewater. J. Hazard. Mater 147:997-1005. doi: 10.1016/j.jhazmat.2007.01.130

Lee S.A., Choo K.H., Lee C.H., Lee H.I., Hyeon T., Choi W., Kwon H.H. (2001) Use of Ultrafiltration Membranes for the Separation of $\mathrm{TiO}_{2}$ Photocatalysts in Drinking Water Treatment. Ind. Eng. Chem. Res. 40:1712-1719. doi: 10.1021/ie000738p

Lee S. S., Kim H.J. Jung K. T., Kim H. S., Shuf, Y. G. (2001) Photocatalytic Activity of Metal Ion (Fe or $\mathrm{W})$ Doped Titania. Korean J. Chem. Eng. 18: 914-918. doi: 10.1007/BF02705618

Li H., Shi J.L., Liang J., Li X., Li L., Ruan M. (2008) Synthesis of well-ordered mesoporous titania powder with crystallized framework. Mater. Lett. 62:1410-1413. doi: 10.1016/j.matlet.2007.08.072

Li W., Wu Z., Wang J., Elzatahry A.A., Zhao D. (2014) A perspective on mesoporous $\mathrm{TiO}_{2}$ materials. Chem. Mater. 26:287-298. doi: 10.1021/cm4014859 
Li X., Wang H., Inoue K., Uehara M., Nakamura H., Miyazaki M., Abe E., Maeda H. (2003) Modified micro-space using self-organized nanoparticles for reduction of Methylene Blue. Chem. Commun. 0:964-965. doi:10.1039/B300765K

Li X.Z., Zhao Y.G. (1999) Advanced treatment of dyeing wastewater for reuse. Water Sci. Technol. 39:249-255. doi: 10.1016/S0273-1223(99)00285-1

Li Y., Li J., Wang X., Ma Y., Guan W., Qian T. (2016) Macrostructure-controlled titania ceramics derived from particle-stabilized emulsions: Preparation and photochemical performance. Mater. Chem. Phys. 182:402-408. doi: 10.1016/j.matchemphys.2016.07.048

Li Z., Hou B., Wu D., Sun Y. (2005) Hydrothermal synthesis, characterization, and photocatalytic performance of silica-modified titanium dioxide nanoparticles. J. Colloid. Interface Sci. 288:149-154. doi: 10.1016/j.jcis.2005.02.082

Liao D.L., Badour C.A., Liao B.Q. (2008) Preparation of nanosized $\mathrm{TiO}_{2} / \mathrm{ZnO}$ composite catalyst and its photocatalytic activity for degradation of Methyl Orange, J. Photochem. Photobiol. A Chem. 194:11-19. doi: 10.1016j.photochem.2007.07.008

Lin C., Liu M., Yang .Z (2016) Performance of a Metal Ion-Doped Titania-Coated Planar Photocatalytic Microreactor. Chem. Eng. Technol. 39:88-96. doi: 10.1002/ceat.201400776

Lin H.F., Liao S.C., Hung S.W. (2005) The dc thermal plasma synthesis of ZnO nanoparticles for visible-light photocatalyst. J. Photochem. Photobiol. A: Chem. 174:82-87. doi: 10.1016/j.jphotochem.2005.02.015

Lin W.C., Yang W.D., Chung Z.J., Chueng H.J. (2011) Preparation and application of titanate nanotubes on Methylene Blue degradation from aqueous media. Appl. Mech. Mater. 117:786-789. doi: 10.4028/ AMM.117-119.786

Lin W.C., Yang W.D., Jheng S.Y. (2012) Photocatalytic degradation of dyes in water using porous nanocrystalline titanium dioxide. J. Taiwan Inst. Chem. Eng. 43:269-274. doi: 10.1016/j.jtice.2011.10.010

Lindstrom H., Wootton R., Iles A. (2007) High surface area titania photocatalytic microfluidic reactors. AIChE J. 53:695-702. doi:10.1002/aic.11096

Linsebigler A., Lu G., Yates J. (1995) Photocatalysis on $\mathrm{TiO}_{2}$ Surfaces: Principles, Mechanisms, and Selected Results. Chem. Rev. 95: 735-758. doi: 10.1021/cr00035a013

Liu F., Liu C.L., Hu B., Kong W.P., Qi C.Z. (2012) High temperature hydrothermal synthesis of crystalline mesoporous $\mathrm{TiO}_{2}$ with superior photocatalytic activity. Appl. Surf. Sci.. 258:7448:7454. doi: 10.1016/j.apsusc.2012.04.059

Liu R., Yang W.D., Chueng H.J., Ren B.Q. (2015) Preparation and Application of Titanate Nanotubes on Dye Degradation from Aqueous Media by UV Irradiation. J. Spectroscopy. doi :10.1155/2015/680183

Ma N., Zhang Y., Quan X., Fan X., Zhao H. (2010) Performing a microfiltration integrated with photocatalysis using an $\mathrm{Ag}-\mathrm{TiO}_{2} / \mathrm{HAP} / \mathrm{Al}_{2} \mathrm{O}_{3}$ composite membrane for water treatment: Evaluating effectiveness for humic acid removal and anti-fouling properties. Water Res. 44:6104-6114. doi: 0.1016/j.watres.2010.06.068

Ma Y., Yao J.N. (1998) Photodegradation of Rhodamine B Catalyzed by $\mathrm{TiO}_{2}$ Thin Films. J. Photochem. Photobiol. A: Chem. 116:167-70. doi: 10.1016/S1010-6030(98)00295-0

Mahlambi M.M., Ngila C.J., Mamba B.B. (2015) Recent developments in environmental photocatalytic degradation of organic pollutants: The case of titanium dioxide nanoparticles - A review. J. Nanomaterials. doi:10.1155/2015/790173

Mahmoodi N.M., Arami M., Limaee N.Y., Tabrizi N.S. (2006) Kinetics of heterogeneous photocatalytic degradation of reactive dyes in an immobilized $\mathrm{TiO}_{2}$ photocatalytic reactor. J. Colloid Interf. Sci. 295: 159-164. doi: 10.1016/j.jcis.2005.08.007

Mahmoodi N.M., Arami M. (2009) Degradation and toxicity reduction of textile wastewater using immobilized titania nanophotocatalysis. J. Photochem. Photobiol. B. 94:20-24 doi: 10.1016/j.jphotobiol.2008.09.004 
Mahmoud H.R., El-Molla S.A., Saif M. (2013) Improvement of physicochemicalproperties of $\mathrm{Fe}_{2} \mathrm{O}_{3} / \mathrm{MgO}$ nanomaterials by hydrothermal treatment for dye removal from industrial wastewater. Powder Technol 249:225-233. doi: 10.1016/j.powtec.2013.08.021

Martorell M.M., Pajot H.F., de Figuerosa L.I.C. (2017) Biological degradation of reactive black 5 dye by yeast trichosporon alkiyoshidainum. J. Environ. Chem. Eng. 5:5987-5993. doi: 10.1016/j.jece.2017.11.012

Melvin Ng H.K., Leo C.P., Abdullah A.Z. (2017) Selective removal of dyes by molecular imprinted $\mathrm{TiO}_{2}$ nanoparticles in polysulfone ultrafiltration membrane. J. Environ. Chem. Eng. 5:3991-3998. doi: 10.1016/j.jece.2017.07.075

Mendret J., Hatat-Fraile M., Rivallin M., Brosillon S. (2013) Hydrophilic composite membranes for simultaneous separation and photocatalytic degradation of organic pollutants. Sep. Purif. Technol. 111:9-19. doi: 10.1016/j.seppur.2013.03.030

Meng Y., Huang X., Yang Q., Qian Y., Kubota N., Fukunaga S. (2005) Treatment of polluted river water with a photocatalytic slurry reactor using low-pressure mercury lamps coupled with a membrane. Desalination 181:121-133. doi: 10.1016/j.desal.2005.02.015

Messina P.V, Schultz P.C. (2006) Adsorption of reactive dyes on titania-silica mesoporous materials. J. Colloid Interface Sci.299:305-320. doi: 10.1016/j.jcis.2006.01.039

Minero C., Maurino V., Pelizzetti E. (1997) Heterogeneous photocatalytic transformation of s-triazine derivatives. Res. Chem. Intermed. 23:291-310.

Mizuno K., Nishiyama Y., Ogaki T., Terao K., Ikeda H., Kakiuchi K. (2016) Utilization of microflow reactors to carry out synthetically useful organic photochemical reactions. J. Photochem. Photobiol. C Photochem. Rev. 29:107-147. doi: 10.1016/j.jphotochemrev.2016.10.002

Mohamed S.K., Amr Ibrahim A., Mousa A.A., Betiha M.A., El-Sharkawy E.A., Hassan H. M.A. (2018) Facile fabrication of ordered mesoporous Bi/Ti-MCM-41 nanocomposites for visible light-driven photocatalytic degradation of Methylene Blue and $\mathrm{CO}$ oxidation. Separation Purification Technol. 195: 174-183. doi: 10.1016/j.seppur.2017.12.008

Molinari R., Mungari M., Drioli E., Di Paola A., Loddo V., Palmisano L., Schiavello M. (2000) Study on a photocatalytic membrane reactor for water purification. Catal.Today 55:71-78. doi: 10.1016/S0920-5861(99)00227-8

Molinari R., Borgese M., Drioli E., Palmisano L., Schiavello M. (2002a) Hybrid processes coupling photocatalysis and membranes for degradation of organic pollutants in water. Catal. Today 75:77-85. doi: 10.1016/S0920-5861(02)00047-0

Molinari R., Palmisano L., Drioli E., Schiavello M. (2002b) Studies on various reactor configurations for coupling photocatalysis and membrane processes in water purification. J. Membr. Sci. 206:399-415. doi:10.1016/S0376-7388(01)00785-2

Molinari R., Pirillo F., Falco M., Loddo V., Palmisano L. (2004) Photocatalytic degradation of dyes by using a membrane reactor. Chem. Eng. Process Process Intensif 43:1103-1114. doi: 10.1016/j.cep.2004.01.008

Molinari R., Pirillo F., Loddo V., Palmisano L. (2006) Heterogeneous photocatalytic degradation of pharmaceuticals in water by using polycrystalline $\mathrm{TiO}_{2}$ and a nanofiltration membrane reactor. Catal. Today 118:205-213. doi: 10.1016/j.cattod.2005.11.091

Molinari R., Caruso A., Argurio P., Poerio T. (2008) Degradation of the drugs Gemfibrozil and Tamoxifen in pressurized and de-pressurized membrane photoreactors using suspended polycrystalline $\mathrm{TiO}_{2}$ as catalyst. J. Membr. Sci. 319:54-63. doi: 10.1016/j.memsci.2008.03.033

Morales-Torres S., Pastrana-Martinez L.M., Figueiredo J.L., Faria J.L. (2012) Design of graphene-based TiO2 photocatalysts-a review. Environ. Sci. Pollut. Res. 19:3676-3687. doi : 10.1007/s11356-012-0939-4 
Moser J., Gratzel M., Galley R. (1987) Inhibition of electron-hole recombination in substitutionally doped colloidal semiconductor crystallites. Helv. Chim. Acta 70:15961604. doi: 10.1002/hlca.19870700617

Mozia S., Tomaszewska M., Morawski A.W. (2005) A new photocatalytic membrane reactor (PMR) for removal of azo-dye Acid Red 18 from water. Appl. Catal. B Environ 59:131137. doi: 10.1016/j.apcatb.2005.01.011

Mozia S., Morawski A.W. (2006a) Hybridization of photocatalysis and membrane distillation for purification of wastewater. Catal. Today 118:181-188. doi: 10.1016/j.cattod.2005.12.003

Mozia S., Tomaszewska M., Morawski A.W. (2006b) Removal of azo-dye Acid Red 18 in two hybrid membrane systems employing a photodegradation process. Desalination 198:183-190. doi: 10.1016/j.desal.2006.01.024

Mozia S., Tomaszewska M., Morawski A.W. (2007a) Photocatalytic membrane reactor (PMR) coupling photocatalysis and membrane distillation-Effectiveness of removal of three azo dyes from water. Catal. Today 129:3-8. doi: 10.1016/j.cattod.2007.06.043

Mozia S., Toyoda M., Inagaki M., Tryba B., Morawski A.W. (2007b) Application of carboncoated $\mathrm{TiO}_{2}$ for decomposition of Methylene Blue in a photocatalytic membrane reactor. J. Hazard. Mater. 140:369-375. doi: 10.1016/j.jhazmat.2006.10.016

Mozia S., Toyoda M., Tsumura T., Inagaki M., Morawski A.W. (2007c) Comparison of effectiveness of methylene blue decomposition using pristine and carbon-coated $\mathrm{TiO}_{2}$ in a photocatalytic membrane reactor. Desalination 212:141-151. doi: 10.1016/j.desal.2006.10.007

Mozia S., Morawski A.W., Toyoda M., Inagaki M. (2008) Effectiveness of photodecomposition of an azo dye on a novel anatase-phase $\mathrm{TiO}_{2}$ and two commercial photocatalysts in a photocatalytic membrane reactor (PMR). Sep. Purif. Technol. 63:386391. doi: 10.1016/j.seppur.2008.05.029

Mozia S., Morawski A.W., Toyoda M., Inagaki M. (2009a) Application of anatase-phase $\mathrm{TiO}_{2}$ for decomposition of azo dye in a photocatalytic membrane reactor. Desalination 241:97105. doi: 10.1016/j.desal.2007.12.048

Mozia S., Morawski A.W., Toyoda M., Tsumura T. (2009b) Effect of process parameters on photodegradation of Acid Yellow 36 in a hybrid photocatalysis-membrane distillation system. Chem. Eng. J. 150:152-159. doi: 10.1016/j.cej.2008.12.012

Mozia S., Morawski A.W. (2009c) Integration of Photocatalysis with Ultrafiltration or Membrane Distillation for Removal of Azo Dye Direct Green 99 from Water. J. Adv. Oxid. Technol. 12:111-121. doi:10.1515/jaots-2009-0114

Mozia S. (2010) Photocatalytic membrane reactors (PMRs) in water and wastewater treatment. A review. Sep. Purif. Technol. 73:71-91. doi: 10.1016/j.seppur.2010.03.021

Mozia S., Darowna D., Szymański K., Grondzewska S., Borchert K.., Wróbel R, Morawski A.W. (2014) Performance of two photocatalytic membrane reactors for treatment of primary and secondary effluents. Catal. Today 236:135-145. doi: 10.1016/j.cattod.2013.12.049

Naboulsi I., Lebeau B., Michelin L., Carteret C., Vidal L., Bonne M., Blin J.L. (2017) Insights into the formation and properties of templated dual mesoporous titania with enhanced photocatalytic activity. ACS Appl. Mater. Interfaces 9:3113-3122. doi: 10.1021/acsami.6b13269

Nalbandian M.J., Greenstein K.E., Shuai D., Zhang M., Choa Y.H., Parkin G.F., Myung N.V., Cwiertny D.M. (2015) Tailored Synthesis of Photoactive $\mathrm{TiO}_{2}$ Nanofibers and $\mathrm{Au} / \mathrm{TiO}_{2}$ Nanofiber Composites: Structure and Reactivity Optimization for Water Treatment Applications. Environ. Sci. Technol., 49:1654-1663. doi: 10.1021/es502963t 
Nandi B.K., Goswami A., Purkait M.K. (2009) Removal cationic dyes from aqueous solutions by kaolin; kinetic and equilibrium studies. Appl. Clay. Sci. 42:583-590. doi: 10.1016/j.clay.2008.03.015

Newman S.G., Jensen K.F. (2013) The role of flow in green chemistry and engineering. Green Chem. 15:1456-1472. doi: 10.1039/C3GC40374B

Nieves-Remacha M.J., Kulkarni A.A., Jensen K.F. (2012) Hydrodynamics of Liquid-Liquid Dispersion in an Advanced-Flow Reactor. Ind. Eng. Chem. Res. 51:16251-16262. doi: 10.1021/ie301821k

Nieves-Remacha M.J., Kulkarni A.A., Jensen K.F. (2013) Gas-Liquid Flow and Mass Transfer in an Advanced-Flow Reactor. Ind Eng Chem Res 52:8996-9010. doi: 10.1021/ie4011707

Ohtani B., Ogawa Y., Nishimoto S. (1997) Photocatalytic activity of amorphous-anatase mixture of titanium(IV) oxide particles suspended in aqueous solutions. J. Phys. Chem. B 101:3746-3752. doi: 10.1021/jp962702+

Oller I., Malato S., Sánchez-Pérez J.A. (2011) Combination of advanced oxidation processes and biological treatments for wastewater decontamination-A review. Sci. Total Environ. 409:4142-4166. doi: 10.1016/j.scitotenv.2010.08.061

Ollis D.F. (2003) Integrating Photocatalysis and Membrane Technologies for Water Treatment Ann. N Y Acad Sci 984:65-84. doi: 10.1111/j.1749-6632.2003.tb05993.x

Padoin N., Andrade L., Ângelo J., Mendes A., Moreira R. de FPM, Soares C. (2016) Intensification of photocatalytic pollutant abatement in microchannel reactor using $\mathrm{TiO}_{2}$ and $\mathrm{TiO}_{2}$-graphene. AIChE J. 62:2794-2802. doi: 10.1002/aic.15262

Pan L., Zou J.J., Wang S., Huang Z.F., Zhang X., Wang L. (2013) Enhancement of visiblelight-induced photodegradation over hierarchical porous $\mathrm{TiO}_{2}$ by nonmetal doping and water-mediated dye sensitization. Appl. Surf. Sci. 268:252-258. doi: 10.1016/j.apsusc.2012.12.074

Papageorgiou S.K., Katsaros F.K., Favvas E.P., Romanos G.E., Athanasekou C.P., Beltsios K.G., Tzialla O.I., Falaras P. (2012) Alginate fibers as photocatalyst immobilizing agents applied in hybrid photocatalytic/ultrafiltration water treatment processes. Water Res. 46:1858-1872. doi: 10.1016/j.watres.2012.01.005

Park S.E., Hwang J.S., Chang J.S., Kim J.M., Kim D.S., Chai H.S. (2002) Titania photocatalyst and its preparing method US patent application publication 2002/0098977 A1

Paz Y. (2006) Preferential photodegradation - why and how? C.R. Chimie 9:774-787. doi: 10.1016/j.cri.2005.03.032

Pelaez M., Nolan N. T., Pillai S.C, Seery M.K., Falaras P., Kontos A. G., Dunlop P.S.M., Hamilton J.W.J., Byrne J.A., O’Shea K., Entezari M.H., Dionysiou D.D. (2012) A review on the visible light active titanium dioxide photocatalysts for environmental applications. Appl. Catal. B Environ. 125: 331-349. doi: 10.1016/j.apcatb.2012.05.036

Pelizzetti E., Minero C., Borgarello E., Tinucci L., Serpone N. (1993) Photocatalytic activity and selectivity of titania colloids and particles prepared by the sol-gel technique: photooxidation of phenol and atrazine. Langmuir 13:2995-3001. doi: 10.1021/la00035a043

Peng Y.G., Chen D.J., Ji J.L., Kong Y., Wan H.X., Yao C. (2013) The preparation of titanium dioxide/parlygorskite composite and its application in the adsorption of Congo Red. Environ. Prog. 32:1090-1095. doi: 10.1002/ep.11717

Pérez-Larios A., Lopez R., Hernández-Gordillo A., Tzompantzi F., Gómez R., Torres-Guerra L.M. (2012) Improved hydrogen production from water splitting using $\mathrm{TiO}_{2}-\mathrm{ZnO}$ mixed oxides photocatalysts. Fuel 100:139-143. doi: 10.1016/j.fuel.2012.02.026 
Preethi P., Padmapriya M.P., Abarna B., Rajarajeswari G.R. (2017) Choline chloride-zinc chloride ionic liquid as a green template for the sol-gel synthesis of mesoporous titania. RSC. Adv. 7:10081-10091. doi: 10.1039/C6RA28478G

Qamar M., Saquib M., Muneer M. (2005) Titanium dioxide mediated photocatalytic degradation of two selected azo dye derivatives, Chrysoidine R and Acid Red 29 (chromotrope 2R), in aqueous suspensions, Desalination 186: 255-271. doi: 10.1016/j.desal.2005.05.021

Qin Q., Ma J., Liu K. (2009) Adsorption of anionic dyes on ammonium-functionalized MCM41, J. Hazard. Mater 162:133-139. doi: 10.1016/j.jhazmat.2008.05.016

Qiu J., Zhang S., Zhao H. (2012) Nanostructured $\mathrm{TiO}_{2}$ photocatalysts for the determination of organic pollutants. J. Hazard. Mater. 211-212:381-388. doi: 10.1016/j.jhazmat.2011.10.093

Rafatullah M., Sulaiman O., Hashim R., Ahmad A. (2010) Adsorption of Methylene Blue on low-cost adsorbents: a review. J. Hazard. Mater. 177:70-80. doi: 10.1016/j.jhazmat.2009.12.047

Rasalingam S., Wu C.M., Koodali R.T. (2015) Modulation of pore sizes of titanium Dioxide photocatalysts by a facile template free hydrothermal synthesis method: Implications for photocatalytic degradation of Rhodamine B. ACS Appl. Mater. Interfaces $7: 4368-4380$. doi: 10.1021/am508883f

Reutergadh L.B., Iangphasuk M. (1997) Photocatalytic decolourization of reactive azo dye: A comparison between $\mathrm{TiO}_{2}$ and us photocatalysis. Chemosphere.35:585-596. doi: 10.1016/S0045-6535(97)00122-7

Rivero M.J., Parsons S.A., Jeffrey P., Pidou M., Jefferson B. (2006) Membrane chemical reactor (MCR) combining photocatalysis and microfiltration for grey water treatment. Water Sci. Technol. 53:173-180. doi: 10.2166/wst.2006.090

Robinson T, McMullan G, Marchant R, Nigam P (2001) Remediation of dyes in textile effluent: a critical review on current treatment technologies with a proposed alternative. Bioresour. Technol. 77:247-255. doi: 10.1016/S0960-8524(00)00080-8

Romanos G.E., Athanasekou C.P., Likodimos V., Aloupogiannis P., Falaras P. (2013) Hybrid Ultrafiltration/Photocatalytic Membranes for Efficient Water Treatment. Ind. Eng. Chem. Res. 52:13938-13947. doi: 10.1021/ie303475b

Rossetti I., Compagnoni M. (2016) Chemical reaction engineering, process design and scaleup issues at the frontier of synthesis: Flow chemistry. Chem. Eng. J. 296:56-70. doi: 10.1016/j.cej.2016.02.119

Ryu J, Choi W, Choo K-H (2005) A pilot-scale photocatalyst-membrane hybrid reactor: performance and characterization. Water Sci. Technol. 51:491-497.

Saquib M., Tariq M.A., Faisal M., Muneer M. (2008a) Photocatalytic degradation of two selected dye derivatives in aqueous suspensions of titanium dioxide. Desalination 219: 301311. doi: 10.1016/j.desal.2007.06.006

Saquib M., Tariq M.A., Haque M.M., Muneer M. (2008b) Photocatalytic degradation of disperse Blue 1 using $\mathrm{UV} / \mathrm{TiO}_{2} / \mathrm{H}_{2} \mathrm{O}_{2}$ process. J. Environ. Management 88: 300-306. doi: 10.1016/j.desal.2007.06.006

Serpone N., Maruthamuthu P., Pichat PPelizzetti., E., Hidaka H. (1995) Exploiting the Interparticle Electron Transfer Process in the Photocatalysed Oxidation of Phenol, 2Chlorophenol and Pentachlorophenol: Chemical Evidence for Electron and Hole Transfer Between Coupled Semiconductors. J. Photochem. Photobiol. A Chem. 85:247-255. doi: 10.1016/1010-6030(94)03906-B

Sharma V.K., Feng M. (2017) Water depollution using metal-organic frameworks-catalyzed advanced oxidation processes: A review, https://doi.org/10.1016/j.jhazmat.2017.09.043 
Shifu C., Wei Z., Wei L., Sujuan Z. (2008) Preparation, characterization and activity evaluation of $\mathrm{p}-\mathrm{n}$ junction photocatalyst $\mathrm{p}-\mathrm{ZnO} / \mathrm{n}-\mathrm{TiO}_{2}$. Appl. Surf. Sci. 255:2478-2484. doi: 10.1016/j.jhazmat.2009.08.007

Shon H.K., Phuntsho S., Vigneswaran S. (2008) Effect of photocatalysis on the membrane hybrid system for wastewater treatment. Desalination 225:235-248. doi: 0.1016/j.desal.2007.05.032

Simonsen M.E., Søgaard E.G. (2010) Sol-gel reactions of titanium alkoxides and water: influence of $\mathrm{pH}$ and alkoxy group on cluster formation and properties of the resulting products. J. Sol-Gel Sci. Technol. 53:485-497. doi:10.1007/s10971-009-2121-0

Sopajaree K., Qasim S.A., Basak S., Rajeshwar K. (1999a) An integrated flow reactormembrane filtration system for heterogeneous photocatalysis. Part I: Experiments and modelling of a batch-recirculated photoreactor. J. Appl. Electrochem. 29:533-539. doi:10.1023/A:1026418208733

Sopajaree K., Qasim S.A., Basak S., Rajeshwar K. (1999b) An integrated flow reactormembrane filtration system for heterogeneous photocatalysis. Part II: Experiments on the ultrafiltration unit and combined operation. J. Appl. Electrochem. 29:1111-1118. doi:10.1023/A:1003633309224

Stathatos E., Papoulis D., Aggelopoulos C.A., Panagiotaras D., Nikolopoulou A. (2012) $\mathrm{TiO}_{2}$ /palygorskite composite nanocrystalline films prepared by surfactant templating route: synergistic effect to the photocatalytic degradation of an azo-dye in water. J. Hazard. Mater. 211:68-76. doi: 10.1016/j.jhazmat.2011.11.055

Su Y., Straathof N.J.W., Hessel V., Noël T. (2014) Photochemical Transformations Accelerated in Continuous-Flow Reactors: Basic Concepts and Applications. Chem. Eur. J. 20:10562-10589. doi: 10.1002/chem.201400283

Subramaniam M.N., Goh P.S., Abdullah N., Lau W.J., Ng B.C., Ismail A.F. (2017) Adsorption and photocatalytic degradation of Methylene Blue using high surface area titanate nanotubes (TNT) synthesized via hydrothermal method. J. Nanopart. Res. 19: 220232. doi:10.1007/s11051-017-3920-9

Sun D., Meng T.T., Loong T.H., Hwa T.J. (2004) Removal of natural organic matter from water using a nano-structured photocatalyst coupled with filtration membrane. Water Sci. Technol. 49:103-110.

Suteu D., Malutan T. (2013) industrial cellolignin wastes as adsorbent for removal of Methylene Blue dye from aqueous solutions. Bioresources 8:42-446.

Tajer-Kajinebaf V., Sarpoolaky H., Mohammadi T. (2014) Sol-gel synthesis of nanostructured titania-silica mesoporous membranes with phot-degradation and physical separation capacities for water purification. Ceram. Int. 40:1747-1757. doi: 10.1016/j.ceramint.2013.07.074

Tanaka H., Hisanaga T., Harada K. (1989) Efficient photocatalytic degradation of chloral hydrate in aqueous semiconductor suspension. J. Photochem. Photobiol. A: Chem. 48: 155159. doi: 10.1016/1010-6030(89)87098-4

Tayade R.J., Kulkarni R.G., Jarsa R.V. (2006) Transition metal ion impregnated mesoporous $\mathrm{TiO}_{2}$ for photocatalytic degradation of organic contaminants in water. Ind. Eng. Chem. Res. 45:5231-5238. doi: 10.1021/ie051362o

Teekateerawej S., Nishino J., Nosaka Y. (2005) Photocatalytic microreactor study using $\mathrm{TiO}_{2}$ coated porous ceramics. J. Appl. Electrochem. 35:693-697. doi:10.1007/s10800-005-1623$\mathrm{X}$

Thejaswini T.V.L., Prabhakaran D., Maheswari M.A. (2016) Soft synthesis of Bi Doped and Bi-N co-doped $\mathrm{TiO}_{2}$ nanocomposites: A comprehensive mechanistic approach towards visible light induced ultra-fast photocatalytic degradation of fabric dye pollutant. J. Environ. Chem. Eng. 4:1308-1321. doi: 10.1016/j.jece.2016.01.031 
Thejaswini T.V.L, Prabhakaran D., Akhila Maheswari M. (2017) Synthesis of mesoporous Worm-like $\mathrm{ZrO}_{2}-\mathrm{TiO}_{2}$ monoliths and their photocatalytic applications towards organic dye degradation J. Photochem. Photobiol., A. 344:212-222. doi: 10.1016/j.jphotochem.2017.05.015

Tian B., Yang H., Liu X., Xie S., Yu C., Fan J., Tu B., Zhao D. (2002) Fast Preparation of highly ordered nonsiliceous mesoporous materials via mixed inorganic precursors. Chem. Commun. 17:1824-1825. doi: 10.1039/B205006D

Tian B., Liu X., Tu B., Yu C., Fan J., Wang L., Xie S., Stucky G.D., Zhao D. (2003) Selfadjusted synthesis of ordered stable mesoporous minerals by acid-base pairs. Nat. Mater. 2: 159-163. doi: 10.1038/nmat838

Toledo J.A., Chavez C.A., Jacome M.A.C, Ramirez F.A., Morales Y.R., Torres G.F., Ortiz L.F.F., Salinas E.L., Lozada y Cassou M. (2014) Nanostructured titanium oxide materials and its synthesis procedure US patent 8,658,126 B2

Tomaszewska M., Gryta M., Morawski A.W. (1998) The influence of salt in solutions on hydrochloric acid recovery by membrane distillation. Sep. Purif. Technol. 14:183--188. doi:10.1016/S1383-5866(98)00073-2

Torres-Martinez C.L., Nguyen L., Kho R., Bae W., Bozhilov K., Klimov V., Mehra R.K. (1999) Biomolecularly capped uniformly sized nanocrystalline materials: glutathionecapped ZnS nanocrystals. Nanotechnology 10:340-354. doi: 10.1088/0957-4484/10/3/319

Tsai C.Y., Liu C.W., Chan Y.H., Chang T.Y., Chen B.C., His H.C. (2017) Development of HCl-treated titania nanotube photocatalysts for dye photodegradation and lowconcentration elemental mercury removal. Catal. Today 297:113-123. doi: 10.1016/j.cattod.2017.04.061

Tsarenko S.A., Kochkodan V.M., Samsoni-Todorov A.O., Goncharuk V.V. (2006) Removal of humic substances from aqueous solutions with a photocatalytic membrane reactor. Colloid. J. 68:341-344. doi: 10.1134/S1061933X06030124

Tsuru T., Toyosada T., Yoshioka T., Asaeda M. (2001) Photocatalytic Reactions in a Filtration System through Porous Titanium Dioxide Membranes. J. Chem. Eng. Jpn. 34:844-847. doi: $10.1252 /$ jcej. 34.844

Vaez M., Abdolsamad Z.M, Niyaz M.M. (2012) Decolorization and degradation of acid dye with immobilized titania nanoparticles. Process. Saf. Environ. Prot. 90:56-64. doi: 10.1016/j.psep.2011.07.005

Van Gerven T., Mul G., Moulijn J., Stankiewicz A. (2007) A review of intensification of photocatalytic processes. Chem. En.g Process Process Intensif 46:781-789. doi: 10.1016/j.cep.2007.05.012

Veliscek-Carolan J., Knott R., Hanley T. (2015) Effects of precursor solution aging and other parameters on synthesis of ordered mesoporous titania powders. J. Phys. Chem. C 119:7172-7183. doi: 10.1021/jp5127927

Wang and Zhang (2012) Physicochemical and photocatalytic activities of self-assembling TiO2 nanoparticles on nanocarbons surface. Curr. Appl. Phys. 12:346-352. doi:10.1016/j.cap.2011.07.030

Wang B., Condi de Godoi F., Sun Z., Zeng Q., Zheng S., Frost R.L. (2015) Synthesis, characterization and activity of an immobilized photocatalyst: Natural porous diatomite supported titania nanoparticles. J. Coll. Interface Sci. 438:204-211. doi: 10.1016/j.jcis.2014.09.064

Wang C., Shao C., Liu Y., Li X. (2009) Water-dichloromethane interface-controlled synthesis of hierarchical rutil $\mathrm{TiO}_{2}$ superstructures and their photocatalytic properties. Inorg. Chem. 48:1105-1113. doi: 10.1021/ic8018138

Wang J., Zhao J., Sun L., Wang X. (2015) A review on the applications of photocatalytic materials on textiles. Textile Res. J. 85:1104-1118. doi: 10.1177/0040517514559583 
Wang N., Zhang X., Wang Y., Yu W., Chan H.L.W. (2014) Microfluidic reactors for photocatalytic water purification. Lab Chip 14:1074-1082. doi:10.1039/C3LC51233A

Wang W.Y., Irawan A., Ku Y. (2008) Photocatalytic degradation of Acid Red 4 using a titanium dioxide membrane supported on a porous ceramic tube. Water Res. 42:4725-4732. doi: 10.1016/j.watres.2008.08.021

Wang Y., Yan Z., Wang X. (2014) Photocatalytic Degradation of Rhodamine B Dye over Novel Porous $\mathrm{TiO}_{2}-\mathrm{SnO}_{2}$ Nanocomposites Prepared by Hydrothermal Method. Int. J. Photoenergy. doi:10.1155/2014/928519

Wang Y., Huijin L., Manling Z., Wubiao D., Bo L. (2017) A dual-functional UiO-66/TiO 2 composite for water treatment and $\mathrm{CO}_{2}$ capture. RSC adv. 7:16232-16237. doi: 10.1039/C7RA00028F

Wegner J., Ceylan S., Kirschning A. (2011) Ten key issues in modern flow chemistry. Chem. Commun. 47:4583-4592. doi: 10.1039/C0CC05060A

Wei W. Yu C., Zhao Q., Qian X., Li G., Wan Y. (2014) Synergy effect in photodegradation of contaminants from water using ordered mesoporous carbon-based titania catalyst. Appl. Catal. B: Environment. 146:151-161. doi:10;1016/j.apcatb.2013.04.048

Willmer I., Ranjit K. (2002) Photocatalysts for the degradation of organic pollutants. US patent 6,365,001 B1.

Woitalka A., Kuhn S., Jensen K.F. (2014) Scalability of mass transfer in liquid-liquid flow. Chem. Eng. Sci .116:1-8. doi: 10.1016/j.ces.2014.04.036

Xi W., Geissen S. (2001) Separation of titanium dioxide from photocatalytically treated water by cross-flow microfiltration. Water. Res. 35:1256-1262. doi: 10.1016/S00431354(00)00378-X

Xiong Z., Jizhen M., Wun J.N., Waite T.D., Zhao X.S. (2011) Silver-Modified Mesoporous $\mathrm{TiO}_{2}$ Photocatalyst for Water Purification. Water Res $45: 2095-2103$. doi: 10.1016/j.watres.2010.12.019.

Xu J.C., Shi Y.L., Huang J.E., Wang B., Li H.L. (2004) Doping metal ions only onto the catalyst surface. J. Mol. Catal. A: Chem. 219:351-355. doi: 10.1016/j.molcata.2004.05.018

Xu J.C., Lu M., Guo X.Y., Li H.L. (2005) Zinc ions surface-doped titanium dioxide nanotubes and its photocatalysis activity for degradation of Methyl Orange in water. J. Mol. Catal. A: Chem. 226: 123-127. doi: 10.1016/j.molcata.2004.09.051

Xu S., Ng J., Zhang X., Bai H., Sun D.D. (2011) Adsorption and photocatalytic degradation of Acid Orange 7 over hydrothermally synthesized mesoporous $\mathrm{TiO}_{2}$ nanotube. Coll. Surf. A: Physicochem. Eng. Aspects 379:169-175. doi: 10.1016/j.colsurfa.2010.11.032

Xu S., Gao Y., Sun X., Yue M., Yue Q., Gao B. (2016) Facile one-pot synthesis of carbon incorporated three-dimensional hierarchical $\mathrm{TiO}_{2}$ nanostructure for highly efficient pollutant removal. RSC Adv. 6 :101198-101207. doi: 10.1039/c6ra20188a

Yang J., Zhang J., Zhu L., Chen S., Zhang Y., Tang Y., Zhu Y., Li Y. (2006) Synthesis of nanotitania embedded in mesoporous SBA-15: Characterization and photocatalytic activity. J. Hazardous Mater B 137:952-958. doi: 10.1016/j.jhazrdmat.2006.03.017

Yang Z., Liu M., Lin C. (2016) Photocatalytic activity and scale-up effect in liquid-solid minifluidized bed reactor. Chem. Eng. J. 291:254-268. doi: 10.1016/j.cej.2016.01.050

Yao X., Chunbao Z., Ru H., Xiaoheng L. (2013) Highly crystalline and silica-embedded titania rhombic shaped nanoparticles with mesoporous structure and its application in photocatalytic degradation of organic compound. Mater. Chem. Phys. 141:705-712. doi: 10.1016/j.matchemphys.2013.05.067

Yi W., Chunyan Y., Peng Y., Faqiang L. (2014) A new perspective for effect of S and Cu on the photocatalytic activity of $\mathrm{S}, \mathrm{Cu}$-codoped $\mathrm{Nano}^{\mathrm{TiO}_{2}}$ under visible light irradiation. J. Sol-Gel Sci. Technol. 69:386-396. doi: 10.1007/s10971-013-3231-2 
Yue J., Luo L., Gonthier Y., Chen G., Yuan Q. (2009) An experimental study of air-water Taylor flow and mass transfer inside square microchannels. Chem. Eng. Sci. 64:3697-3708. doi: 10.1016/j.ces.2009.05.026

Zaleska A. (2008) Doped-TiO 2 : A Review. Recent Patents on Engineering 2:157-164. doi: $10.2174 / 187221208786306289$

Zhang H., Banfield, J. F. (2000a) Understanding Polymorphic Phase Transformation Behavior during Growth of Nanocrystalline Aggregates: Insights from $\mathrm{TiO}_{2}$. J. Phys. Chem. B 104:3481-3487. doi: 10.1021/jp000499j

Zhang H., Quan X., Chen S., Zhao H., Zhao Y. (2006a) Fabrication of photocatalytic membrane and evaluation its efficiency in removal of organic pollutants from water. Sep. Purif. Technol. 50:147-155. doi: 10.1016/j.seppur.2005.11.018

Zhang H., Quan X., Chen S., Zhao H., Zhao Y. (2006b) The removal of sodium dodecylbenzene sulfonate surfactant from water using silica/titania nanorods/nanotubes composite membrane with photocatalytic capability. Appl. Surf. Sci. 252:8598-8604. doi: 10.1016/j.apsusc.2005.11.090

Zhang H., Wang J.J., Fan J., Fang Q. (2013) Microfluidic chip-based analytical system for rapid screening of photocatalysts. Talanta 116:946-950. doi: 10.1016/j.talanta.2013.08.012

Zhang J., Wu Y., Xing M., Leghari S.A.K., Sajjad S. (2010) Development of modified N doped $\mathrm{TiO}_{2}$ photocatalyst with metals, nonmetals and metal oxides. Energy Environ. Sci. 3:715-726. doi: 10.1039/b927575d

Zhang J., Wang K., Teixeira A.R., Jensen K.F., Luo G. (2017) Design and Scaling Up of Microchemical Systems: A Review. Annu. Rev. Chem. Biomol. Eng. 8:285-305. doi:10.1146/annurev-chembioeng-060816-101443

Zhang R., Wang Q., Liang J., li Q., Dai J., Li W. (2012) Optical properties of N and transition metal $\mathrm{R}(\mathrm{R}=\mathrm{V}, \mathrm{Cr}, \mathrm{Mn}, \mathrm{Fe}, \mathrm{Co}, \mathrm{Ni}, \mathrm{Cu}$, and $\mathrm{Zn})$ codoped anatase $\mathrm{TiO}_{2}$. Physica B 407:27092715. doi: 10.1016/j.physb.2012.03.068

Zhang X, Wang DK, Lopez DRS, Diniz da Costa JC (2014) Fabrication of nanostructured $\mathrm{TiO}_{2}$ hollow fiber photocatalytic membrane and application for wastewater treatment. Chem. Eng. J. 236:314-322. doi: 10.1016/j.cej.2013.09.059

Zhang, W.F.; He, Y.L.; Zhang, M.S.; Yin, Z. and Chen, Q. (2000b) Raman scattering study on anatase $\mathrm{TiO}_{2}$ nanocrystals. J. Phys. D: Appl. Phys 33:912-916. doi: 10.1088/00223727/33/8/305

Zhao T., Yuan R., Jianping Y., Lianjun W., Wan J., Elzatahry A.A., Abdulaziz A., Yonghui D., Dongyuan Z., Luo W. (2016) Hierarchical Ordered Macro/mesoporous Titania with a Highly Interconnected Porous Structure for Efficient Photocatalysis. J. Mater. Chem. A 4:16446-53. doi:10.1039/C6TA06849A.

Zhu H., Jiang R., Fu Y., Guan Y., Yao J., Xiao L., Zeng G. (2012) Effective Photocatalytic Decolorization of Methyl Orange Utilizing $\mathrm{TiO}_{2} / \mathrm{ZnO} /$ Chitosan Nanocomposite Films under Simulated Solar Irradiation. Desalination 286:41-48. doi: 10.1016/j.desal.2011.10.036

Zimny K., Ghanbaja J., Carteret C., Stébé M.J., J.L. Blin (2010) Highly ordered mesoporous titania with semi crystalline framework templated by large or small nonionic surfactants. New J. Chem. 34:2113-2117. doi: 10.1039/c0nj00488j

Zimny K., Roques-Carmes T., Carteret C., Stébé M.J., Blin J.L. (2012) Synthesis and photoactivity of ordered mesoporous titania with a semicrystalline framework. J. Phys. Chem. C, 116: 6585-6594. doi: 10.1021/jp212428k

Znad H., Abbas K., Hena S., Md Awual R. (2018) Synthesis a novel multilamellar mesoporous $\mathrm{TiO}_{2} / \mathrm{ZSM}-5$ for photo-catalytic degradation of Methyl Orange dye in aqueous media. J. Environ. Chem. Eng. 6:218-227. doi: 10.1016/j.jece.2017.11.077 
Table 1 : Characteristics of the main polymorphs of titanium dioxide

\begin{tabular}{llll}
\hline & Anatase & Rutile & Brookite \\
\hline $\begin{array}{l}\text { Crystallographic system } \\
\text { Space group }\end{array}$ & Tetragonal & Tetragonal & Orthorhombic \\
& I4 ${ }_{1} /$ amd & P4 $/$ mnm & Pbca \\
Cell parameters $\left(\mathrm{A}^{\mathrm{o}}\right)$ & $\mathrm{a}: 3.793$ & $\mathrm{a}: 4.5937$ & $\mathrm{a}: 5.456$ \\
& $\mathrm{c}: 9.512$ & $\mathrm{c}: 2.9618$ & $\mathrm{~b}: 5.497$ \\
Density $\left(\mathrm{cm}^{3} / \mathrm{g}\right)$ & 3.89 & 4.42 & $\mathrm{c}: 5.1$ \\
Bandgap $(\mathrm{eV})$ & 3.2 & 3.0 & 4.12 \\
refractive index & 2.561 & 2.605 & 3.4 \\
\hline
\end{tabular}


Table 2 : $\mathrm{TiO}_{2}$ for dyes removal from water

\begin{tabular}{|c|c|c|c|c|c|c|c|}
\hline Dye family & Dye & $\begin{array}{l}\text { Materials used for } \\
\text { the removal }\end{array}$ & $\begin{array}{l}\text { Depollution } \\
\text { water process }\end{array}$ & Parameters & $\begin{array}{l}\text { Lamp } \\
\text { informations }\end{array}$ & Conclusions & References \\
\hline \multirow[t]{5}{*}{ Anionic dye } & $\begin{array}{l}\text { Acid Black } \\
26\end{array}$ & $\begin{array}{l}\text { Immobilized } \\
\mathrm{TiO}_{2} \\
\text { nanoparticles }\end{array}$ & $\begin{array}{l}\text { Photodegradation } \\
\text { and } \\
\text { photocatalytic } \\
\text { oxidation }\end{array}$ & 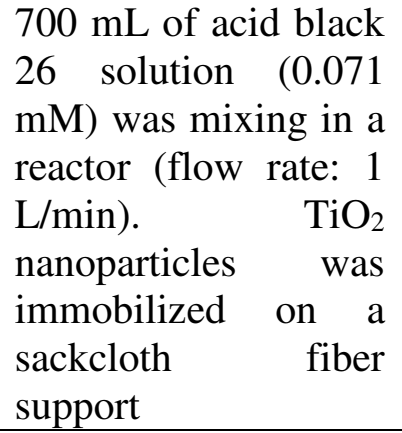 & $\begin{array}{l}\text { UV lamp } \\
\text { with an } \\
\text { intensity of } \\
1.8 \mathrm{~mW} / \mathrm{cm}^{2}\end{array}$ & $\begin{array}{l}\text { In acidic } \\
\text { conditions, with } \\
\mathrm{H}_{2} \mathrm{O}_{2} \text { for } \\
\text { oxidation } \\
\text { reaction, } 80 \% \text { of } \\
\text { dye would be } \\
\text { removed from the } \\
\text { solution }\end{array}$ & $\begin{array}{l}\text { (Vaez et al. } \\
2012 \text { ) }\end{array}$ \\
\hline & Acid Blue 25 & $\mathrm{P} 25$ & $\begin{array}{l}\text { Photocatalytic } \\
\text { oxidation }\end{array}$ & $\begin{array}{l}\text { A solution containing } \\
50 \mathrm{mg} / \mathrm{L} \text { of dye with } \\
\text { various quantity of } \\
\mathrm{P} 25 \text { and } \mathrm{H}_{2} \mathrm{O}_{2}\end{array}$ & $\begin{array}{l}\text { Two UV-C } \\
\text { lamp }(15 \mathrm{~W})\end{array}$ & $\begin{array}{l}\text { In optimized } \\
\text { conditions, the } \\
\text { system was able } \\
\text { to remove } 99 \% \\
\text { of dye in solution }\end{array}$ & $\begin{array}{l}\text { (Mahmoodi } \\
\text { and Arami } \\
\text { 2009) }\end{array}$ \\
\hline & $\begin{array}{l}\text { Acid Orange } \\
7\end{array}$ & $\begin{array}{l}\mathrm{S}, \mathrm{Cu}-\quad \text { codoped } \\
\mathrm{TiO}_{2} \\
\text { nanoparticles }\end{array}$ & Photodegradation & $\begin{array}{l}20 \mathrm{mg} / \mathrm{L} \text { acid orange } 7 \\
\text { aqueous with various } \\
\text { masses of catalyst in } \\
\text { acidic conditions }\end{array}$ & $\begin{array}{l}\text { Visible light } \\
\text { source is } 18 \\
\mathrm{~W} \text { lamp } \\
(>447 \mathrm{~nm})\end{array}$ & $\begin{array}{l}\text { In optimized } \\
\text { conditions, } 60 \% \\
\text { of dye was } \\
\text { converted in the } \\
\text { solution }\end{array}$ & $\begin{array}{l}\text { (Yi et al. } \\
2014)\end{array}$ \\
\hline & $\begin{array}{l}\text { Acid Orange } \\
7\end{array}$ & $\begin{array}{l}\text { Mesoporous } \\
\mathrm{ZrO}_{2} / \mathrm{TiO}_{2}\end{array}$ & Adsorption & $\begin{array}{l}0.01 \mathrm{~g} \text { of mesoporous } \\
\text { powder was mixing } \\
\text { with } 10 \mathrm{~mL} \text { of acid } \\
\text { orange } 7 \text { solution at } \\
\text { various } \\
\text { concentrations }\end{array}$ & - & $\begin{array}{l}\text { In the better } \\
\text { conditions, } 101 \\
\mathrm{mg} / \mathrm{g} \text { of dye } \\
\text { would } \\
\text { adsorbed on the } \\
\text { materials }\end{array}$ & $\begin{array}{l}\text { (Kimling, } \\
\text { Chen, and } \\
\text { Caruso } \\
\text { 2015) }\end{array}$ \\
\hline & Congo Red & $\begin{array}{l}\mathrm{TiO}_{2} \text { nanotubes } \\
\text { doped } \mathrm{La}_{2} \mathrm{O}_{3}\end{array}$ & Adsorption & $\begin{array}{l}\text { Adsorption kinetics: } \\
0.20 \mathrm{~g} \text { of adsorbant } \\
\text { was mixing at } 200\end{array}$ & - & $\begin{array}{l}\text { Equilibrium time } \\
\text { is obtained after }\end{array}$ & $\begin{array}{l}\text { (Guo et al. } \\
2014 \text { ) }\end{array}$ \\
\hline
\end{tabular}




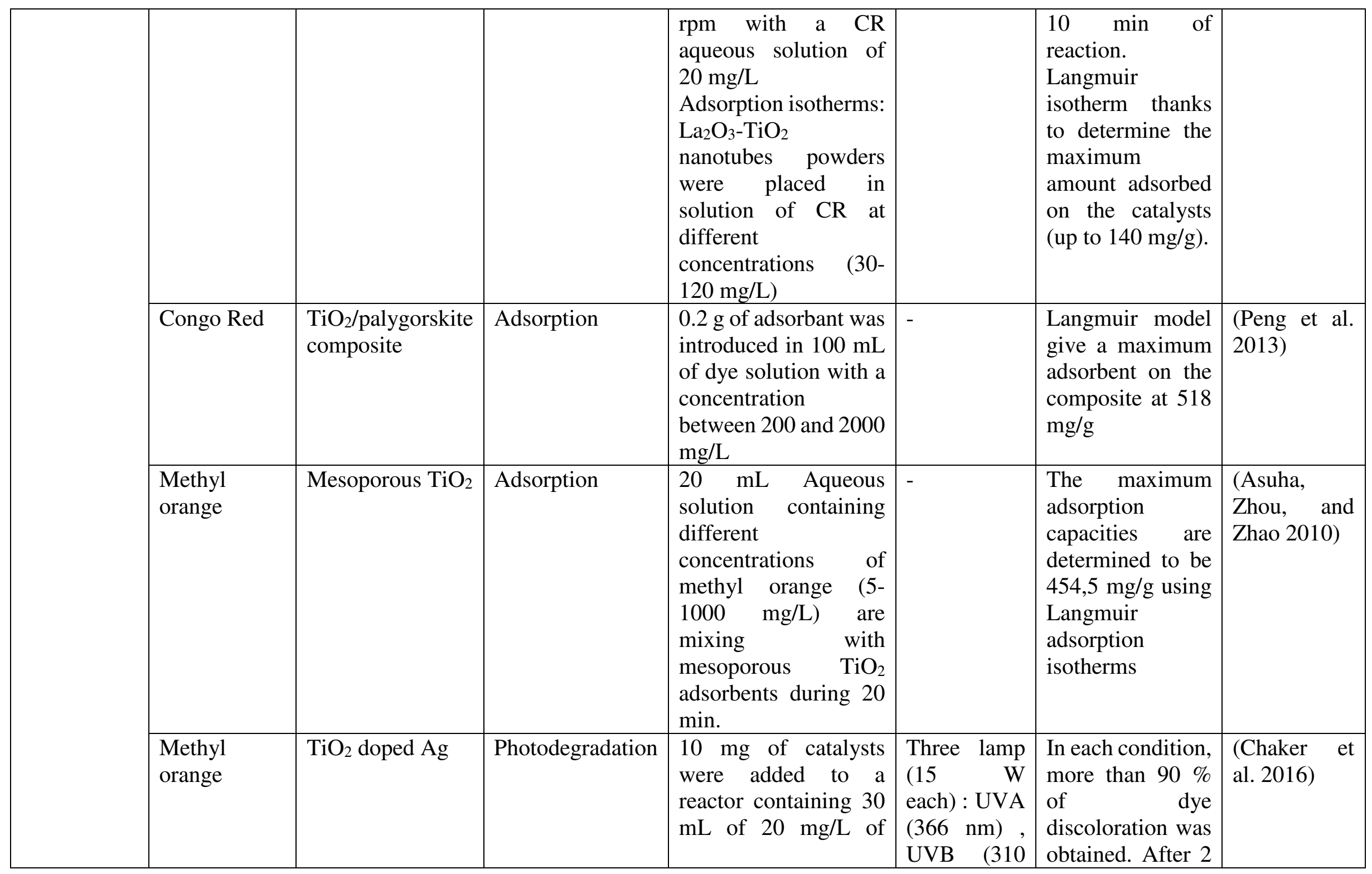




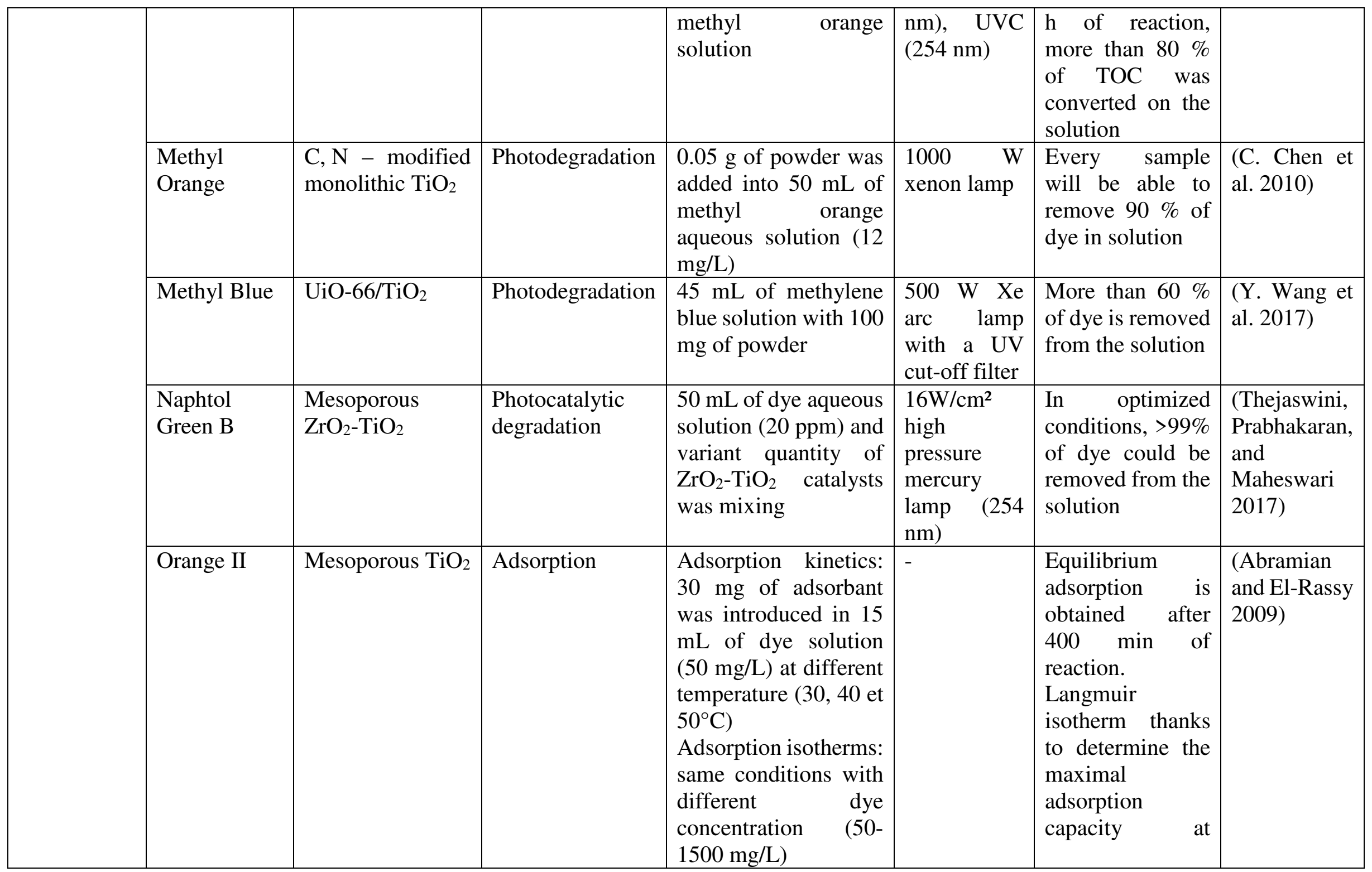




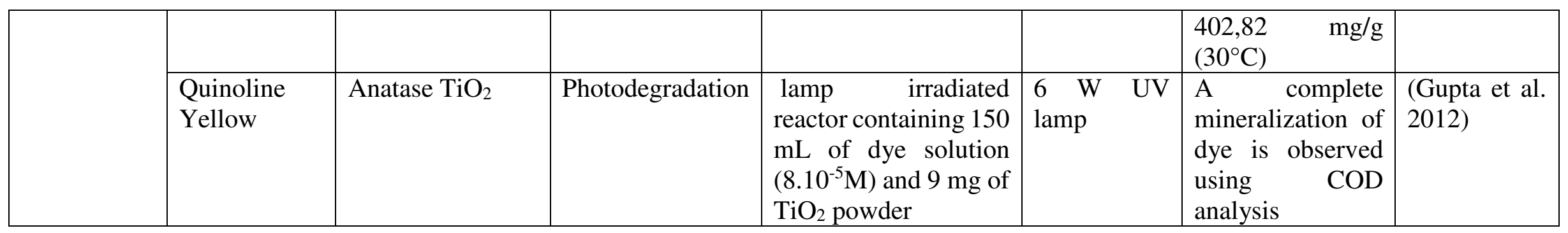

\begin{tabular}{|c|c|c|c|c|c|c|c|}
\hline $\begin{array}{l}\text { Dye } \\
\text { classification }\end{array}$ & Dye & $\begin{array}{l}\text { Reactive } \\
\text { materials }\end{array}$ & $\begin{array}{l}\text { Depollution water } \\
\text { process }\end{array}$ & Parameters & $\begin{array}{l}\text { Lamp } \\
\text { informations }\end{array}$ & Conclusions & References \\
\hline
\end{tabular}




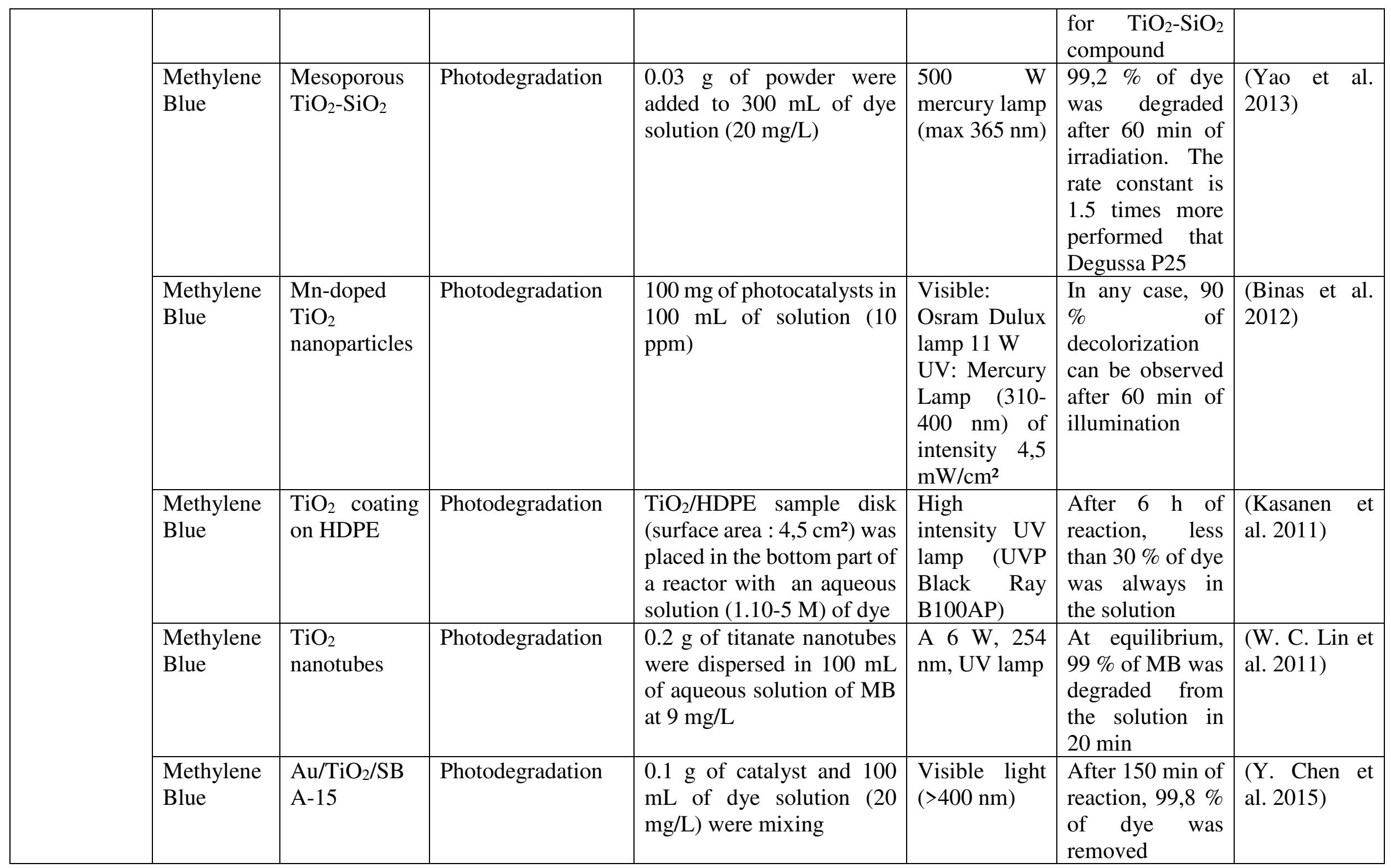




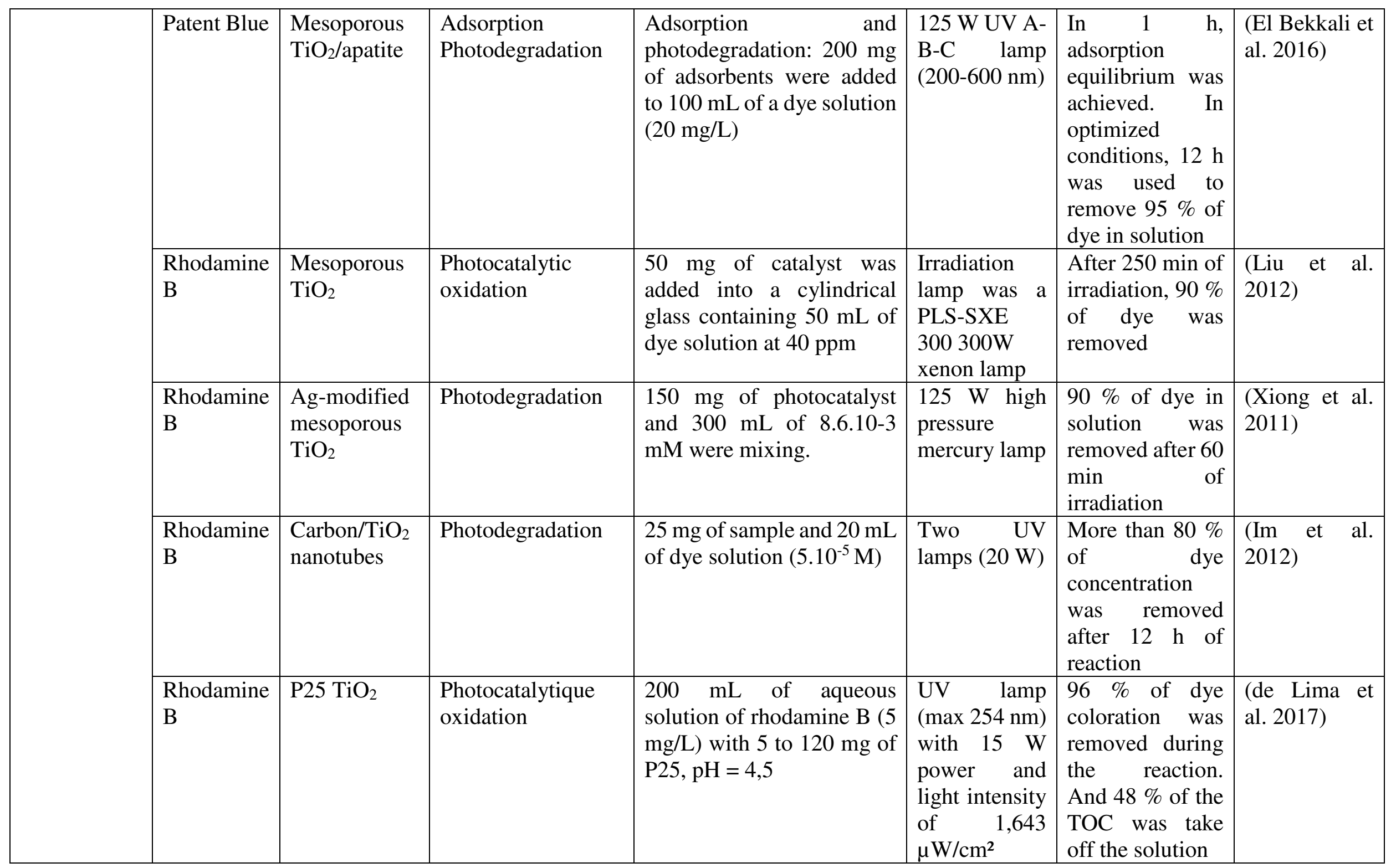




\begin{tabular}{|c|c|c|c|c|c|c|c|}
\hline & $\begin{array}{l}\text { Rhodamine } \\
\text { B }\end{array}$ & $\begin{array}{l}\text { Meso- } \\
\text { macroporous } \\
\mathrm{TiO}_{2}\end{array}$ & Photodegradation & $\begin{array}{l}50 \mathrm{~mL} \text { of aqueous solution } \\
\text { of rhodamine } \mathrm{B}\left(10^{-5} \mathrm{M}\right) \\
\text { containing } 50 \mathrm{mg} \text { of } \mathrm{TiO} 2\end{array}$ & $\begin{array}{l}300 \quad \mathrm{~W} \\
\text { mercury lamp }\end{array}$ & $\begin{array}{l}\text { In } 8 \text { min of } \\
\text { illumination, } 97 \\
\% \text { of dye was } \\
\text { removed }\end{array}$ & $\begin{array}{l}\text { (Zhao et al. } \\
2016)\end{array}$ \\
\hline
\end{tabular}


Figure 1 : Structure of the main synthetic dyes studied in degradation. "Reprinted with permission from (Forgas et al. 2004). Copyright 2004 Elsevier, Environment International."

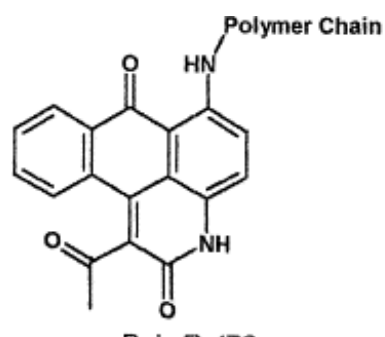<smiles>Nc1c(S(=O)(=O)O[Na])cc(NNc2cccc(S(=O)(=O)CCOS(=O)(=O)O[Al])c2)c2c1C(=O)c1ccccc1C2=O</smiles>

Remazol Brilliant Blue $\mathrm{R}$<smiles>CCN(CC)c1ccc2c(-c3ccccc3C(=O)O)c3ccc(=[N+](CC)CC)cc-3oc2c1</smiles>

Rhodamine B<smiles>CN(C)c1ccc(C(=C2C=CC(=[N+](C)[O-])C=C2)c2ccc(N(C)C)cc2)cc1</smiles><smiles>Oc1ccc2ccccc2c1/N=N/c1ccccc1</smiles>

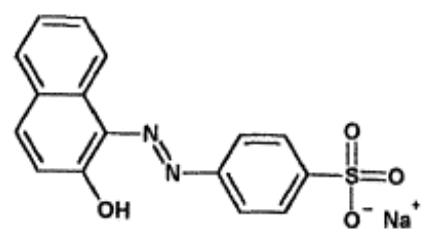

Acid Orange 7<smiles></smiles>

Reactive Black 5 $0=11$

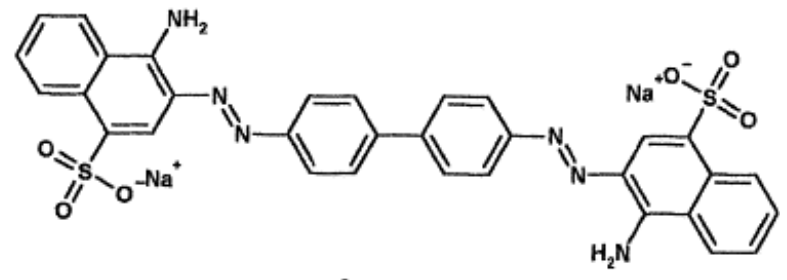

Congo Red

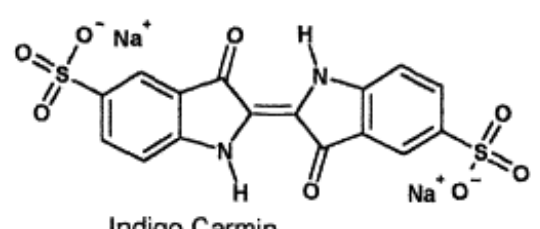
Indigo Carmin

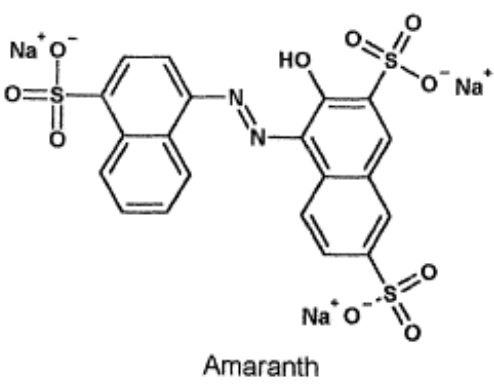

Amaranth 
Figure 2 : Dye classification on the basis of dye chemical constitution and its application. Reprinted with permission from (Ajmal et al. 2014). Copyright 2014 RSC, RSC Advances.

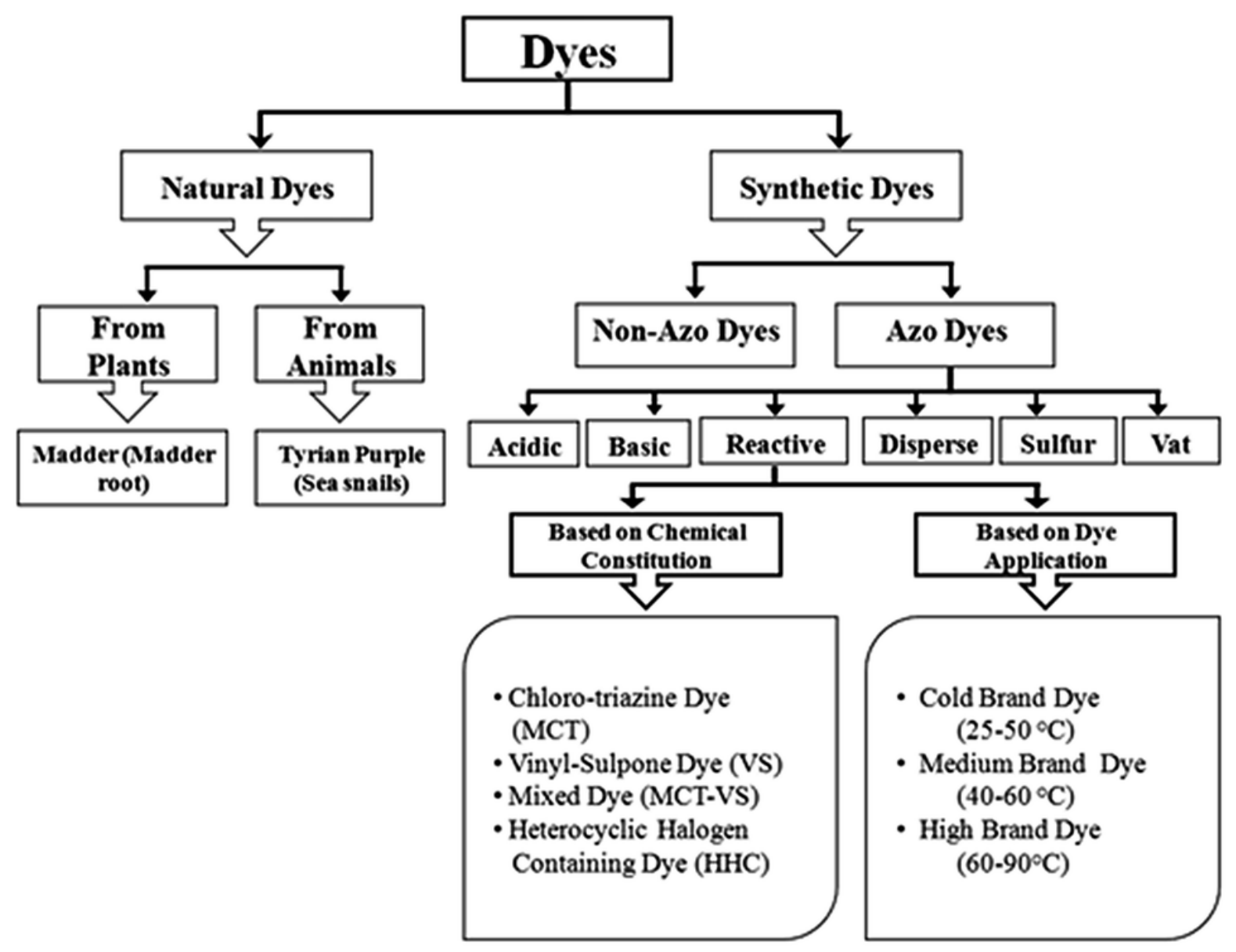


Figure 3 : Structure of the main polymorphs of titanium dioxide: anatase (a), rutile (b) and brookite (c). "Reprinted with permission from (Pelaez et al. 2012). Copyright 2012 Elsevier, Applied Catalysis B: Environmental."

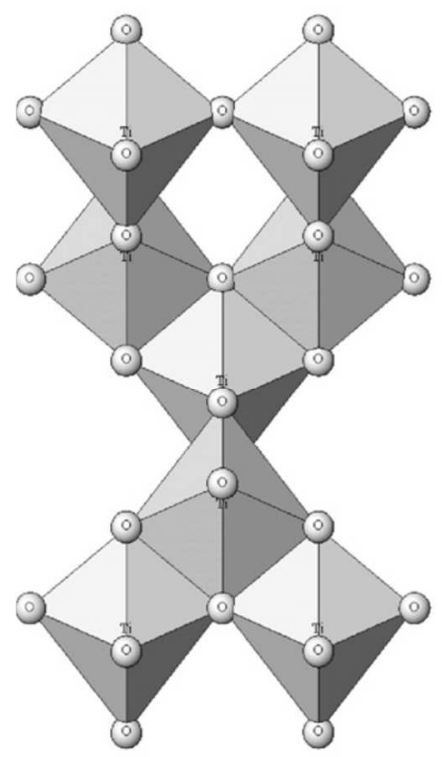

(a)

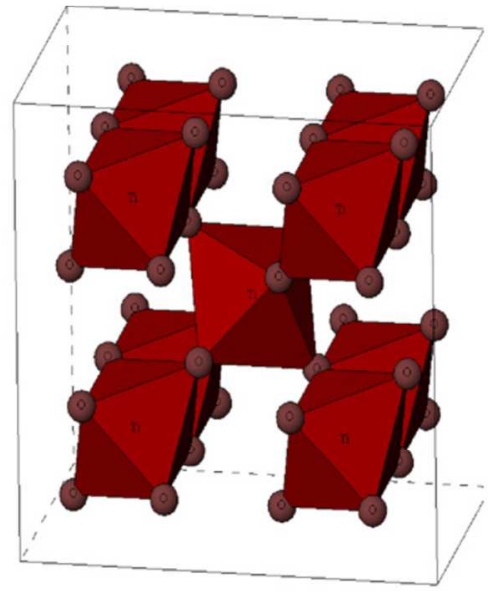

(b)

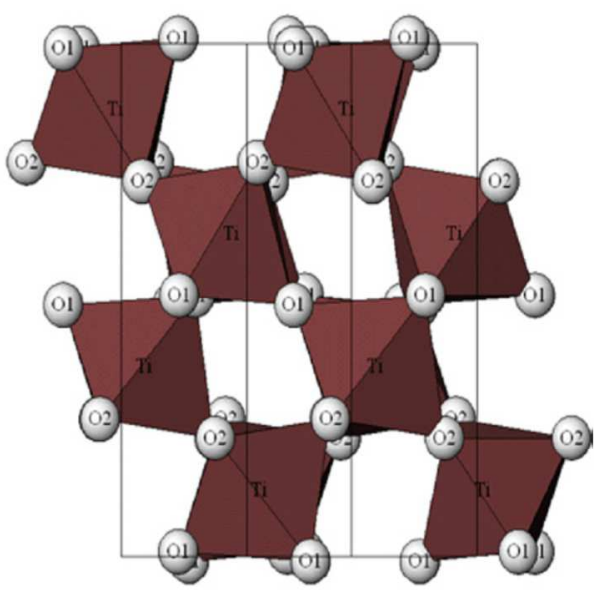

(c) 
Figure 4 : Indirect (a) and direct (b) dye degradation processes. "Reprinted with permission from (Ajmal et al. 2014). Copyright 2014 Royal Society of Chemistry, RSC Advances".

b

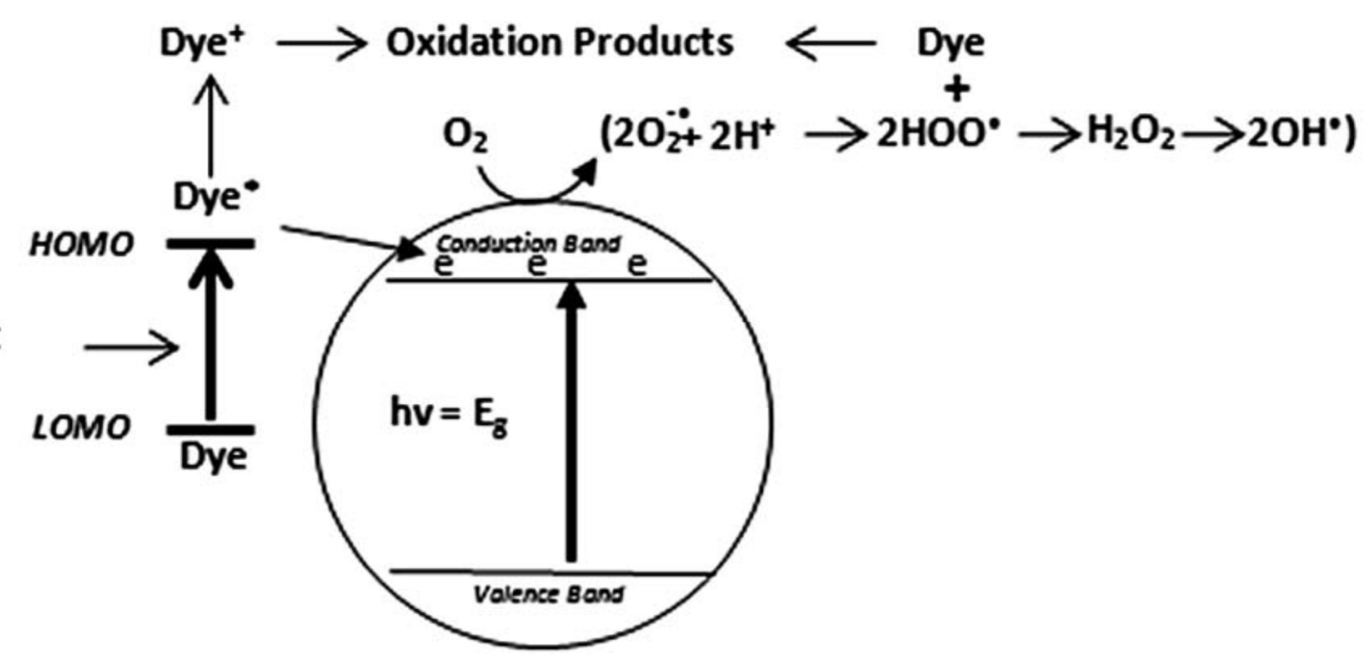

$\mathbf{a}$

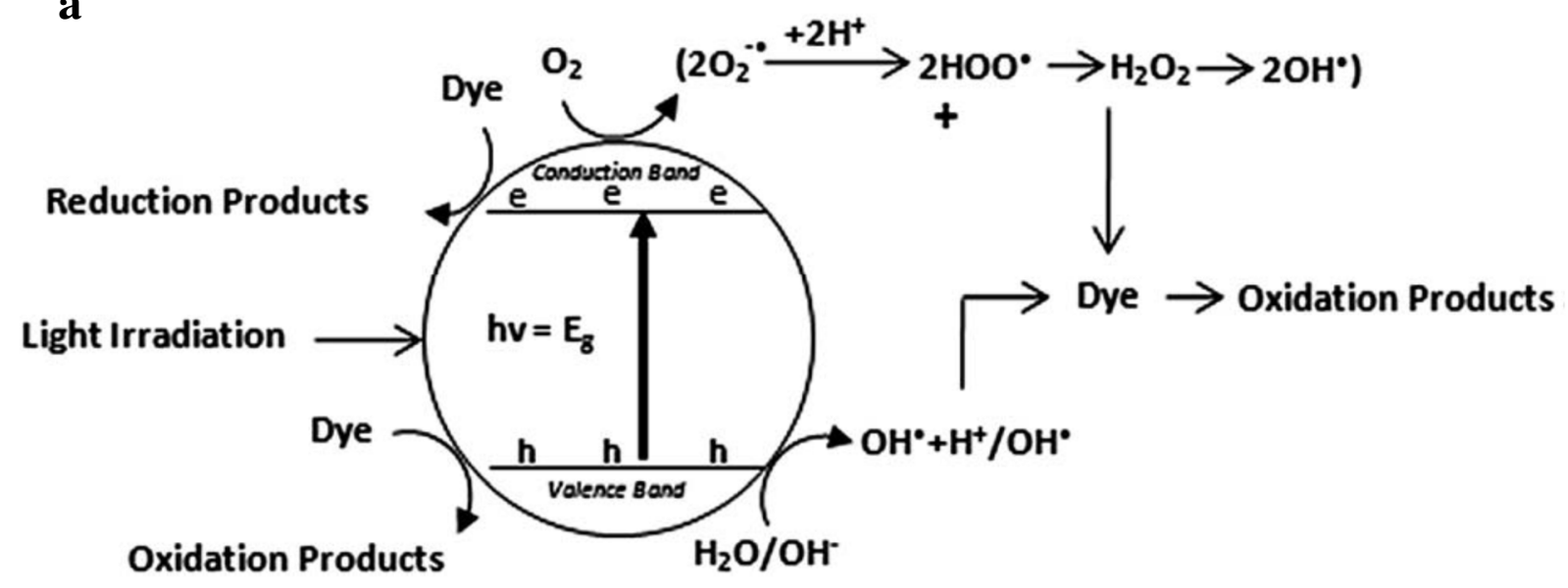


Figure 5 : Scheme of an experimental setup working with a photocatalytic membrane $\left(\mathrm{TiO}_{2}\right.$ immobilized in or on the membrane). "Reprinted with permission from (Mozia 2010). Copyright 2010 Elsevier, Separation and Purification Technology."

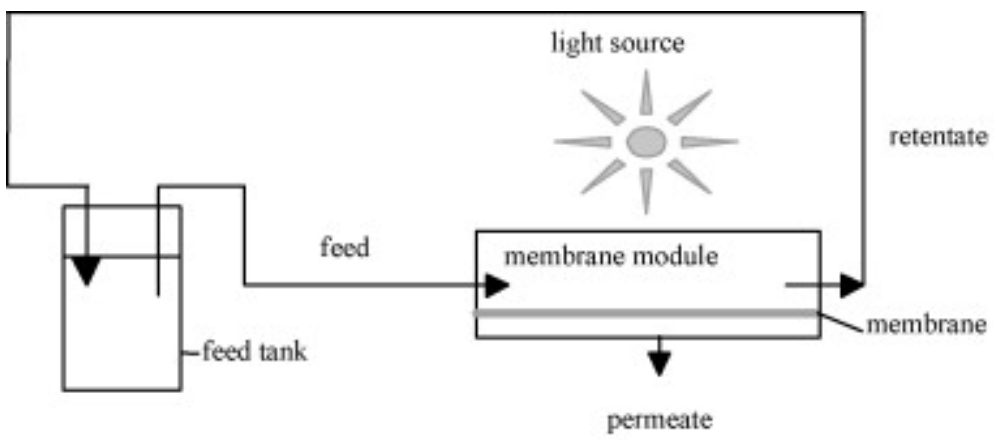

(a)

(b)

membrane module

membrane module

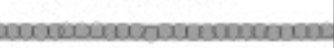


Figure 6 : Operating principle of a photocatalytic membrane with photoactive separation layer (a) and with photocatalytic membrane with non-photoactive separation layer and photoactive support (b). "Reprinted with permission from (Mozia 2010). Copyright 2010 Elsevier, Separation and Purification Technology."
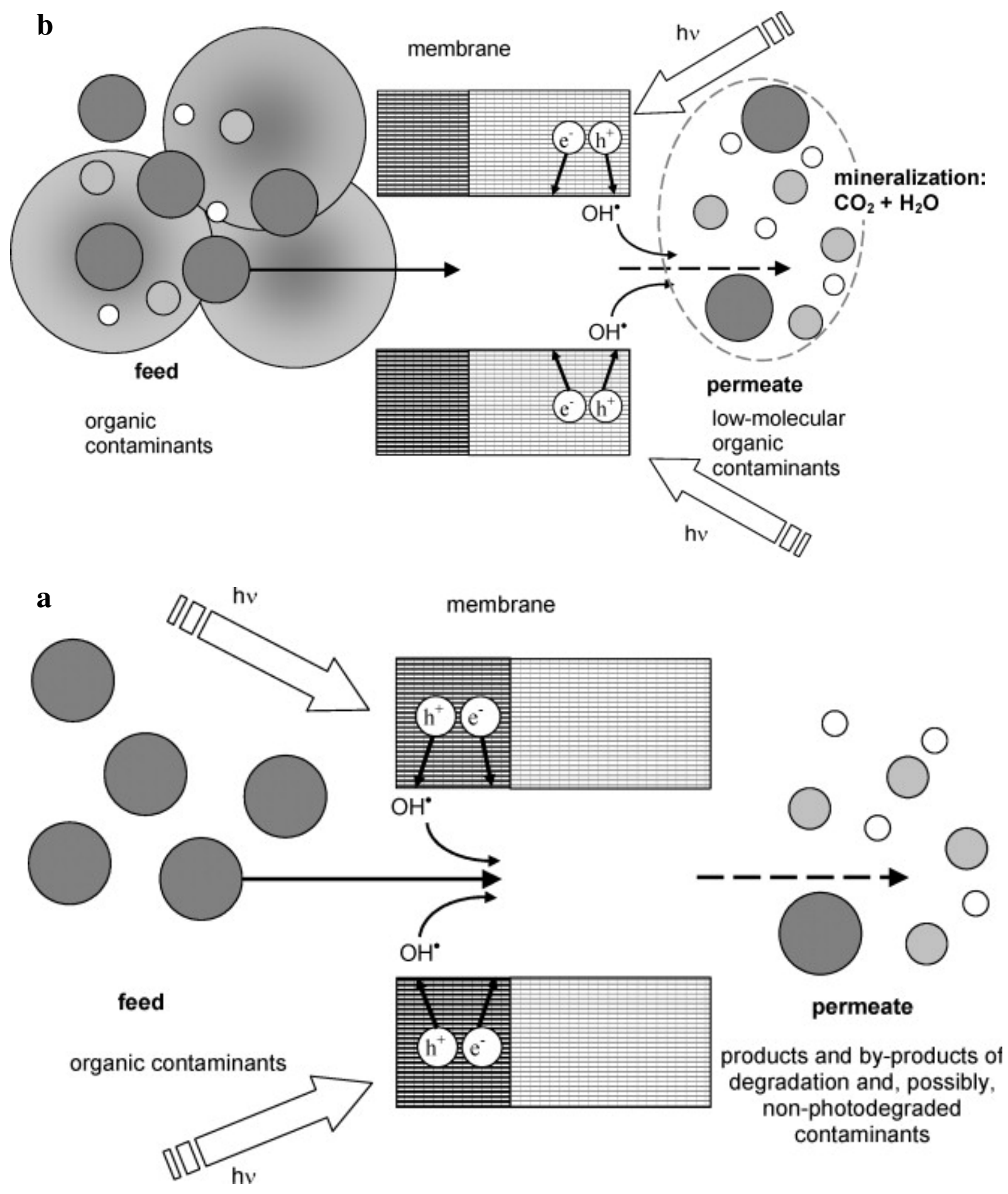
Figure 7 : Operating principle of a micro-reactor. "Reprinted with permission from (Cambié et al. 2016). Copyright 2016 ACS, Chemical Review."

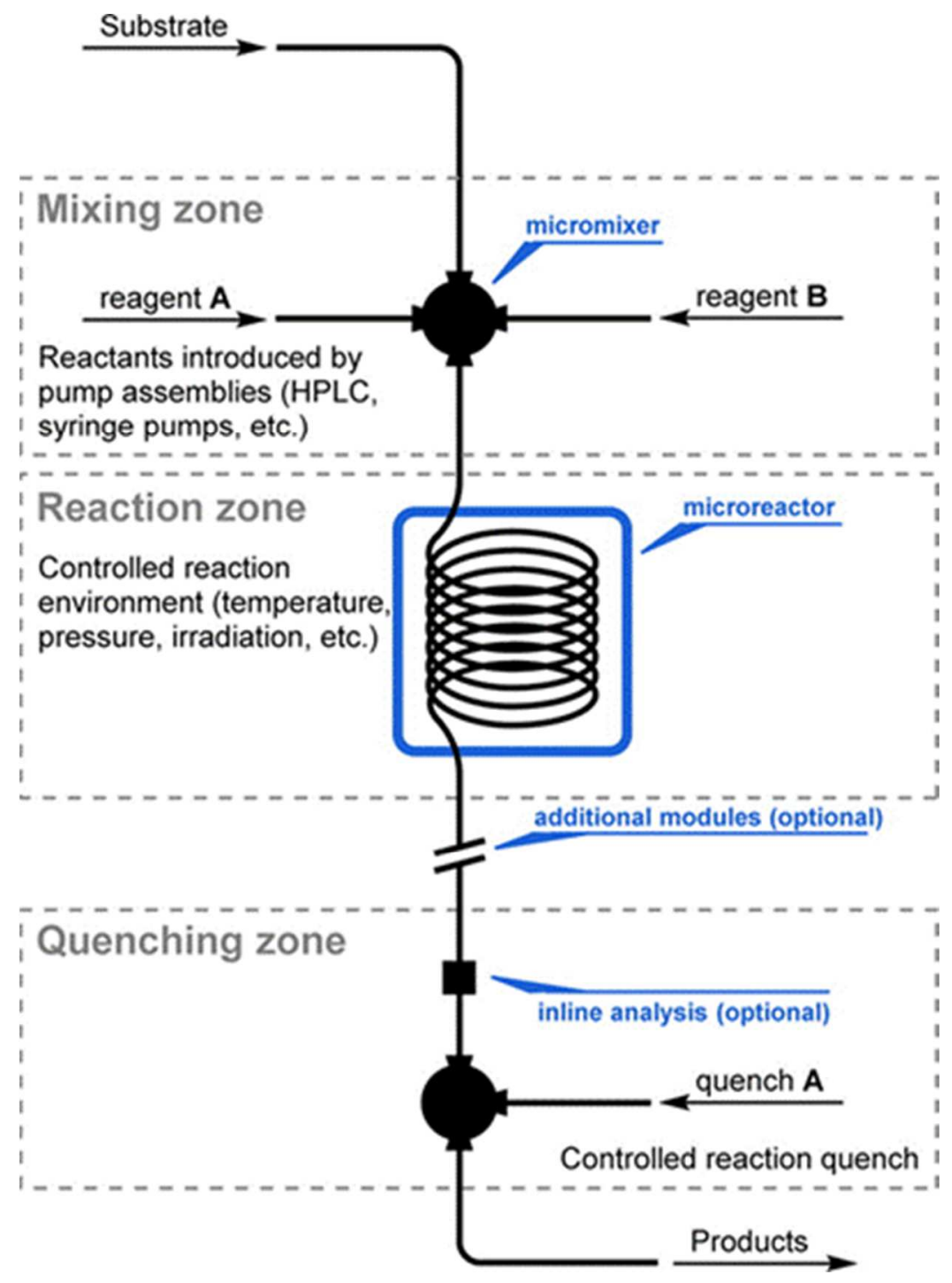


Figure 8 : Photocatalytic membrane-based tri-phasic flow reactor implemented by Aran et al. "Reprinted with permission from (Aran et al. 2011). Copyright 2011 Elsevier, Journal of Photochemistry and Photobiology A: Chemistry".

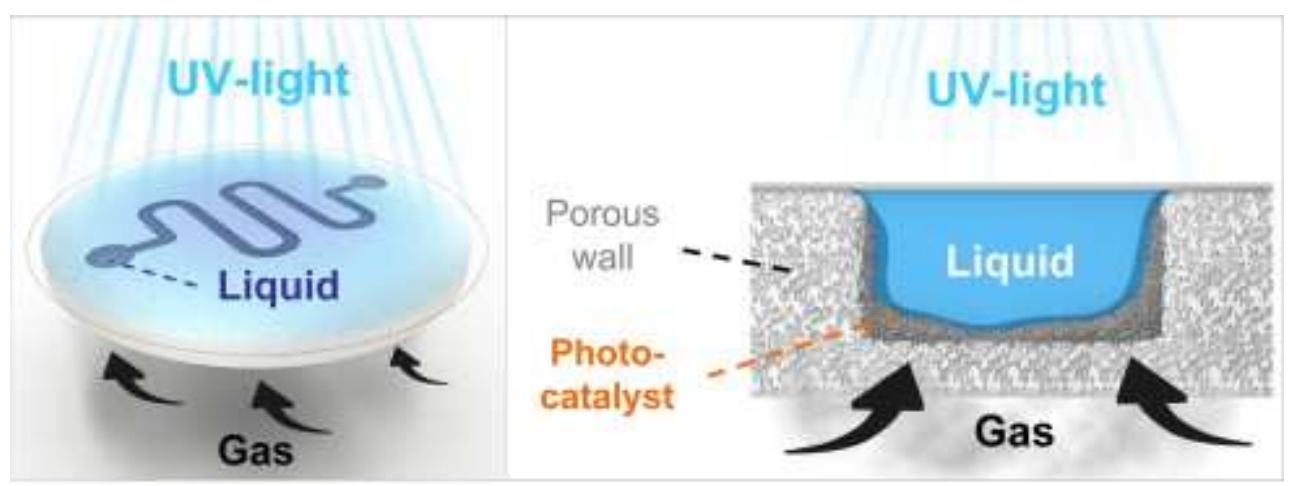

